\title{
POST-FIRE VARIATION IN AEOLIAN DEPOSITION IN THE NORTHERN GREAT BASIN
}

by

Clayton Roehner

\author{
A thesis \\ submitted in partial fulfillment \\ of the requirements for the degree of \\ Master of Science in Hydrologic Sciences \\ Boise State University
}

December 2018 
(C) 2018

Clayton Roehner

ALL RIGHTS RESERVED 


\section{BOISE STATE UNIVERSITY GRADUATE COLLEGE}

\section{DEFENSE COMMITTEE AND FINAL READING APPROVALS}

of the thesis submitted by

Clayton Roehner

Thesis Title: Post-Fire Variation in Aeolian Deposition in the Northern Great Basin

Date of Final Oral Examination: 26 October 2018

The following individuals read and discussed the thesis submitted by student Clayton Roehner, and they evaluated his presentation and response to questions during the final oral examination. They found that the student passed the final oral examination.

Jennifer Pierce, Ph.D.

Elowyn Yager, Ph.D.

Frederick B. Pierson, Ph.D.

Nancy Glenn, Ph.D.
Chair, Supervisory Committee

Member, Supervisory Committee

Member, Supervisory Committee

Member, Supervisory Committee

The final reading approval of the thesis was granted by Jennifer Pierce, Ph.D., Chair of the Supervisory Committee. The thesis was approved by the Graduate College. 


\begin{abstract}
Aeolian processes play a significant role in the redistribution of sediment and nutrients in sparsely vegetated sagebrush-steppe ecosystems. When fire is introduced to the landscape, decreased surface roughness and associated threshold friction velocities allow for the increased mobility of surface sediments and burnt organic material, mobilizing previously stable material. Once material is entrained, interactions between a dynamic atmosphere and complex topography control the spatial distribution of aeolian deposition over a landscape. Given the significant impact of fire on aeolian processes in semi-arid deserts, we posit that postfire aeolian redistribution of material is an important control on the spatial variability of soil depth and characteristics in semi-arid deserts with complex topography. Our study uses over two years of continuous passive dust trap data collected following the Soda Fire of August 2015 in the northern Great Basin. We analyze the mass flux, organic material content, grain size distribution, and geochemistry of the collected samples to trace the fingerprint of the Soda Fire through space and time. As such, the results of this study will inform research on postfire sediment and carbon redistribution, the spatial variability of soil characteristics, and landform evolution in western rangelands. Our results indicate that seasonal variation in aeolian mass flux is pronounced, with the fall months generating the highest rates of dust flux. Immediately following the Soda Fire of August 2015, the mass flux of both sediment and organic material increased by two to three-fold within and proximal to the burned area. Increases
\end{abstract}


in flux lasted on the landscape until the revegetation of the burned area in the spring of 2016, leaving roughly 8 months of disturbed soil surface conditions. Samples impacted by fire contained $88 \%$ fine silt and clay-sized material while undisturbed samples averaged $94 \%$, indicating a temporary increase in the particle size distribution within the burned area. A geochemical comparison of regional and local dust and its sources also indicates a pulse of local sediment mobility following the fire through an increase in the relative concentrations of Titanium (found in local soil) and a decrease in the relative concentrations of Barium and Strontium (found in regional soluble salts). We interpret the cessation in local mobility after revegetation to adequate surface roughness provided from spring "green up" (grasses and forbes) to return vertical fluxes of organic matter and sediment to within pre-disturbance fluctuations.

Recent studies in the northern Great Basin have found aspect-controlled differences in soil depth and volumetric water content in mid-elevation sagebrush-steppe ecosystems. North-facing aspects tend to have deeper soils, with higher organic content and greater volumetric water contents throughout the water year than south-facing slopes. Our results indicate that local material is suspended and deposited over small scales (0-10 $\mathrm{km})$ to spatially controlled locations within the watershed following wildfire, while background rates of dust flux and aerosol characteristics are spatially homogenous.

The preferential redistribution of locally derived material onto sheltered, leeward slopes and topographically low positions via aeolian processes following fire adds a layer of complexity to our understanding of the spatial variability of soil characteristics, typically explained with an aspect-controlled water-energy balance within the Great Basin. Future studies should focus on quantifying and modeling the extent, magnitude, 
and character of postfire horizontal flux of sediment and organic material from exposed windward slopes to sheltered leeward hollows in the sagebrush steppe ecosystem using tracers, saltation sensors, and ground-based dust traps to better understand the implications of aeolian processes in semi-arid deserts. 


\section{TABLE OF CONTENTS}

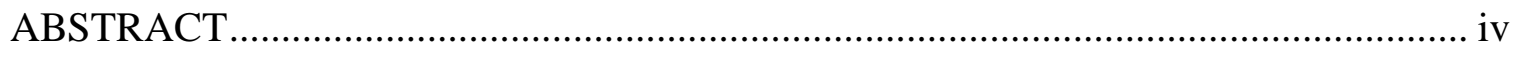

TABLE OF CONTENTS ................................................................................... vii

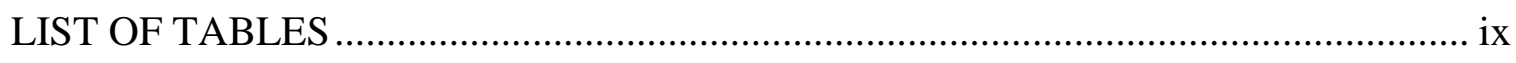

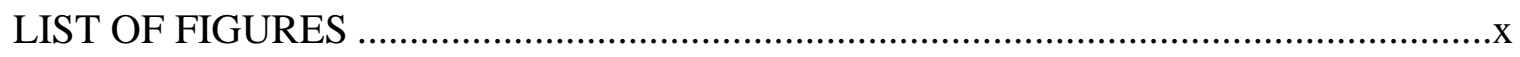

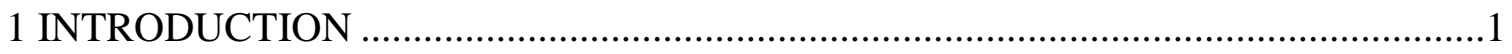

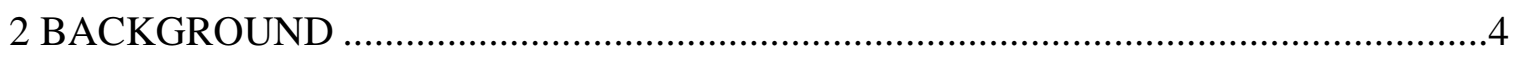

2.1 Mechanisms of Aeolian Deposition ....................................................

2.2 Postfire Influences on Aeolian Deposition ...........................................6

2.3 Intersection of Topography and Atmosphere ............................................8

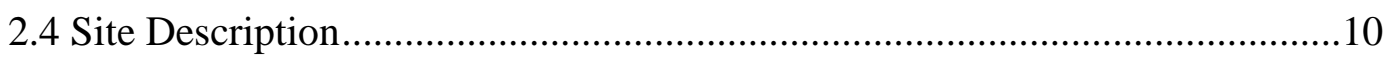

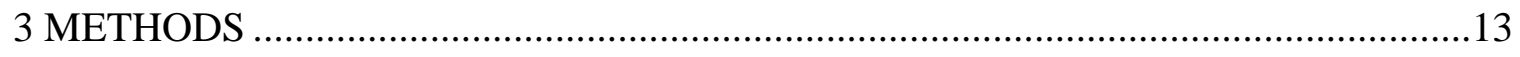

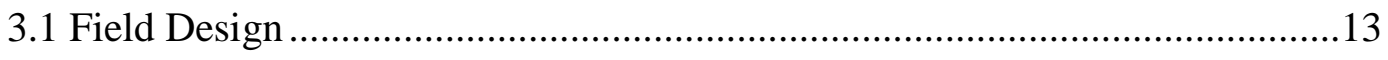

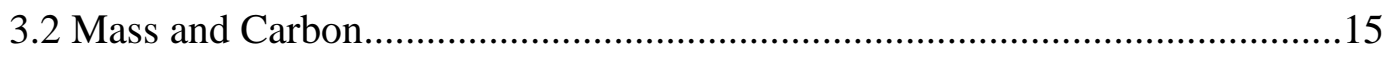

3.3 Particle Size Distribution ............................................................... 16

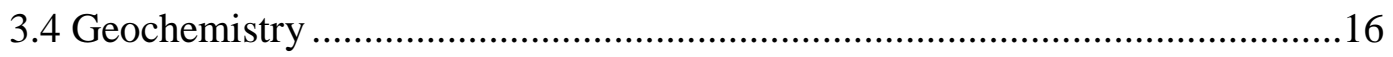

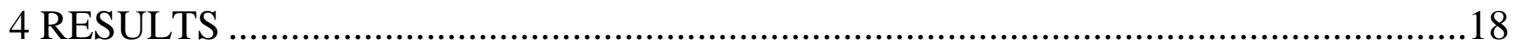

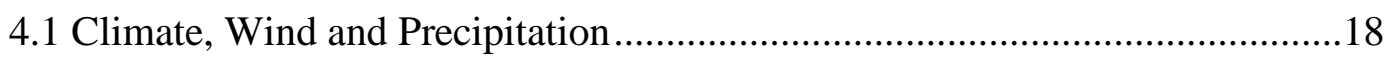

4.2 Mass and Organic Matter Flux .......................................................... 18 
4.3 Particle Size

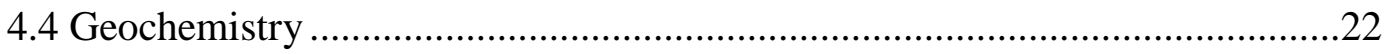

5 DISCUSSION

5.1 Seasonal and Climactic Controls on Aeolian Deposition .................................24

5.2 Characteristics of Aeolian Material Without the Influence of Fire .................25

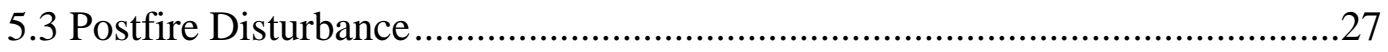

5.4 Aeolian Influence on the Semi-Arid Landscape ................................................30

5.5 Deposition Over Millennial Scales ................................................................33

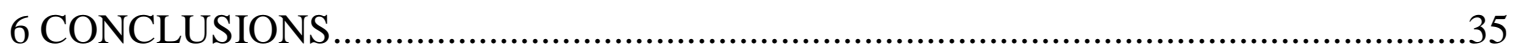

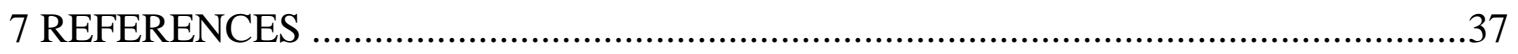

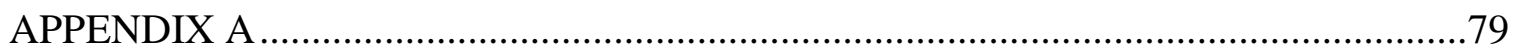

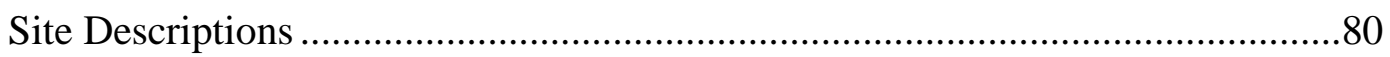

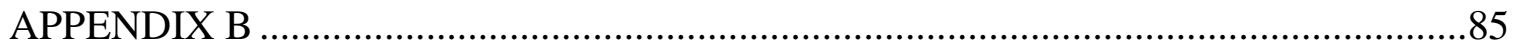

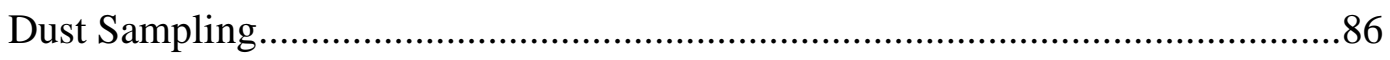

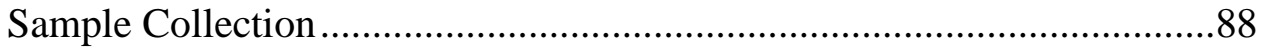

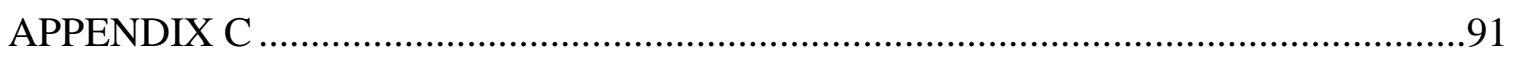

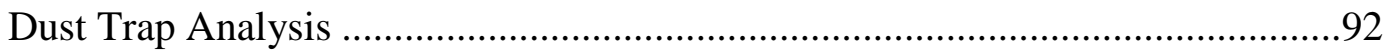

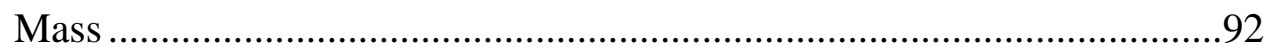

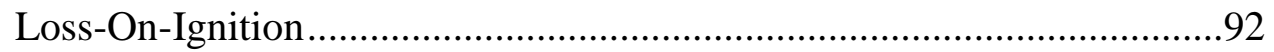

Particle Size Distribution .....................................................................93

ICPMS 


\section{LIST OF TABLES}

Table 2-1: $\quad$ Summary of wind and precipitation data from sites within the RCEW... 47

Table 3-1: $\quad$ Site descriptions and summary data for individual dust traps. ................. 48

Table 4-1: $\quad$ Flux variation for the entire watershed for individual sampling intervals.49

Table 4-2: Annual amounts of total dust deposition, both mineral and organic, for the

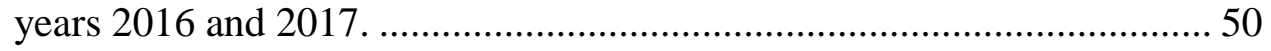

Table 4-3: Individual site deposition rates with calculated mean and standard deviation for watershed variability and interval variability................... 51

Table 4-4: Organic matter percentages over space and time across the RCEW....... 52

Table 4-5: $\quad$ Particle size distribution metrics for all sampling intervals..................... 53

Table 4-6: $\quad$ Trace element data from the dust trap samples throughout the sampling

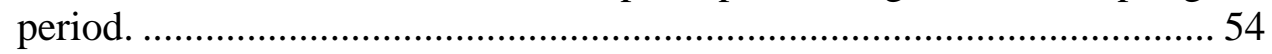

Table 5-1: $\quad$ Deposition rates over 100,000 year time scales for various topographic positions and vegetation types across the RCEW .................................. 55 


\section{LIST OF FIGURES}

Figure 2-1: Images depicting the analogous behavior of postfire sediment, organic material and snow. .................................................................................... 56

Figure 2-2: Conceptual model depicting differences in aeolian deposit characteristics

following fire in the northern Great Basin. 57

Figure 2-3: Reynolds Creek Experimental Watershed, located in southwestern Idaho, is a xeric watershed with complex topography and strong precipitationvegetation gradients. 58

Figure 2-4: $\quad$ 15-minute wind direction data of intervals above $6 \mathrm{~m} / \mathrm{s}$ from three sites across the watershed. 59

Figure 2-5: Map depicting hypothesized dust source area from wind direction data.. 60

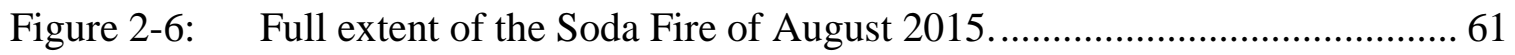

Figure 3-1: $\quad$ Raw data output from laser diffractometry particle size analysis............ 62

Figure 4-1: $\quad$ Summary of regional trends in precipitation and drought index validated with point data from multiple elevations within the RCEW. 63

Figure 4-2: Flux data of the subset groups for the two years following the Soda Fire of August 2015. 64

65

Figure 4-3: $\quad$ Seasonal differences in watershed wide average flux rates indicate that the winter season deposits significantly less material than fall and summer.. 65

66

Figure 4-4: $\quad$ Sagebrush and conifer sites are not statistically different from each other while samples collected in the first sampling interval following fire within the burned area contained statistically higher dust flux rates.

Figure 4-5: $\quad$ RCEW flux rates are comparable to other sites from around the world with regional sources. 67 
Figure 4-6: Ratio of mineral flux to organic flux at all sites.

Figure 4-7: Comparison of Murphy Creek Lower (MCL, left) and Reynolds Mountain Cabin (RMC, right) samples from fall of 2015 immediately following the Soda Fire.

Figure 4-8: Ratio values for individual sites divided by the UPW ("control") site..... 70

Figure 4-9: Despite an increase in the deposition of burnt organic material following the fire, the increase in local mineral soil deposition drove the organic percentages down across the watershed for the first two sampling intervals following the Soda Fire.

Figure 4-10: Particle size cumulative density functions show an increase in the coarse size fractions following fire.

Figure 4-11: Cumulative density functions of grain size distribution reveal a decrease in watershed wide variance one-year postfire in the RCEW.

Figure 4-12: A two end member model indicates that sites within the burned area are composed of more locally derived material before the first growing season.

Figure 4-13: A spidergram showing Rare Earth Element (REE) compositions of samples from the Low Sites within the burned area. 75

Figure 5-1: Boxplots of mineral and organic material flux indicate that mean values of dust flux are not statistically different across the watershed. 76

Figure 5-2: $\quad$ Photos from each sampling interval within the 100\% burned Murphy Creek Watershed of the RCEW.

Figure 5-3: Spatially-controlled locations of increased soil water availability, soil depth, and vegetation density found on leeward hollows below topographic slope breaks on north east facing aspects. 78 


\section{INTRODUCTION}

Dust, or mineral aerosols, interact with earth system processes in a number of important ways. At the largest scale, aeolian circulation of mineral aerosols impacts the global energy budget (Mahowald et al, 2006), global nutrient cycling (McTainish and Strong, 2006) and landform evolution (McTainish and Strong, 2006; Ravi et al., 2011). Dust flux spans all spatial scales (global to microsite) and can travel as large dust storms depositing millions of tons of material in one event or small, yet steady, inputs over vast distances (Simonson, 1995). For instance, mineral aerosols sourced from African deserts provide roughly 24,000 tons of phosphorus to the Amazon Basin annually, an input vital to forest productivity (Yu et al., 2015). Global dust emissions are estimated at 1000-5000 million tons per year and $25 \%$ of total yearly emissions are attributed to anthropogenic influences such as increasing aridification and land use changes (Ginoux et al., 2012; Huneeus et al. 2011).

Semi-arid regions of the world, which cover $~ 30 \%$ of continental surfaces, are the primary source of mineral aerosols at the global scale (d'Almeida and Shutz, 1983). Not only are semi-arid regions the principal source of atmospheric mineral aerosols but semiarid systems also rely on dust input as a key source of sediment and nutrients (Reynolds et al, 2001; Delany and Zenchelsky, 1976; Yaalon and Ganor, 1973). Due to the large specific surface area of clay and silt-sized particles, dust deposits, or loess, can provide substantial pools of available nutrients in otherwise nutrient and water limited systems (Caravaca et al., 1999). However, the fine size fraction is also the easiest material to 
entrain and erode in semi-arid regions through both wind and water erosion processes (Stocking, 1984). Loss of the fine fraction from semi-arid soils has implications for soil productivity, soil carbon storage, and vegetation distribution throughout the semi-arid west (Hasselquist et al, 2011, Reynolds et al., 2001; Okin et al., 2004). Fire, land-use and invasive species all increase the amount of erosion that occurs across the semi-arid landscape (Balch et al., 2013; Green et al., 1993; Pierson and Williams, 2016; Williams et al., 2016).

Non-native annual grasses have altered plant communities across the Great Basin and increased wildfire frequency and extent (Brooks et al., 2004; Whisenant, 1990; Ypsilantis, 2003). Specifically, the invasion of cheatgrass, Bromus tectorum, has changed the horizontal fuel structure, filling in previously bare ground interspaces with fine-fuel loads (Pierson et al., 2015). Estimates of historic fire return intervals for low sagebrush, A. arbuscular, range from 100-200 years, while modern cheatgrass fire recurrence intervals range from 3-5 years (Miller and Tausch, 2001). Increases in fire size and extent within the Great Basin negatively impact a landscape already susceptible to wind erosion (Breshears et al., 2003, Pierson et al., 2001)

Following fire in a semi-arid ecosystem, wind erosion increases significantly until the revegetation of the landscape (Dukes et al., 2018; Sankey et al., 2009). While the landscape is disturbed, wind events can cause large dust storms resulting in increased air pollution and respiratory illness downwind (Bowman and Johnston, 2005). While aeolian deposition rates and aerosol composition is well documented within the Mojave Desert and the southern Great Basin (Reheis, 2006), few studies have characterized the vertical flux of dust in the northern Great Basin and Snake River Plain and fewer have looked at 
the influence of wildfire on aeolian inputs to soils out of suspension. Previous postfire studies in the region have described the remobilization of soil, through both saltation and suspension, at the microsite to plot scale (Hasselquist et al., 2011; Ravi et al., 2007; Sankey et al., 2009, Sankey et al ., 2010; Wagenbrenner et al., 2013) Studies from study areas with simple topography indicate a homogeneous redistribution of soil sediment and nutrients following wildfire disturbance (Dukes et al., 2018; Ravi and D’Odorico, 2009). The scientific community requires a better understanding of the postfire spatial redistribution of aeolian material at the hillslope to landscape-scale in complex topography.

This study describes the spatial and temporal variation in the magnitude and characteristics of aeolian deposition following fire in the northern Great Basin, USA. We use mass flux, organic content, particle size distribution and geochemistry data to trace the influence of wildfire on the landscape through time and space at the watershed scale. Our study suggests that wildfire can substantially alter the magnitude of aeolian deposition on aspect-controlled locations across the landscape. As such, the results of this study will inform research on postfire sediment and nutrient redistribution, mineral aerosol composition and the spatial variability of soil characteristics in semi-arid sagebrush-steppe ecosystems. 


\section{BACKGROUND}

\subsection{Mechanisms of Aeolian Deposition}

Aeolian input to Earth systems is a three-step process starting from detachment and entrainment, continuing to transport, and culminating in the deposition of mineral aerosols (Gillies, 2013). The detachment of particles from the land surface is a function of the wind's ability to move particles (shear stress) and soil erodibility or the soil's ability to resist movement (threshold friction velocity) (Bagnold, 1941; Gillies, 2013, Okin et al, 2006; Sankey et al, 2009). Similar to fluvial processes, particle detachment in the aeolian realm is tied to turbulent forces in the boundary layer, a vertical region above the ground surface where fluid flow is influenced by roughness on the surface (Ellis and Sherman, 2013). A study in the semi-arid, Snake River Plain of southern Idaho, found that sagebrush vegetation and soil biological crusts maintained sufficient roughness to resist particle detachment and wind erosion at any significant level (Wagenbrenner et al, 2013).

Following detachment, particles are transported via creep, saltation, or suspension (Bagnold, 1941). Creep is defined as the tumbling of particles across the soil surface without ever leaving the ground. Saltation is the dominant form of horizontal sediment flux in semi-arid regions (Breshears et al., 2003). During saltation events, turbulent wind at the soil surface works to transport particles across a landscape below the two meter height. Suspension occurs when the vertical component of turbulent wind exceeds the 
settling velocities of the particles being transported. Typically, only particles $<70 \mu \mathrm{m}$ are susceptible to long-range transport via suspension (Kok et al., 2012).

Once in suspension, various forces work to pull dust out of the atmosphere through either dry deposition or wet deposition (Mahowald et al., 2014; Ravi et al., 2011; Shao, 2008). Dry deposition occurs primarily to particles larger than $5 \mu \mathrm{m}$ and is due to gravitational settling whenever turbulence decreases in the atmosphere. In wet deposition, particles less than $5 \mu \mathrm{m}$ can serve as rain or snow nuclei and precipitate onto the surface, or precipitation can collect mineral aerosols from the lower atmosphere en route to the Earth's surface (Kok et al., 2012; Shao, 2008).

The mineral aerosols deposited as atmospheric fallout have a bimodal grain size distribution with a consistent mode at $3 \mu \mathrm{m}$ and a more variable mode around $30 \mu \mathrm{m}$ (d'Almeida and Shultz, 1983). The $3 \mu \mathrm{m}$ mode represents the well-sorted fine fraction of material undergoing global transport while the $30 \mu \mathrm{m}$ mode represents coarser silt-sized regional material. The mixing involved in long-range transport creates a mineral aerosol deposit of homogeneous geochemistry comparable to the average composition of the upper continental crust (UCC). Larger silt-sized particles in suspension deviate from UCC values and contain a signature of more local source areas (Schütz and Sebert, 1986). Previous studies from around the world have found high variability, both seasonally and annually, in the organic component of mineral aerosols (Cattle et al., 2009; Zaady et al., 2001).

Climate and landscape play a role in the vertical flux of mineral aerosols at the regional to global scale, influencing the aeolian transport process from detachment to deposition (Prospero and Lamb, 2003; Okin and Reheis, 2002; Reheis et al, 2006). 
Seasonal variability in the amount of entrainment and deposition in the Great Basin is controlled by antecedent soil moisture, vegetation type, precipitation, humidity, and source area (Ravi and D’Odorico, 2005; Reheis and Urban, 2011; Wagenbrenner et al., 2013). Snowfall and frozen top soil limit the available sediment in source areas during winter months. Melting snow leads to moist spring soil conditions and vegetation growth, both of which increase threshold wind velocities and result in negligible vertical fluxes of dust (Wagenbrenner et al., 2013). As soils dry and vegetation density deceases throughout summer, soil deflation and decreased roughness allow for lower threshold friction velocities, resulting in the entrainment of fine silt and clay-sized particles into the atmosphere (Sankey et al., 2009). However, precipitation and associated wet deposition, are rare in the summer months before precipitation increases in the fall (Table 2-1). Fall months contain the highest flux potential due to changing soil moisture conditions from wetting and drying of intermittent precipitation (increases detachment and entrainment), stronger wind speeds associated with frontal storms (increases transport regionally), and more frequent wet deposition events. Regional climate conditions and local weather events are highly variable over time, leading to high inter-annual variability in dust flux. However, our study reveals that wildfire disturbance overprints any climate controlled variability in flux.

\subsection{Postfire Influences on Aeolian Deposition}

Postfire conditions are known to drastically alter aeolian processes in semi-arid deserts (Ravi et al., 2011; Sankey et al., 2009). Decreased surface roughness, due to the incineration of protective shrub cover, increases the shear stress in the boundary layer over the soil surface. Burned soils are far more susceptible to particle detachment due to a 
loss of vegetative cover (Ford and Johnson, 2006; Whicker et al., 2001) as well as decreased aggregate stability from the physical burning of soils (Varela et al., 2010). Estimates of $\mathrm{PM}_{10}$ and $\mathrm{PM}_{2.5}$ dust emission from the Great Basin during the 2012 fire season indicate that postfire wind erosion is capable of producing more dust than all of the fire plumes from active burning combined (Wagenbrenner et al., 2017). In the semiarid desert of the Snake River Plain, dust emissions were three orders of magnitude greater on burned surfaces relative to unburned surfaces. In the same study, threshold wind velocity for saltation values ranged from $10-10.6 \mathrm{~m} / \mathrm{s}$ within the burned area while the unburned sites recorded insufficient saltation events to determine threshold wind velocity (Sankey et al., 2012).

Within the Great Basin, fire typically occurs in summer and vegetation does not return to the landscape until the following spring, leaving a long period of time during which bare soils are available for transport (Sankey et al, 2009). Given the localized effect of fire on a landscape, we posit that postfire differences in the magnitude and characteristics of aeolian deposition last on the landscape as long as the disturbance is effective in increasing shear stress (removal of protective vegetation cover) and decreasing threshold friction velocity (altering of soil properties) locally. While a growing amount of research investigates the postfire redistribution of sediment and nutrients at the microsite-to-plot scale (Ravi et al., 2006; Dukes et al., 2018), less has been done to quantify postfire redistribution in complex landscapes where interactions between topography and atmosphere control the deposition of material at the hillslope to landscape scale (Hirmas and Graham, 2011). 


\subsection{Intersection of Topography and Atmosphere}

In a semi-arid, sagebrush ecosystem with little topographic complexity, the redistribution of vital nutrient and sediment resources following fire leads to an increase in homogeneity across the landscape at the microsite to plot scale (Dukes et al., 2018; Ravi et al., 2007). In undisturbed regions, shrubs act as dust traps and create nutrient-rich soil patches beneath the shrub termed "Islands of Fertility" (Ravi and D'Odorico., 2009). Nutrient poor, bare ground patches between shrubs create a patchwork of varying soil nutrients across the landscape. Immediately following fire, wind redistribution spreads the nutrient rich soil beneath the burned shrub homogenously over the landscape (Dukes et al., 2018; Ravi et al., 2007). However, when strong winds interact with complex topography, material is preferentially moved from exposed locations to sheltered hollows (Winstral and Marks, 2002). This phenomenon is widely recognized in the hydrologic community where deeper snow depths, greater snow water equivalents (SWE), and persistent snow drifts are consistently found on leeward slopes below exposed ridgelines and cornices (Burke et al., 1989; Litaor et al., 2008; Winstral et al., 2013). The spatially preferential distribution of snow on the landscape coupled with aspect-controlled differences in insolation controls a water-energy balance that drives increased soil moisture, vegetation density, and soil depths on north facing slopes relative to south facing (Burke et al., 1989; Geroy et al., 2011; McNamara et al., 2018). Field observations from our study site indicate that postfire sediment and carbon, entrained by wind, behave analogously to snow when redistributed across complex topography (Figure 2-1).

Anecdotal evidence of the postfire redistribution of sediment and carbon is common, though little has been done to quantify the thickness and extent of the wind- 
blown deposits (Pierson, personal communication). Following the Soda Fire of August 2015 in southwest Idaho, drifts of sediment and burnt organic material covered leeward slopes and colluvial hollows throughout the burned area. The distribution of dust drifts closely matched the distribution of local snow drifts throughout the winter (Figure 2-1). The presence of burnt organic material deposited within snow drifts in the winter following the Soda Fire validates the analogous process of sediment saltation in complex terrain with that of snow redistribution (Figure 2-1).

Given the constant and widespread influx of material through aeolian processes and the subsequent preferential redistribution of material over the landscape, relatively small annual rates of deposition have large morphological impacts on semi-arid landscapes (McAuliffe et al., 2018). In the Dry Creek Experimental Watershed, Stark (2012) determined that the loess fraction of north-facing soils was twice that of southfacing slopes ( 0.38 and 0.16 respectively). Given the significant impact of fire on aeolian processes in semi-arid deserts, we posit that postfire aeolian redistribution of material is an important control on the spatial variability of soil depth and characteristics in semiarid deserts with complex topography.

Previous studies in postfire aeolian processes have focused on entrainment conditions (Ravi et al, 2007; Sankey et al., 2009), resource distribution at the plot scale (Okin and Gillette, 2001; Ravi and D'Odorico, 2009; Sankey et al., 2010), threshold wind velocities (Whicker et al, 2001), and emission rates (Wagennbrenner et al, 2013). Our study uses mass flux, particle size distribution, and geochemistry to track changes in the aeolian deposition of material at the watershed scale over a two-year period following fire in the northern Great Basin. We hypothesize that samples impacted by wildfire will 
contain increased dust flux, coarser grain size distributions, and a geochemical signature of local material mobilized by decreased threshold friction velocity and increased shear stress locally (Figure 2-2).

\subsection{Site Description}

Our study is located within Reynolds Creek Experimental Watershed (RCEW) in the Owyhee Mountains of southwestern Idaho. The $239 \mathrm{~km}^{2}$, xeric watershed, rises in elevation from $1100 \mathrm{~m}$ at the outlet of Reynolds Creek to $2245 \mathrm{~m}$ in the headwater peaks (Figure 2-3). Tertiary volcanic and sedimentary rocks are underlain by granitics of the Idaho Batholith (McIntyre, 1972). Mean annual precipitation closely follows the elevation gradient such that lower elevation sites receive $\sim 240 \mathrm{~mm}$ of precipitation annually and higher elevations receive $\sim 1100 \mathrm{~mm}$ (Slaughter et al, 2001).

Vegetation trends also follow the elevation-precipitation gradient with sagebrush and bitterbrush species (Artemisia tridentata, Artemisia arbuscular, Purshia tridentata) occupying the lower elevations and aspen (Populus tremuloides) and fir species (Abies lasiocarpa) above 1700 meters (Seyfried et al., 2001). In the mid-elevations, aspect, topography, and hydrology influence vegetation distribution (Burke et al., 1989). North through east facing colluvial hollows and riparian corridors contain the densest shrub coverage across the mid-elevation landscape (Poley, 2017).

Previous studies in the RCEW have shown that prevailing winds are out of the southwest between $225^{\circ}$ and $230^{\circ}$ (Winstral et al, 2013). Resultant mean wind direction data from weather stations during the study fit the southwesterly trend with notable sitespecific exceptions where complex topography controls wind direction (Figure 2-4). Seasonally, the strongest winds occur in the winter months (Table 2-1). With prevailing 
winds from the southwest, the regional dust source for the RCEW is the semi-arid sagebrush desert and playa complex of southeast Oregon and northeast California (Figure 2-5)

The topography of the RCEW is rugged with the exception of the broad low lying valley floor and terrace complex of Reynolds Creek. In the northwest corner of the watershed, in the Murphy and Salmon Creek drainages, north and south-facing hillslopes are asymmetric. North-facing slopes have average slopes of $20^{\circ}$ and comprise $31 \%$ of the watersheds while south-facing slopes have an average slope of $17^{\circ}$ and cover $17 \%$ of the watershed.

Soil development and thickness are controlled by landscape stability, precipitation, and aspect in the RCEW. In the rugged terrain of the uplands, low slope stability and constant soil creep cause poor soil horizonation and little soil development (Patton et al., 2018). In the Reynolds Creek valley, gentle gradients and terrace formation have allowed for the development of meter thick aridisols with highly developed pedogenic calcium carbonate horizons and large stores of soil-inorganic carbon (Stanbery, 2016). North-facing aspects contain loams with clay loam subsoils and poorly defined Bt horizons on slopes. South facing aspects are shallow, well-drained, gravelly, and very stony clay loams (Stephenson, 1977).

From August $10^{\text {th }}$ to August $22^{\text {nd }}$ the Soda Fire burnt nearly 280,000 acres of southwestern Idaho and eastern Oregon (BLM, 2016), including the northwest corner of the RCEW (Figure 2-6). The fire burnt fast through sagebrush and cheatgrass, creating a mosaic of moderate and low soil burn severity. Most of the vegetation was completely incinerated within the burned area, but sparse pre-fire shrub coverage and bare 
interspaces kept soil burn severity moderate to low. High soil burn severity was isolated to riparian corridors and colluvial hollows where relatively dense pre-fire vegetation provided an adequate fuel source to alter soils. A particularly wet winter and spring of 2016 following the Soda Fire helped vegetation rehabilitation, with native and invasive forbes and grasses returning as the snow receded by the end of March.

The RCEW has a spatially-extensive record of hydroclimatic data spanning the last 60 years and became one of ten National Critical Zone Observatories in 2013. Working in the RCEW offers a rare chance to study postfire processes in a wellinstrumented watershed with 15-minute interval hydroclimatic data. Data collected from our long-term monitoring of aeolian flux will contribute to interdisciplinary soil and water geochemistry studies within the Critical Zone Observatory. 


\section{METHODS}

\subsection{Field Design}

The dust traps used in this study are designed following the procedures outlined by Reheis (1995) and are used commonly within the aeolian research community. The traps consist of an inverted angel food cake pan placed atop a two-meter high post. The two-meter post ensures that the samples are not impacted by horizontal inputs from saltation in undisturbed areas. Glass marbles are placed atop a Teflon mesh screen to create surface roughness and retain dust once captured. Statistical analysis by Reheis et al. (2009) shows the traps have an error of $20-40 \%$.

The traps are located across all elevations within the RCEW from Reynolds Mountain in alpine conifer forest at $2100 \mathrm{~m}$ to the valley floor sagebrush sites at $1180 \mathrm{~m}$. Twelve of the 14 passive dust traps are co-located at meteorological sites throughout the watershed. The weather stations collect an array of environmental variables including temperature, precipitation, wind speed, and wind direction. Two sites are in the South Fork of Murphy Creek, a second order headwater tributary to Reynolds Creek. Murphy Creek was $100 \%$ burned by the Soda Fire, incinerating all vegetation and leaving mostly a mosaic of moderate and low soil burn severity. A new weather station was installed, and a decommissioned weir was re-established following the fire to support several interdisciplinary postfire studies.

Initial deployment of the traps began on July $31^{\text {st }}, 2015$, two weeks after the fire had burned through the Murphy Creek drainage. Sampling of the dust traps occurred at 
seasonal intervals depending on snow cover and access issues. Snow at higher elevations required the combination of the winter and spring seasons (from November to May) to maintain consistency across the sites. Collection occurred at the end of May (winter/spring interval), the beginning of September (summer interval) and the beginning of November (fall interval). The traps were collected in the field and brought to the lab for total mass, organic content, particle size distribution and geochemical analysis.

Due to the high temporal sampling resolution and the nature of aeolian deposition, individual site samples were combined with geographically similar sites to compile enough material for statistically significant analysis. The 14 traps were combined into five subsets based on distance from fire, topographic and geographic position, and vegetation type (Figure 2-3). The Valley and High subsets of sites are both located within the burned area, but in sheltered and exposed locations respectively. The Valley sites are located on the Reynolds Creek floodplain, far removed from the influence of the surrounding complex topography. The Upper East sites are located in the low-midelevation mountains on the east side of the watershed. Finally, the Upper West sites are located in the high elevation conifer forests in the southern portion of the watershed. The Upper West sites were unaffected by the Soda Fire and are also the only sites removed from the semi-arid sagebrush ecosystem. The particle size distribution and geochemistry results were calculated from the combined subset sample population.

Sites located within or downwind of the burned area before the first growing season (spring of 2016) following fire are referred to as "disturbed" based on the visual and geochemical results presented. Sites that were not influenced by the fire due to geographic location or time since burning are referred to as "undisturbed" and act as a 
proxy for pre-fire conditions. The highest elevation and furthest south sites of the Upper West subset were entirely unaffected by the Soda Fire and record undisturbed aeolian flux throughout the study period.

Our field campaign also included 20 soil pits dug on north and south facing slopes within the Murphy Creek drainage, proximal to our Low and High subsets of sites. We sampled in the summer of 2016, one year postfire, in $10 \mathrm{~cm}$ increments until bedrock was encountered. Soil samples underwent the same analysis as the aeolian material methods described hereafter.

\subsection{Mass and Carbon}

Sample analysis required the use of deionized water to extract the material from the dust trap. Wet methods introduce error by causing a loss of soluble salts and very fine clay minerals (Mahowald et al., 2014). Due to the sampling design and study plan, wet methods provided the only reasonable approach to extract the samples from the traps. Once extracted and dried at $60^{\circ} \mathrm{C}$, samples were photographed and the coarse organic material was counted where necessary (see Appendix C). We weighed the samples before and after burning at $575^{\circ} \mathrm{C}$ to determine the amount of organic material present following the loss-on-ignition (LOI) methods of Simon Frasier University Soil Science Lab (2011) (see Appendix C). Individual samples were burned multiple times until burned weights stabilized and there was no further organic consumption recorded. Final weights represent the amount of mineral aerosol deposited during a single sampling interval while the mass lost from ignition represents the organic material deposited over a single sampling interval (Table 3-1). 


\subsection{Particle Size Distribution}

Once the organic material was removed via LOI, we used a Malvern Mastersizer optical diffractometer with a 2000MU wet dispersion unit at the Utah State University Luminescence Lab to analyze the particle size distribution of the combined samples (see Appendix C). Our study followed the guidelines for optical parameterization of Sperezza et al. (2004). Due to the specific optical properties of aeolian material, we analyzed a suite of absorption and refractive indices until weighted residual values were below one, a common metric used to assess data quality (Sperezza et al., 2004). Samples were subset into triplicates and each aliquot was measured three times. Root mean squared error values were satisfactorily low within individual aliquot (one subset sample analyzed three times) and sample triplicate (three aliquots taken from one subset sample) measurements to allow for confident comparison between single subset samples over space and time (Figure 3-1). We analyzed the probability distribution functions, $\mathrm{D}_{16}, \mathrm{D}_{50}$ and $\mathrm{D}_{90}$ values of each sample to determine changes in sample grain size distribution over space and time.

\subsection{Geochemistry}

We used Inductively Coupled Plasma - Mass Spectroscopy (ICPMS) to determine the trace element and rare earth element composition of the samples. Where possible, samples were split into triplicates and prepared using lithium tetraborate fusion protocols (Stark, 2012). The small sample size required the use of only $50 \mathrm{mg}$ of material per aliquot, $100 \mathrm{mg}$ below the recommended value. We analyzed the same sample of dust at 150,100 , and $50 \mathrm{mg}$ and obtained results within acceptable error $(<6 \%)$ to accurately represent the geochemistry of our samples at $50 \mathrm{mg}$. Elements analyzed include $\mathrm{Al}, \mathrm{As}$, 
Ba, Ca, Ce, Co, Cr, Cs, Cu, Dy, Er, Eu, Fe, Ga, Gd, Hf, Ho, K, La, Lu, Mg, Mn, Na, Nb, Nd, Ni, P, Pb, Pr, Rb, Sc, Si, Sm, Sr, Ta, Tb, Th, Ti, Tm, U, V, Y, Yb, Zn, Zr. Analysis of subset samples were done in triplicate with an average reproducibility of $4 \%$ RSD. In order to determine changes in aeolian deposition over time and the relative influence of local material on aeolian deposition at the two meter height of the dust traps, our study required elements that contained a large variance in composition across the sampled materials (aeolian material, local soil, and local bedrock). Vanadium (V) and Titanium (Ti) values contained the greatest variance in composition between local soil, local bedrock and the collected aeolian material. Bedrock values for Ti and $\mathrm{V}$ were high (mean values of 7632 ppm and 165 ppm), while dust trap samples (assumed 100\% aeolian composition) contained low mean values of Ti and V (3113 ppm and $39 \mathrm{ppm}$ respectively). To determine the relative contribution of local material to postfire aeolian redistribution, we traced the relative concentrations of $\mathrm{Ti}$ and $\mathrm{V}$ in the dust trap samples over space and time. 


\section{RESULTS}

\subsection{Climate, Wind and Precipitation}

Climatic conditions from the regional to the plot scale influenced the mass flux rates and characteristics throughout the study period. From fall of 2015 to fall of 2017 the Palmer Drought Severity Index (PDSI) increased from -4 (dry) to 2 (wet) for the region. April 1 SWE increased each year from 2015 to 2017 for the RCEW and its aeolian source areas to the southwest (Figure 4-1). The fall of 2016 had higher rates of precipitation than any other fall sampling interval. The winter 2016/2017 interval received the highest rates of precipitation within the RCEW and the northern Great Basin region experienced April 1, 2017 SWE's between 100-200\% (compared to 25-50\% in 2015). The fall season had higher per day rates of wind gusts above $6 \mathrm{~m} / \mathrm{s}$ (Table 2-1) and greater precipitation than the summer sampling intervals on a site by site basis (Figure 4-1), both of which increase dust flux over a landscape (Whicker et al., 2001).

\subsection{Mass and Organic Matter Flux}

Undisturbed flux rates across the watershed were not statistically different from site to site within a given sampling interval but displayed strong variation seasonally (Figure 4-2). Winter aeolian deposition rates were statistically smaller (p-value <0.05) than deposition rates for the summer and fall sampling intervals (Figure 4-3). While fall and summer rates were not statistically different, the fall deposition rates contained higher variance annually than summer deposition rates. The fall sampling intervals produced the largest magnitude flux rate regardless of disturbance state (Table 4-1). 
Watershed wide variance within an individual sampling interval was low relative to seasonal variance (Table 4-3). No statistical difference was observed between any individual sites or subset of sites. While sagebrush sites (Low, High, Valley and UPE) received an average of 1.7 times the flux rate of the higher elevation conifer sites no statistical difference existed between the flux rates of the two ecosystems (Figure 4-4).

Undisturbed deposition rates were comparable to other regionally derived mineral aerosol deposition rates from across the globe (Figure 4-5). For 2016 and 2017 the RCEW recorded average dust flux rates of $11.0 \mathrm{~g} / \mathrm{m}^{2} / \mathrm{year}$ with a standard deviation of $4.9 \mathrm{~g} / \mathrm{m}^{2} /$ year across the watershed. $2016 \mathrm{had}$ an average flux rate of $12.27 \mathrm{~g} / \mathrm{m}^{2} /$ year while $2017 \mathrm{had}$ an average rate of $10.00 \mathrm{~g} / \mathrm{m}^{2} /$ year across the watershed (Table 4-2). In comparison, rates in the arid Mojave Desert averaged $11.4 / \mathrm{m}^{2} /$ year from 1982-2003 (Reheis, 2006). Assuming a largely regional input from playa and alluvial surfaces in Oregon and California based on grain size and geochemistry results, the observed dust flux rates are comparable to previous studies with regional inputs from around the world (Figure 4-5).

Following the Soda Fire in 2015, a significant increase in dust flux occurred within and proximal to the burned area while distal sites recorded fluxes representative of background, "undisturbed," rates (Figure 4-4). The disparity in flux rates caused by increases in deposition within the burned area led to a watershed wide mass flux standard deviation of $2.88 \mathrm{~g} / \mathrm{m}^{2}$, compared to $0.19 \mathrm{~g} / \mathrm{m}^{2}$ watershed wide standard deviation in the undisturbed fall of 2019. (Table 4-3). Within the burned area at the Low subset of sites, $13.2 \mathrm{~g} / \mathrm{m}^{2}$ of dust was deposited before the first growing season (an eight-month period) 
while only $21.04 \mathrm{~g} / \mathrm{m}^{2}$ was deposited for the following two years, indicating a 190\% increase in deposition rate following fire (Table 4-2).

The high elevation, Upper West sites (UPW) located in the southern portion of the watershed were unaffected by the Soda Fire (Figure 4-6). Sites impacted by the fire contained common coarse burnt organic matter $(<1 \mathrm{~mm})$ and showed substantial increases in mineral mass flux following the fire. The UPW sites were south of the fire perimeter and contained no evidence of postfire aeolian influence. While these sites experience the same seasonal variability as the rest of the watershed, the lack of fire influence created a pseudo control site. By simply dividing the mass flux rate at each site by the mass flux rate at the UPW sites, we can observe trends in the ratio between disturbed and undisturbed sites. Undisturbed sagebrush sites produce 2-3 times the dust flux observed in the subalpine conifer ecosystem of the UPW sites (Table 4-3). Following fire, sites within the burned area produced four to eight times the mass flux recorded at the UPW sites indicating a three to five fold increase in dust flux within the burned area until revegetation occurred (Figure 4-7).

Organic matter deposition over the watershed is variable over space and time. The highest elevation sites, within the subalpine conifer ecosystem, received the highest percentage of organic mass over the watershed at an average of $47 \%$ per sample (Table 44). Lower elevation sites received an average of $39 \%$ organic mass. In the absence of fire, the average organic matter mass percentage across the watershed is $46 \%$ while fire impacted sites received and average of $29 \%$ organic matter until revegetation (Figure 48). Samples collected from within the burned area before the first growing season contain thousands of visible fragments of coarse organic matter $>1 \mathrm{~mm}$ (Figure 4-6). After the 
first growing season and outside of the burn perimeter, coarse organic material was rare and charred organic material was non-existent. The organic material present after the burnt organic material dissipated was in the form of fine residual vegetative matter as noted in Delany and Zenchelsky (1976).

Organic matter results contain higher variance than the mineral aerosol component due to inputs from non-aeolian processes, including insect and avian contamination. Also, given the disparity in density between the mineral aerosols and aeolian derived organic matter, organic matter percentages throughout the study were related more to the mass of mineral aerosol deposited than the amount of organic matter present. Even though there was far more organic matter deposited in the fall of 2015 than the fall of 2017, the organic matter percent is higher in the fall of 2017 due to a lack of substantial mineral aerosol deposition (Figure 4-9).

Soil samples from the Murphy Creek drainage near the Low and High sites contained significantly less organic material than the aeolian material deposited in the dust traps. On exposed ridge sites, the A horizon from 0-6 cm depth contained only $0.6 \%$ carbon while on northeast facing hollows below exposed ridgelines average values were 1.5\% (Table 4-4). Will (2017) observed average soil organic carbon (SOC) values of $1.79 \%$ across the entire RCEW. Both values are significantly lower than the average $45 \%$ organic component of the dust trap samples in the RCEW (Table 4-4).

\subsection{Particle Size}

In undisturbed regions particle size is expected to remain fairly homogenous for aeolian deposition at the watershed scale because of the sorting processes involved in the long range transport of material (Schütz and Sebert, 1986). Atmospheric dust contains a 
$\mathrm{D}_{50}$ between 1 and $10 \mu \mathrm{m}$ while more regionally sourced loess is siltier in size (10-60 $\mu \mathrm{m})$ (d'Almeida and Shultz, 1983). The sample population $\mathrm{D}_{50}$ mean, not including the disturbed samples collected in the first interval following the Soda Fire, is $21.4 \mu \mathrm{m}$ across the RCEW. Watershed scale variation among all sites is relatively low with a total population $\mathrm{D}_{50} \sigma^{2}=2.6 \mu \mathrm{m}$ and $\mathrm{D}_{90} \sigma^{2}=7.6 \mu \mathrm{m}$. A $17 \%$ increase (outside of one standard deviation) in the $\mathrm{D}_{90}$ occurred at the postfire sites within the burned area before the first growing season (Table 4-5). Particle size distributions of the dust samples also reveal a larger variance in watershed wide aeolian deposition in the samples collected before the first growing season (Figure 4-10). Variance over time is greatest at the Low site within the burned area, as larger particles were deposited at topographically sheltered traps before the first growing season. The standard deviation of watershed wide $\mathrm{D}_{50}$ values dropped from $2.7 \mu \mathrm{m}$ following the fire to $0.8 \mu \mathrm{m}$ one-year postfire (Figure 4-10). Fall of 2017 did not have adequate sample sizes for analysis at any of the sites.

\subsection{Geochemistry}

Trace element analysis of the dust trap samples reveals a pulse of local material input to the traps within the burned area before the first growing season (Figure 4-11). As a function of bedrock weathering and aeolian input, soils plot compositionally between bedrock and regional loess deposits (Stark, 2012). Titanium (Ti) values for the two end members of the soil composition mixing model, bedrock and aeolian material, contain Ti values of 7000-8000 ppm and 3,500-4,500 ppm respectively. Soils from within the burned area have a mean Ti concentration of $6668 \mathrm{ppm}$ while the undisturbed dust trap samples contain concentrations of $3113 \mathrm{ppm}$. The dust trap samples are all compositionally related to the loess deposits, with one major exception. Ti values for 
samples collected within the burned area before the first growing (spring of 2016) are $6358 \mathrm{ppm} \mathrm{Ti}$, double that of the undisturbed average (Figure 4-11). After the first growing season, Ti values decrease within the burned area and samples plot with the remaining undisturbed dust traps.

Further geochemical evidence of the fire signature on the landscape exists in the trace elements Barium (Ba) and Strontium (Sr), elements related to soluble salts (Capo and Chadwick, 1999; Kaur, 2013;Van der Hoven and Quade, 2002). Ba and Sr are depleted in the postfire samples but are more enriched relative to the average upper continental crust (UCC) composition after the first growing season (Figure 4-12). Potassium, Uranium and Europium are also consistently enriched relative to UCC values in the dust trap samples (Table 4-6). Additionally, dust samples across the watershed contain an average of 9.5 weight percent ( $95,000 \mathrm{ppm})$ Calcium. 


\section{DISCUSSION}

\subsection{Seasonal and Climactic Controls on Aeolian Deposition}

To understand the impact of fire on aeolian deposition within the RCEW we must understand the natural controls on seasonal variability and the rates and characteristics of undisturbed dust flux. Seasonal variability in the magnitude and character of aeolian deposition occurs as climate influences the balance between shear stress and threshold friction velocity at both source and depositional locations. Increases in wind turbulence alone do not always correspond to increases in dust flux as numerous climactic variables control the threshold friction velocity of source areas (Reheis, 2006). For example, winter sampling intervals contain the highest wind speeds but concurrent persistent snow cover and increases in soil moisture across the region increase threshold friction velocities resulting in less entrainment and smaller dust fluxes (Fécan et al., 1998). Springtime saturated soils, vegetation growth, and high relative humidity all reduce dust flux (Ravi and D'Odorico, 2005). Summer is the dry period throughout the Great Basin, leading to low wet deposition driven flux rates (Figure 4-1). Fall sampling intervals within the RCEW contain the potential for the highest flux rates due to increased wind gusts associated with convective storms and increased rainout of dust from precipitation following dry summer months (Table 2-1).

Regional, larger-scale, environmental factors also influence the point data flux rates within the RCEW. High antecedent winter moisture can increase biological crusting as well as the amount and height of vegetation over the semi-arid land surface, increasing 
roughness and decreasing the availability of sediment (Brazel and Nickling, 1986). The winter of 2016/2017 was particularly wet in the northern Great Basin (April $1^{\text {st }}$ SWE of 125-200\%), leading to very small fluxes in the summer and fall of 2017 (Figure 4-2). On the other hand, winter of 2015/2016 was below average for the April $1^{\text {st }}$ percent of mean annual SWE (0-50\%), and low antecedent soil moisture drove higher dust flux in the fall of 2016 sampling interval (Figure 4-2). While dust flux was high in the fall of 2016, a lack of burnt organic material (Figure 4-7) and no local geochemical fingerprint (Figure 4-12) indicates that the increased flux was driven by the environmental conditions and not by any postfire influence.

\subsection{Characteristics of Aeolian Material Without the Influence of Fire}

Over our sampling period, seasonal variability at any individual site is greater than variability across the watershed over an individual sampling interval (Table 4-3). The results indicate that watershed scale input is not significantly different across the watershed but highly variable over time (Figure 5-1). The mid-low elevation sagebrush sites recoded mean deposition rates an average of 1.5 times greater than the higher elevation conifer sites but this difference is not statistically significant (Figure 4-4)/

The organic component of aeolian deposition was highly variable over space and time regardless of disturbance state. Previous studies have indicated that aeolian inputs to soils contain vital carbon resources for semi-arid landscapes (McTainish and Strong, 2007; Reynolds et al., 2001). Will (2017) observed average watershed wide SOC of $1.79 \%$ across the RCEW. Soil samples collected from the A-horizon of soils in Murphy Creek, within the burned area, contained an average of $1.5 \%$ carbon on north-facing slopes and $0.6 \%$ on south-facing slopes. Dust samples from our sampling period 
contained an average of $45 \%$ organic matter, further evidence that aeolian deposition provides vital organic material to sparsely vegetated landscapes.

In the absence of fire, the particle size distribution of aeolian material is not influenced by topographic position, vegetation type or precipitation regime at individual sites due to the shared nature of its source (Figure 4-11). Dust trap samples showed low standard deviations in grain size distribution across the watershed indicating a relatively homogenous input (Figure 4-11). The median $\mathrm{D}_{50}$ grain size of $24.1 \mu \mathrm{m}$ indicates a regional silt-sized loess signature. The regional input of silt-sized particles at our dust traps occurs homogenously across the watershed as indicated by the low variance in the $\mathrm{D}_{50}$ at all sites (Table 4-5). The silt-sized fraction is key to the retention of water and nutrient availability of soils in the semi-arid sagebrush ecosystem (Caravaca et al., 1999).

Small seasonal variations do exist in the grain size distribution data (Figure 4-10). Winter sampling intervals contain the finest grain sizes. High soil moisture contents and persistent snow cover limit the amount of entrainment that can occur locally through increased interparticle cohesion and bare ground cover (Prospero and Lamb, 2003, Reheis, 2006). Therefore, a higher percentage of the dust sample is derived from finer, well-sorted, atmospheric mineral aerosols as opposed to seasonally unavailable regional material. Summer sampling intervals are characterized by dry soils, fewer wind speeds above $6 \mathrm{~m} / \mathrm{s}$ and rare precipitation events (Figure 4-1) that all lead to limited local coarse material entrainment and less overall deposition (Figure 4-2). The fall sampling intervals produced the coarsest grain size distributions (Figure 4-10) due to high winds capable of entrainment of particles up to $70 \mu \mathrm{m}$ and precipitation events that effectively deposit 
material. However, postfire aeolian processes overprint any seasonal variation in grain size distribution within and proximal to the burned area.

Geochemistry and climactic data results indicate that aeolian input to the RCEW is likely sourced from the playa and alluvial fan complex of southeastern Oregon and northwestern California (Figure 2-4). Wind direction data indicates that frontal storms capable of producing sufficient wind to entrain material move through the RCEW from the southwest (Figure 2-3). Samples from across the watershed are enriched Barium, Potassium, Uranium, and Strontium values relative to the average upper continental crustal values (Table 4-6). Strontium is associated with the formation of strontianite, aragonaite, and celestite of playa sediments in the Great Basin (Witherow and Lyons, 2011).

\subsection{Postfire Disturbance}

Geochemistry and mass flux data, along with field observations from RCEW, show that the mobilization of local material lasted until the revegetation of the landscape in the spring of 2016. Postfire disturbance increases aeolian mass flux by mobilizing local sediment and redistributing it from the microsite scale through to the landscape scale (Ravi et al., 2009). The removal of vegetation and the burning of soil both lead to a decrease in surficial threshold friction velocity through the removal of vegetative roughness and decreased soil aggregate stability, allowing wind to more effectively entrain material (Ravi et al., 2011). Within the burned area, sagebrush and bitterbrush were completely consumed by fire in August of 2015 and replaced the following April by grasses (native and non-native) and forbes (Figure 5-2). Increases in mass flux and $\mathrm{D}_{90}$ grain size, coupled with geochemical analysis, indicate that local sediment and organic 
material, made available by fire, are preferentially redistributed to sheltered positions in complex terrain.

Mass flux within the burned area was up to ten times as great in the fall of 2015 ( $250 \mathrm{mg} / \mathrm{m}^{2} /$ day) relative to the fall of $2017\left(25 \mathrm{mg} / \mathrm{m}^{2} /\right.$ day) at the Low subset of sites. While the High sites within the burned area also recorded large fluxes postfire, their position on exposed ridgelines potentially limited the amount of deposition that occurred. Exposed sites within the burned area, which are more susceptible to high wind speeds (Figure 2-4), may have kept material entrained during wind events above threshold entrainment velocities, decreasing the amount of deposition relative to more sheltered sites. The Low sites, located in sheltered valley bottoms within the burned area, received nearly twice the amount of deposition as their exposed counterparts within the burned area. After revegetation in the spring of 2016, both the Low and High sites, all located within $<1$ square mile and separated by one drainage divide, received mass flux values that were not significantly different (Figure 4-4).

The mid and low-elevation sagebrush sites record mass fluxes $\sim 1.7$ times greater than the higher elevation, conifer "control" sites. Without the disturbance of the Soda Fire and based on the determined ratio of subalpine ecosystem dust flux to sagebrush ecosystem dust flux, we estimate a three to five-fold increase in the total mass flux directly related to the postfire wind redistribution of local material within the burned area. Studies from the Snake River Plain indicate that negligible amounts of material move through saltation or vertical flux during undisturbed conditions (Hasselquist et al., 2011; Sankey et al., 2009). Changes in fire disturbance regime due to invasive species will increase the amount of bare ground open to disturbance and increase the flux of material 
from windward to sheltered slopes (Whisenant, 1990). Given the stable background conditions and low sediment flux rates of the semi-arid sagebrush steppe, episodic pulses of increased postfire aeolian flux may contribute substantially to millennial scale flux rates.

At a height of two meters, the dust traps were designed to collect material falling out of atmospheric suspension, not material saltating above the ground surface. Through height filtering of saltating material, the samples collected contain negligible amounts of material above silt-sized dimensions. However, the collectors within the burned area following fire recorded a $17 \%$ increase in the average $\mathrm{D}_{90}$ for the sampling intervals before revegetation. The lack of vegetative roughness and decreased threshold friction velocities due to soil burn severity following fire potentially allowed for the entrainment of previously stable material, adding local sediment, of a larger size class, to the postfire samples.

Geochemistry data indicates that the increase in flux within the burned area following the fire was derived from local soil enriched in Ti (Figure 4-12). Local soils within the complex topography of the burned area are poorly developed with little horizon formation. As such, the local soils plotted compositionally more similar to the bedrock end member of soil formation and contained higher Ti values than soils found in stable regional valleys, composed of largely aeolian material (Figure 4-12). We attribute the increase in Ti found in the burned area dust traps before the first growing season to local sediment input. During stable, undisturbed periods, local material is either immobile or saltating below the two meter height of the dust traps. After fire, local material is easily entrained and redistributed preferentially around the burned area. 
The mass flux, grain size distribution and geochemical results indicate the potential for orders of magnitude greater mass flux at topographically controlled positions on a landscape due directly to wind redistribution of locally derived sediment and organic material. In a landscape with relatively low background erosion rates, the implications of large pulse events can control hydrogeochemical processes (Kirchner et al., 2001). Topographically lower and sheltered sites (Low sites) within the watershed had the greatest increase in postfire deposition while higher sites (High sites) on exposed ridgelines saw only moderate increases (Figure 4-2). Field observations of spatially preferential "dust drifts" of sediment and organic material validate the importance of topographic position on the redistribution of sediment, organic material and nutrients where complex topography, fire, and a dynamic atmosphere intersect.

\subsection{Aeolian Influence on the Semi-Arid Landscape}

Disparities in north and south facing slope morphology and soil characteristics are well documented and are often explained in the literature by a water-energy balance (Beaudette and O'Geen, 2009; Kunkel et al., 2011; McNamara et al., 2018; Poulus, 2012). In water-limited systems, such as the mid to low elevations of the Great Basin, differences in aspect derived insolation intensity begin a biogeomorphic feedback leading to increased soil water retention, vegetation density, soil organic carbon, and soil depths on steeper north facing slopes (Istanbulluoglu et al., 2008; Reid, 1973). Recent investigations into the variability of soil characteristics at the landscape scale have used aspect (Beaudette and O'Geen, 2009) and hillslope curvature (Patton et al., 2018) to predict the location of Mollisols (soils with a dark, humus rich surface layer) and the depth of total-mobile-regolith, respectively. All of these studies agree that topography has 
an impact on soil characteristics, but few consider the influence of aeolian deposition of sediment and organic matter.

Our study indicates that a seasonally variable flux of regionally sourced dust is input homogenously over complex topography in semi-arid regions. With the disturbance of wildfire, threshold friction velocity is decreased across the landscape as stabilizing vegetation is removed and biological soil crusts are destroyed (Ford and Johnson, 2006; Sankey et al., 2009). Concurrently, shear stress is increased in the boundary layer above the soil surface where pre-fire vegetation previously added roughness. We posit that aspect and wind direction controlled differences in shear stress lead to preferential mobilization of material across a burned landscape. While the decrease in threshold friction velocity occurs on all aspects and hillslope positions, aspects exposed to prevailing winds and exposed ridgeline locations receive higher shear stresses than the sheltered leeward hollows and lower slopes. The aspect-dependent variation in shear stress likely leads to the preferential distribution of material to topographically controlled locations on the landscape.

While the traps used in our study were located two meters above the soil surface, and therefore should not receive any material larger than $70 \mu \mathrm{m}$, we clearly delineated an input of coarse grained material with a geochemical fingerprint of the soils within the burned area. Dust taps located in topographically sheltered locations received the largest postfire interval fluxes and coarsest grain sizes. Our results, coupled with field observations, demonstrate that local sediment and organic material, mobilized by fire, is heterogeneously redistributed at the hillslope scale with substantially higher flux rates until the revegetation of the landscape. 
In semi-arid soils, silt content is directly linked to soil water retention and Stark (2012) concluded that semi-arid soils in the Dry Creek Experimental Watershed (DCEW) in southwestern Idaho, contained 38\% loess (silt-sized material) on north facing slopes and $16 \%$ on south facing slopes. The increased dust component on north facing slopes increases soil water availability, vegetation density and soil thickness. Dust in the RCEW collected in the burned area before revegetation contained $88 \%$ silt and clay, recorded fluxes up to an order of magnitude greater than background rates, and were preferentially deposited in sheltered, leeward areas on north through east facing aspects. The contributions of episodic pulses of large magnitude sediment fluxes to aspect and wind direction controlled locations across the semi-arid landscape should be considered in our understanding of the spatial variability of soil characteristics at the hillslope scale.

Our study suggests an aspect dependent control on soil characteristics where wind is efficiently moving material from windward to leeward aspects in episodic pulses following fire. In our study area, the combined influence of topography and wind direction preferentially deposit material to northeast-facing hollows and swales, as well as north facing toe slopes and confined valley bottoms. Mass flux, geochemistry, and grain size data collected from passive dust traps confirm that local material is temporarily mobile following fire, and is preferentially deposited in sheltered locations across complex topography (Figure 4-2). Disentangling the relative importance of postfire wind redistribution from the traditional model of aspect-derived differences in insolation, as well as the aspect-controlled distribution of increased snow water equivalent and subsequent water availability, would better constrain future attempts to model the spatial variability of soil characteristics in the semi-arid regions of the world. 


\subsection{Deposition Over Millennial Scales}

Assuming a particle density of silt-sized mineral aerosols of $1 \times 10^{6} \mathrm{~g} / \mathrm{m}^{3}$

(Mahowald et al, 2014), we calculated the depth of aeolian deposition for 100,000-year time scales using averaged flux rates from our study period. Without disturbance, we determined an influx of 1.2, 1.1 and $0.74 \mathrm{~m} / \mathrm{m}^{2}$ at valley, mid-elevation sagebrush, and subalpine sites respectively over $100 \mathrm{ka}$ (Table 5-1). Along the Boise River, the Whitney Terrace is capped with 1-2 meters of loess and sits atop basalt flows dated to $\sim 120 \mathrm{ka}$ (Othberg and Gillerman, 1994). The rates described only record flux during current climactic conditions and measure the gross deposition of material onto the landscape, not the subsequent postfire redistribution of material. However, the $100 \mathrm{ka}$ rates demonstrate the ability of small and steady flux rates to alter landscapes and provide nutrients and sediment to semi-arid ecosystems. The presence of abundant calcium in the dust collected also provides a viable source material for the formation of pedogenic calcium carbonate deposits found throughout the stable valley bottoms in the region (Stanbery, 2016;

Othberg and Gillerman, 1994). While aeolian deposition is homogenous across the low to mid elevation sagebrush-steppe ecosystem (Figure 5-1), postfire redistribution is spatially controlled and severely heterogeneous at the hillslope to landscape scale (Figure 5-3).

The 100 ka year rates describe a deposition rate without any disturbance from fire. In our study, aeolian deposition within the burned area increased by three times until the first growing season. Given a fire recurrence interval of 200 years for a low sagebrush ecosystem, dust flux would triple $0.5 \%$ of the time. With the alteration of semi-arid plant communities by non-native annual grasses, the fire recurrence interval is lowered to 20 years (a conservative estimate) and increases dust flux by an order of magnitude. 
Vegetation density and plant community distribution is tied to aspect-controlled soil depth and productivity in the semi-arid west (Burke et al., 1989). The increased flux of local sediment and organic material following fire feeds a growing soil productivity gap between windward and leeward slopes. Windward slopes, more frequently stripped bare due to increased fire disturbance, will continue to lose top-soil through postfire wind erosion processes and leeward slopes will continue to obtain the vital sediment and organic material load. To better understand the distribution and characteristics of soil resources and landform evolution in semi-arid ecosystems, future research must consider the influence of aeolian deposition and the subsequent wind redistribution of sediment and nutrients beyond the microsite and plot-scale in complex terrain. 


\section{CONCLUSIONS}

Two years of continuous passive dust trap collector data were used to analyze the spatial and temporal influence of wildfire on aeolian deposition following the 2015 Soda Fire in southwestern Idaho. Differences in mass flux, particle size distribution, and geochemistry between postfire samples and samples collected after revegetation in the following spring indicate that fire effectively decreases threshold friction velocities until the first growing season, allowing for increased mobility of local sediments. Increases in $\mathrm{D}_{90}$ indicate the mobility of a coarser size fraction within the burned area relative to undisturbed regions. Geochemistry data reveals a local signature of sediment deposited in the traps, sourced from local soil before the first spring green-up following fire.

When complex topography and turbulent wind interact after wildfire in a sagebrush ecosystem, the increased mobility of surface sediments and organic material, coupled with a lack of vegetative roughness, leads to the preferential redistribution of material based on topography and wind direction. Two to four-fold increases in vertical mass flux of $>80 \%$ silt-sized particles and $>40 \%$ organic matter material provides an important fine fraction and organic component to spatially controlled soils in a water and nutrient limited landscape.

While threshold friction velocity is reduced throughout the entirety of the watershed, shear stress is likely partitioned preferentially to windward slopes controlled by wind direction and topography. The presence of local material at the two meter height of our dust traps indicates that temporary decreases in threshold friction velocity allows 
for small-scale (tens of meters) suspension and deposition of material at wind speeds less than $10 \mathrm{~m} / \mathrm{s}$ from windward to leeward slopes. In northeast-facing colluvial hollows, sheltered toe slopes, and leeward slopes in swale systems, deeper, finer-grained, and organic rich soils provide more nutrients and plant available water to slope stabilizing and dust trapping vegetation than south facing and windward slopes. Spatially controlled, episodic pulses of postfire aeolian sediment and organic material must be considered when describing soil pedogenesis and spatial variability in semi-arid sagebrush ecosystems with complex topography. 


\section{REFERENCES}

Bagnold R.A. 1941. The Physics of Blown Sand and Desert Dunes, Methuen: London.

Balch J.K., Bradley B.A., D'Antonio C.M., Gomez-Dans J. 2013. Introduced annual grass increases regional fire activity across the arid western U.S.A. (1980-2009). Global Change Biology; 19:173-183.

Beaudette D.E., O'Geen, A.T. 2009. Quantifying the aspect effect: an application of solar radiation modeling for soil survey. Soil Science Society of America Journal; 73, 1245-1352.

Brazel A.J., Nickling W.G. 1986. The relationship of weather types to dust storm generation in Arizona (1965-1980) Journal of. Climatology; 6 pp. 255-275

Breshears, D. D., Whicker J. J., Johansen M. P., and Pinder J. E. 2003. Wind and water erosion and transport in semi-arid shrubland, grassland and forest ecosystems: Quantifying dominance of horizontal wind-driven transport, Earth Surface Processes and Landforms; 28, 1189-1209, DOI:10.1002/esp.1034.

Brooks M. L., D'antonio C. M., Richardson D. M., Grace J. B., Keeley J. E., DiTomaso J. M., ... Pyke D. 2004. Effects of invasive alien plants on fire regimes. BioScience; $54,677-688$.

Bowman D.M., Johnston F.H. 2005. Wildfire smoke, fire management, and human health. EcoHealth; 2(1):76-80 DOI: 10.1007/s10393-004-0149-8.

Burke, I.C., Reiners, W.A., Olson, R.K. 1989. Topographic control of vegetation in a mountain big sagebrush steppe. Vegetatio; 84: 77. DOI:10.1007/BF00036508

Capo, R. C. and Chadwick, O. A. 1999. Sources of strontium and calcium in desert soils and calcrete. Earth and Planetary Science Letters; 170, 61-72. 
Caravaca, F., Lax, A., Albaladejo, J. 1999. Organic matter, nutrient contents and cation exchange capacity in fine fractions from semi-arid calcareous soils. Geoderma; 93 pp. 161-176.

Cattle, S., McTainsh H., Sherwin G. 2009. Aeolian dust deposition rates, particle-sizes and contributions to soils along a transect in semi-arid New South Wales, Australia. Sedimentology; 56. DOI:10.1111/j.1365-3091.2008.00996.x.

d'Almeida, G. A., and Schutz L. 1983. Number, mass and volume distributions of mineral aerosol and soils of the Sahara. Journal of Climatology and Applied Meteorology; 22, 233-243.

Delany, A. C. and Zenchelsky, S. 1976. The organic component of wind-erosion generated soil-derived aerosol. Soil Science; 121, 146-155.

Dukes, D., Gonzales, H. B., Ravi, S., Grandstaff, D. E., Van Pelt, S., Junram, L., Wang, G., Sankey, J. B. 2018. Quantifying postfire aeolian sediment transport using rare earth element tracers. Journal of Geophysical Research: Biogeosciences; 123, 288-299. DOI:10.1002/ 2017JG004284.

Ellis, J.T., Sherman, D.J. 2013. Fundamentals of Aeolian Sediment Transport: WindBlown Sand J.F. Shroder (Ed.), Treatise on Geomorphology, Academic Press, San Diego. pp. 85-108

Fécan F., Marticorena B., Bergametti G. 1999. Parametrization of the increase of the aeolian erosion threshold wind friction velocity due to soil moisture for arid and semi-arid areas. Annales Geophysicae; 17, 1, 149.

Ford, P. L., and G. V. Johnson. 2006. Effects of dormant- vs. growing-season fire in shortgrass steppe: biological soil crust and perennial grass responses. Journal of Arid Environments 67:1-14.

Geroy I.J., Gribb M.M., Marshall H.P. 2011. Aspect influences on soil water retention and storage. Hydrological Processes; 25: 3836-3842.

Gillies, J.A., 2013. Fundamentals of aeolian sediment transport: dust emissions and transport - near surface. In: Shroder, J. (Editor in Chief), Lancaster, N., Sherman, 
D.J., Baas, A.C.W. (Eds.), Treatise on Geomorphology. Academic Press, San Diego, CA, 11, Aeolian Geomorphology; 43-63.

Ginoux, P., Prospero, J., Gill, T., Hsu, N., Zhao. M. 2012. Global-scale attribution of anthropogenic and natural dust sources and their emission rates based on MODIS Deep Blue aerosol products. Reviews of Geophysics; 50 (3) DOI:10.1029/2012RG000388.

Hasselquist N., M. J. Germino, J. Sankey, N. Glenn, and J. Ingram. 2011. Aeolian nutrient fluxes following wildfire in sagebrush steppe: Implications for soil carbon storage. Biogeosciences; 8(12): 3649-3659 DOI: 10.5194/bg-8-3649-2011.

Hirmas, D. R., and R. C. Graham. 2011. Pedogenesis and Soil-Geomorphic Relationships in an Arid Mountain Range, Mojave Desert, California. Soil Sci. Soc. Am. J. 75:192-206. doi:10.2136/sssaj2010.0152

Huneeus, N.; Schulz, M.; Balkanski, Y.; Griesfeller, J.; Prospero, J.; Kinne, S.; Bauer, S.; Boucher, O.; Chin, M.; Dentener, F.; Diehl, T.; Easter, R.; Fillmore, D.; Ghan, S.; Ginoux, P.; Grini, A.; Horowitz, L.; Koch, D.; Krol, M. C.; Landing, W.; Liu, X.; Mahowald, N.; Miller, R.; Morcrette, J. -J.; Myhre, G.; Penner, J.; Perlwitz, J.; Stier, P.; Takemura, T.; Zender, C. S. 2011. "Global dust model intercomparison in Aero Com phase I". Atmospheric Chemistry and Physics; 11(15): 7781. DOI:10.5194/acp-11-7781-2011.

Istanbulluoglu, E. Y., Vivoni, E., Gutiérrez-Jurado, H., Bras, R. 2008. Eco-geomorphic implications of hillslope aspect: Inferences from analysis of landscape morphology in central New Mexico. Geophysical Research Letters; 35. DOI:10.1029/2008GL034477.

Kaur, M. 2013. The Terrestrial Biogeochemical Cycle of barium: A proposed study to examine barium flux in Mojave Desert dust. Scripps Senior Theses; 150. http://scholarship.claremont.edu/scripps_theses/150

Kirchner J.W., Finkel R.C., Riebe C.S., Granger D.E., Clayton J.L., King J.G., Megahan W.F. 2001. Mountain erosion over 10 yr, 10 k.y. and 10 m.y. time scales. Geology; 29: 591-594. 
Kok J .F., Parteli J.R., Michaels T.I. and Bou Karam, D. 2012. The physics of windblown sand and dust. Reports on Progress in Physics; 75. 106901.

Kunkel M.L., Flores A.N., Smith T.J., McNamara J.P., Benner S.G. 2011. A simplified approach for estimating soil carbon and nitrogen stocks in semi-arid complex terrain. Geoderma; 165, 1-11.

Lawrence, C.R. and Neff, J.C. 2009. The contemporary physical and chemical flux of aeolian dust: a synthesis of direct measurements of dust deposition, Chemical Geology; 267 (1-2) (2009), pp. 46-63, DOI: 10.1016/j.chemgeo.2009.02.005.

Litaor, M. I., Williams, M., and Seastedt T. R. 2008. Topographic controls on snow distribution, soil moisture, and species diversity of herbaceous alpine vegetation, Niwot Ridge, Colorado. Journal of Geophysical Research. 113, G02008, DOI:10.1029/2007jg000419.

Mahowald, N. M., Muhs D. R., Levis S., Rasch P. J., Yoshioka M., Zender C. S., Luo, C. 2006. Change in atmospheric mineral aerosols in response to climate: Last glacial period, preindustrial, modern, and doubled carbon dioxide climates, Journal of Geophysical Research; 111. DOI:10.1029/2005JD006653.

Mahowald N., Albani S., Kok J.F,. Engelstaeder S, Scanza R., Ward D.S, Flanner M.G.. 2014. The size distribution of desert dust aerosols and its impact on the earth system Aeolian Research; 15. 53-71.

McAuliffe, J.R., McFadden L.D., and Hoffman M. T. 2018. Role of Aeolian Dust in Shaping Landscapes and Soils of Arid and Semi-Arid South Africa. Geosciences 2018, 8(5), 171. DOI:10.3390/geosciences8050171.

McNamara JP, Benner SG, Poulos MJ, et al. 2018. Form and function relationships revealed by long-term research in a semiarid mountain catchment. WIREs Water. DOI: $10.1002 /$ wat2.1267.

McIntyre, D. H. 1972. Cenozoic geology of the Reynolds Creek Experiemental Watershed, Owyhee County, Idaho. Idaho Bureau of Mines and Geology, Pamphlet P-151. 
McTainsh G.H., Strong, C. 2007. The role of aeolian dust in ecosystems Geomorphology; 89. 39-54.

Miller, R.F., and Tausch R.J. 2001. The role of fire in juniper and pinyon woodlands: a descriptive analysis. pp. 15-30 in K.E.M. Galley and T.P. Wilson, editors, Proceedings of the Invasive Species Workshop: the role of fire in the control and spread of invasive species. Fire conference 2000: the first national congress on fire ecology, prevention, and management. Miscellaneous Publication No. 11; Tall Timbers Research Station, Tallahassee, FL.

Okin, G. S., and Gillette D.A. 2001. Distribution of vegetation in wind dominated landscapes: Implications for wind erosion modeling and landscape processes Journal of Geophysical Research; 106. 9673-9683.

Okin, G. S., and Reheis M.C. 2002. An ENSO predictor of dust emission in the southwestern United States. Geophysical Research Letters; 29. 9. DOI:10.1029/2001GL014494.

Okin, G. S., Mahowald, N., Chadwick, O. A., Artaxo, P. 2004. Impact of desert dust on the biogeochemistry of phosphorus in terrestrial ecosystems. Global Biogeochemical Cycles; 18. DOI:10.1029/2003GB002145.

Okin, G. S., D. A. Gillette, Herrick J. E. 2006. Multi-scale controls on and consequences of aeolian processes in landscape change in arid and semi-arid environments. Journal of Arid Environments; 65, 253-275, DOI:10.1016/j.jaridenv.2005.06.029.

Othberg K.L. and V.S. Gillerman, 1994. Field Trip Guide to the Geology of the Boise Valley. Idaho Geologic Survey, Special Report.

Patton, N. R., Lohse, K. A., Godsey, S. E., Crosby, B. T., \& Seyfried, M. S. (2018). Predicting soil thickness on soil mantled hillslopes. Nature Communications; 9, 3329. https://doi.org/10.1038/s41467-018-05743-y

Pierson, F.B., Williams, C.J., and Robichaud, P.R. 2015. Assessing impacts of fire and postfire mitigation on runoff and erosion from rangelands. Great Basin Factsheet Series, Number 11. Published jointly by the Joint Fire Science Program, Great Basin Fire Science Exchange, Great Basin Research and Management 
Partnership, Great Basin Landscape Conservation Cooperative, and the Sagebrush Steppe Treatment Evaluation Project. 6 p.

Pierson, F. B., Robichaud P. R., Spaeth K. E. 2001. Spatial and temporal effects of wildfire on the hydrology of a steep rangeland watershed. Hydrologic

Processes, 15. 2905-2916.

Pierson Jr, F.B., Williams, C.J. 2016. Ecohydrologic impacts of rangeland fire on runoff and erosion: A literature synthesis. Gen. Tech. Rep. RMRS-GTR-351. Fort Collins, CO: U.S. Department of Agriculture, Forest Service, Rocky Mountain Research Station. 110 p.

Poley, A. 2017. "Deriving Landscape-Scale Vegetation Cover and Aboveground Biomass in a Semi-Arid Ecosystem Using Imaging Spectroscopy". Boise State University Theses and Dissertations. 1360. https://doi.org/10.18122/B25Q72

Prospero, J. M. \& Lamb, J. P. 2003.African droughts and dust transport to the Caribbean: Climate change and implications. Science; 302. 1024-1027.

Poulos, Michael John, "Hillslope Asymmetry Maps Reveal Widespread, Multi-Scale Organization" (2012). Boise State University Theses and Dissertations. 309. https://scholarworks.boisestate.edu/td/309.

Ravi, S., and D'Odorico P. 2005. A field-scale analysis of the dependence of wind erosion threshold velocity on air humidity. Geophysical. Research. Letters; 32. L21404. DOI:10.1029/2005GL023675.

Ravi, S., \& D'Odorico, P. 2009. Post-fire resource redistribution and fertility island dynamics in shrub encroached desert grasslands: A modeling approach. Landscape Ecology; 24(3), 325-335. DOI:10.1007/s10980-008-9307-7.

Ravi, S., D'Odorico, P., Zobeck, T. M., Over, T. M., \& Collins, S. L. 2007. Feedbacks between fires and wind erosion in heterogeneous arid lands. Journal of Geophysical Research. 112. G04007. DOI:10.1029/2007JG000474.

Ravi, S., P. D’Odorico, Herbert B., Zobeck T., Over T. M. 2006. Enhancement of wind erosion by fire-induced water repellency. Water Resources Research; 42. 
Ravi, S., et al. 2011 Aeolian processes and the biosphere Reviews of Geophysics., 49, DOI:10.1029/2010RG000328.

Reid, I. 1973. The influence of slope orientation upon the soil moisture regime, and its hydrogeomorphological significance. Journal of Hydrology; 19:309-321.

Reheis, M. 1995. Dust deposition in southern Nevada and California, 1984-1989: Relations to climate, source area, and source lithology. Journal of Geophysical Research; 100. 8893-8918.

Reheis, M, 2006. A 16-year record of eolian dust in Southern Nevada and California, USA: Controls on dust generation and accumulation. Journal of Arid Environment; 67. 487-520.

Reheis, M.C., Budahn J.R., Lamothe P.J., Reynolds R.L. 2009 Compositions of modern dust and surface sediments in the Desert Southwest, United States. Journal of Geophysical Research Earth Surface, 114. p. F01028

Reynolds R. L., Belnap J., Reheis M. C., Lamothe P., Luiszer F., 2001. Aeolian dust in Colorado Plateau soils: Nutrient inputs and recent change in source. Proceedings of the National Academy of Sciences U.S.A; 98. 7123-7127.

Reheis M.C., Urban F.E. 2011. Regional and climatic controls on seasonal dust deposition in the southwestern U. S. Aeolian Research, 3. pp. 3-21.

Sankey JB, Germino MJ, Glenn NF. 2009. Aeolian sediment transport following wildfire in sagebrush steppe. J Arid Environ 73(10):912-19.

Sankey JB, Germino MJ, Sankey TT, Hoover AN. 2012. Fire effects on the spatial patterning of soil properties in sagebrush steppe, USA: a meta-analysis. Int $\mathbf{J}$ Wildland Fire 21(5):545-56.

Sankey, J.B., Glenn, N.F., Germino, M.J., Gironella, A.I.N. and Thackray, G.D. 2010. Relationships of aeolian erosion and deposition with LiDAR-derived landscape surface roughness following wildfire. Geomorphology; 119: 135-145.

Schütz, L., Sebert, M., 1987. Mineral aerosols and source identification. Journal of Aerosol Science 18 (1), 1-10. 
Seyfried, M., Harris, R., Marks, D. and Jacob, B. 2001. Geographic database, Reynolds Creek Experimental Watershed, Idaho, United States. Water Resources Research; 37. $2825-2829$.

Shao, Y., 2008. Physics and modelling of wind erosion. Springer Verlag.

Simon Frasier University Soil Science Lab 2011, Direct Estimation of Organic Matter by Loss on Ignition: Methods, practical and tutorial manual, Burnaby, Canada.

Simonson, R.W. 1995. Airborne dust and its significance to soils. Geoderma. 65, 143.

Slaughter, C.W., Marks D., Flerchinger G.N., Van Vactor S.S., and Burgess M.. 2001. Thirty-five years of research data collection at the Reynolds Creek Experimental Watershed, Idaho, United States. Water Resources Research; 37:2819-2824.

Sperazza, M., Moore, J.N., Hendrix M.S. 2004. High-Resolution Particle Size Analysis of Naturally Occurring Very Fine-Grained Sediment Through Laser Diffractometry. Journal of Sedimentary Research ; 74 (5): 736-743. DOI:10.1306/031104740736.

Stanbery, C.A. 2016. "Controls on the Presence, Concentration, Storage, and Variability of Soil Inorganic Carbon in a Semi-Arid Watershed" Boise State University Theses and Dissertations. 1233. https://scholarworks.boisestate.edu/td/1233

Stark, B. J. 2012. Assessing Eolian Dust Inputs to Soils in Dry Creek Experimental Watershed, SW Idaho. 323. http://scholarworks.boisestate.edu/td/323.

Stephenson, G. R. 1977. Soil-geology-vegetation inventories for Reynolds Creek Watershed, Miscellaneous series No. 42, Agricultural Experiment Station, University of Idaho College of Agriculture.

Stocking M.A. 1984. Erosion and soil productivity: A review. Consultantś Working Paper 1, Land and Water Development Division, Food and Agriculture Organization, Rome.

Van der Hoven, S. J., \& Quade, J. 2002. Tracing spatial and temporal variations in the sources of calcium in pedogenic carbonates in a semiarid 
environment. Geoderma; 108(3-4), 259-276. DOI: 10.1016/S00167061(02)00134-9.

Varela, M.E., Benito, E., Keizer, J. 2010. Wildfire effects on soil erodibility of woodlands in NW Spain Land Degradation and Development, 21. pp. 7582, DOI:10.1002/ldr.896.

Wagenbrenner, N., Chung, S., Lamb, B. 2017. A large source of dust missing in Particulate Matter emission inventories? Wind erosion of postfire landscapes. Elem Science of the Anthropocene; 5: 2, DOI: 10.1525/elementa. 185

Wagenbrenner, N.S., Germino M.J., Lamb B.K., Robichaud P.R., Foltz R.B. 2013. Wind erosion from a sagebrush steppe burned by wildfire: measurements of $\mathrm{PM}_{10}$ and total horizontal sediment flux. Aeolian Research; 10 pp. 25-36.

Will, Ryan Matthew, 2017. "Mapping Soil Organic Carbon (SOC) in a Semi-Arid Mountainous Watershed Using Variables From Hyperspectral, Lidar and Traditional Datasets". Boise State University Theses and Dissertations. 1364. https://doi.org/10.18122/B2113D.

Whicker, J. J., Breshears D. D., Wasiolek P. T., Kirchner T. B., Tavani R. A., Schoep D. A., Rodgers J. C. 2001. Temporal and Spatial Variation of Episodic Wind Erosion in Unburned and Burned Semiarid Shrubland. Journal of Environmental Quality; 31:599-612. DOI10.2134/jeq2002.5990.

Whisenant, S.G. 1990. Changing fire frequencies on Idaho's Snake River Plains: ecological and management implications. Pages 4-10 In: McArthur, E. Durant; Romney, Evan M.; Smith, Stanley, Tueller, D., Paul T. (eds.). Proceedings Symposium on cheatgrass invasion, shrub die-off, and other aspects of shrub biology and management. General Technical Report INT-GTR-276. Ogden, UT: USDA Forest Service.

Williams C.J., Pierson F.B., Kormos P.R., Al-Hamdan O.Z., Hardegree S.P., Clark P.E. 2016. Ecohydrologic response and recovery of a semi-arid shrubland over a five year period following burning. Catena; 144. 163-176. 
Winstral, A., and Marks D. 2002. Simulating wind fields and snow redistribution using terrain based parameters to model snow accumulation and melt over a semi-arid mountain catchment. Hydrological Processes; 16. 3585-3603.

Winstral, A., Marks D., and Gurney R. 2013. Simulating wind-affected snow accumulations at catchment to basin scales. Advances in Water Resources; 55. 64-79.

Witherow, R. A., \& Lyons, W. B. 2011. The fate of minor alkali elements in the chemical evolution of salt lakes. Saline Systems; 7, 2. DOI:10.1186/1746-1448-7-2

Yaalon D. H. and Ganor, E. 1973. The influence of dust on soils in the Quaternary Soil Science; 116, 146-155.

Ypsilantis, W. G. 2003. Risk of Cheatgrass Invasion After Fire in Selected Sagebrush Community Types. Bureau of Land Management Resource Notes. 63. 1-2.

Yu, H., Chin, M., Yuan, T., Bian, H., Remer, L., Prospero, J., Omar, A., Winker, D., Yang, Y., Zhang, Y., Zhang, Z., and Zhao, C., 2015. The fertilizing role of African dust in the Amazon rainforest: A first multiyear assessment based on data from Cloud-Aerosol Lidar and Infrared Pathfinder Satellite Observations. Geophysical Research. Letters; 42, 1984-1991. DOI:10.1002 /2015GL063040.

Zaady, Eli \& Offer, Z.Y. \& Shachak, M. 2001. The content and contributions of deposited Aeolian organic matter in a dry land ecosystem of the Negev Desert, Israel. Atmospheric Environment; 35. 769-776.

DOI:10.1016/S1352310(00)00263-6. 
Table 2-1: Summary of wind and precipitation data from sites within the RCEW.

Wind speeds measured at 3 meters above the ground surface and precipitation data from unbaffled buckets. Sankey et al (2009) recorded saltation following fire in the Snake River Plain, ID at $10 \mathrm{~m} / \mathrm{s}$. New research shows that dust emission does occur before saltation initiation and the $6 \mathrm{~m} / \mathrm{s}$ value is a conservative estimate for threshold friction velocities for dust emissions in semi-arid deserts after fire (Sankey personal communication).

\begin{tabular}{|c|c|c|c|c|c|c|c|c|c|}
\hline \multirow[b]{2}{*}{ Site \# } & \multicolumn{4}{|c|}{$\begin{array}{l}\text { Wind gusts above } \\
6 \text { meters per second }\end{array}$} & \multicolumn{5}{|c|}{ Precipitation } \\
\hline & 76 & 12 & 31 & 163 & 76 & 12 & 31 & 95 & 163 \\
\hline $\begin{array}{c}\text { Associated Dust } \\
\text { Traps }\end{array}$ & Valley & Low & High & UPW & Valley & Low & High & UPW & $U P W$ \\
\hline & \multicolumn{4}{|c|}{ hrs/day } & \multicolumn{5}{|c|}{$m m / d a y$} \\
\hline Fall 2015 & 0.43 & 0.03 & 1.73 & 0.17 & 0.23 & 0.48 & 0.02 & 0.41 & 0.98 \\
\hline Winter 2015/2016 & 1.01 & 0.41 & 8.34 & 0.57 & 0.87 & 1.92 & 0.00 & 1.70 & 3.84 \\
\hline Summer 2016 & 0.05 & 0.02 & 1.41 & 0.07 & 0.11 & 0.42 & 0.29 & 0.23 & 0.58 \\
\hline Fall 2016 & 0.60 & 0.05 & 2.98 & 0.36 & 0.45 & 0.97 & 0.80 & 1.03 & 1.96 \\
\hline Winter 2016/2017 & 0.88 & 0.50 & 7.32 & 0.47 & 1.18 & 2.29 & 1.65 & 1.80 & 4.55 \\
\hline Summer2017 & 0.06 & 0.01 & 1.37 & 0.18 & 0.45 & 0.80 & 0.74 & 0.60 & 1.17 \\
\hline Fall 2017 & 0.35 & 0.01 & 3.64 & 0.33 & 0.38 & 0.97 & 0.90 & 0.75 & 1.16 \\
\hline
\end{tabular}


Table 3-1: Site descriptions and summary data for individual dust traps.

See Appendix A for full description of individual sites. Latin names for vegetation as follows: Big sagebrush - Artemisia tridentate, Snowberry Symphoricarpos, Low sagebrush - Artemisia arbuscular, Conifer - Pinophyta, Bitterbrush - Purshia tridentate. Data from Seyfried et al. (2000).

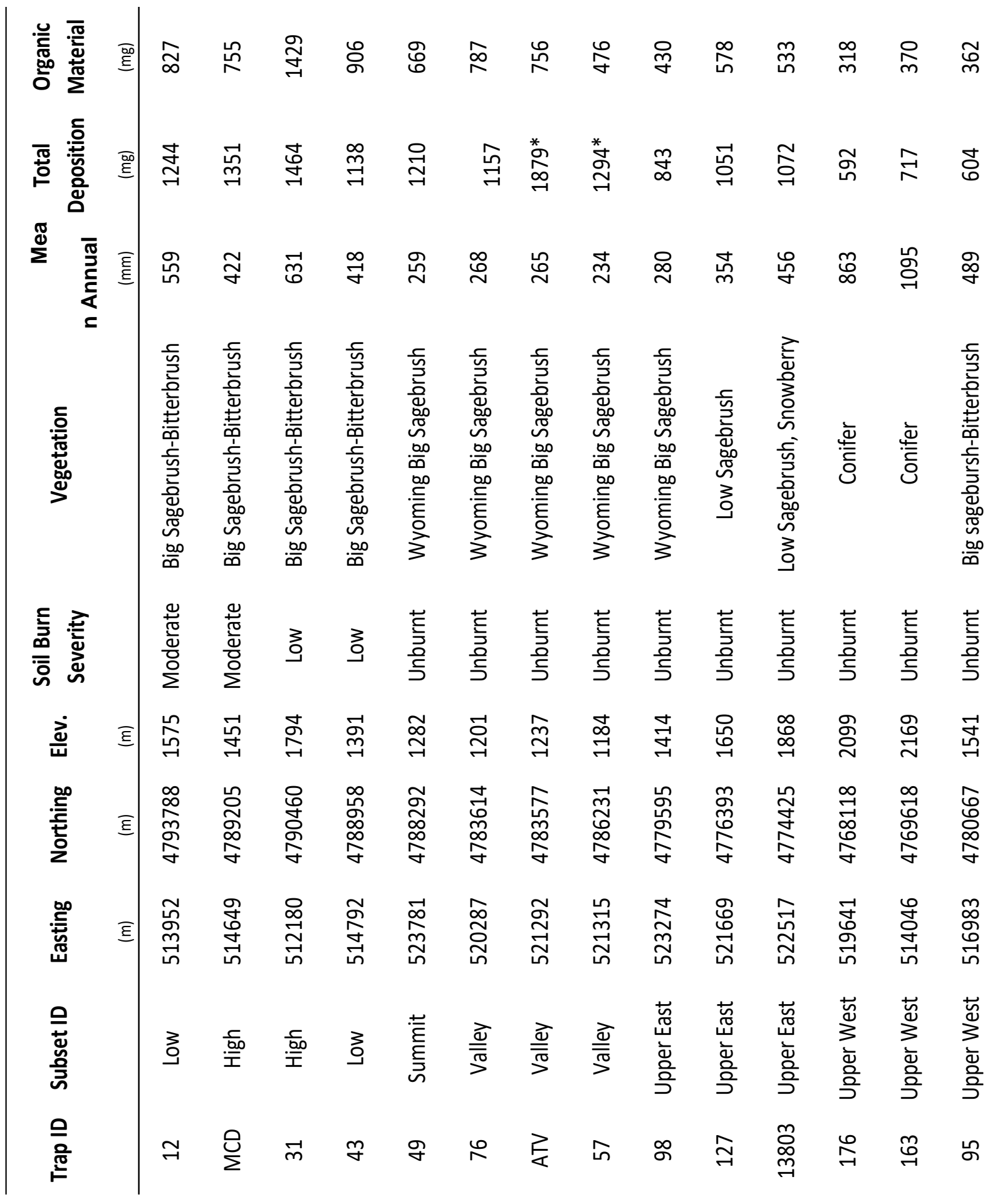


Table 4-1: Flux variation for the entire watershed for individual sampling intervals.

The masses reported represent the sum total of dust collected at all sites for each sampling interval. The results indicate that winter months contain the least amount of dust flux while fall produced the highest per day rates.

\begin{tabular}{cccccc}
\hline Interval & Season & Total Mass & $\begin{array}{c}\text { Total Mineral } \\
\text { Mass } \\
(\mathrm{mg})\end{array}$ & $\begin{array}{c}\text { Interval } \\
(\text { days })\end{array}$ & $\begin{array}{c}\text { Dust flux } \\
\left(\mathrm{mg} / \mathrm{m}^{2} / \text { day }\right)\end{array}$ \\
\hline 1 & Fall 15 & 2389 & 1638 & 46 & 1228 \\
2 & Winter 15/16 & 861 & 550 & 208 & 98 \\
3 & Summer 16 & 2998 & 1851 & 123 & 579 \\
4 & Fall 16 & 2414 & 1735 & 44 & 1307 \\
5 & Winter 16/17 & 992 & 436 & 201 & 117 \\
6 & Summer 17 & 1985 & 833 & 127 & 371 \\
7 & Fall 17 & 396 & 193 & 50 & 188
\end{tabular}


Table 4-2: Annual amounts of total dust deposition, both mineral and organic, for the years 2016 and 2017.

The values presented represent the average deposition at multiple sites within each subset. Over $80 \%$ of the traps recorded greater deposition in 2016 than 2017 without any disturbance over the watershed. Notice that the Low Site recorded a greater amount of deposition in the Fall following fire than in the entire year of 2017. Also within the burned area, the High Site recorded only moderate increases in flux after the fire due to the exposed nature of the sites.

\begin{tabular}{|c|c|c|c|c|c|c|c|}
\hline Interval & $\begin{array}{l}\text { Low } \\
\left(\mathrm{g} / \mathrm{m}^{2}\right)\end{array}$ & $\begin{array}{l}\text { High } \\
\left(\mathrm{g} / \mathrm{m}^{2}\right)\end{array}$ & $\begin{array}{l}\text { Valley } \\
\left(\mathrm{g} / \mathrm{m}^{2}\right)\end{array}$ & $\begin{array}{l}\text { UPW } \\
\left(\mathrm{g} / \mathrm{m}^{2}\right)\end{array}$ & $\begin{array}{c}\text { UPE } \\
\left(\mathrm{g} / \mathrm{m}^{2}\right)\end{array}$ & $\begin{array}{l}\text { Mean } \\
\left(\mathrm{g} / \mathrm{m}^{2}\right)\end{array}$ & $\begin{array}{c}\text { Standard } \\
\text { Deviation } \\
\left(\mathrm{g} / \mathrm{m}^{2}\right)\end{array}$ \\
\hline 2016 & 15.00 & 16.82 & 10.12 & 7.64 & 11.76 & 12.27 & 3.30 \\
\hline 2017 & 6.38 & 15.17 & 12.87 & 6.56 & 9.04 & 10.00 & 3.49 \\
\hline Fall 15 & & & & & & & \\
\hline $\begin{array}{l}\text { Post } \\
\text { Fire }\end{array}$ & 13.17 & 8.73 & 8.26 & 2.07 & 4.40 & 7.33 & 3.83 \\
\hline
\end{tabular}


Table 4-3: Individual site deposition rates with calculated mean and standard deviation for watershed variability and interval variability.

Mean standard deviation across the watershed for a given interval is $1.63 \mathrm{~g} / \mathrm{m}^{2}$ while variability at individual sites across sampling intervals is higher at $2.49 \mathrm{~g} / \mathrm{m}^{2}$ indicating that seasonal variability is greater than spatial variability over the RCEW.

\begin{tabular}{|c|cccccccccc|}
\hline Site & Fall 15 & Winter 15/16 & Summer 16 & Fall 16 & Winter 16/17 & Summer 17 & Fall 17 & Mean & $\boldsymbol{\sigma}$ \\
\hline \multicolumn{2}{r}{} & {$\left[\mathrm{g} / \mathrm{m}^{2}\right]$} & {$\left[\mathrm{g} / \mathrm{m}^{2}\right]$} & {$\left[\mathrm{g} / \mathrm{m}^{2}\right]$} & {$\left[\mathrm{g} / \mathrm{m}^{2}\right]$} & {$\left[\mathrm{g} / \mathrm{m}^{2}\right]$} & {$\left[\mathrm{g} / \mathrm{m}^{2}\right]$} & {$\left[\mathrm{g} / \mathrm{m}^{2}\right]$} & {$\left[\mathrm{g} / \mathrm{m}^{2}\right]$} & {$\left[\mathrm{g} / \mathrm{m}^{2}\right]$} \\
\hline Vallley & 3.97 & 1.42 & 4.44 & 4.26 & 6.91 & 5.10 & 0.87 & 3.85 & 1.94 \\
Low & 10.12 & 3.31 & 6.24 & 5.44 & 2.06 & 3.15 & 1.17 & 4.50 & 2.82 \\
High & 4.77 & 2.67 & 7.77 & 6.37 & 1.17 & 13.24 & 0.76 & 5.25 & 4.06 \\
UPE & 4.35 & 0.60 & 5.96 & 5.20 & 1.31 & 7.16 & 0.57 & 3.59 & 2.53 \\
UPW & 1.30 & 0.87 & 3.48 & 3.30 & 3.24 & 2.53 & 0.79 & 2.21 & 1.11 \\
Mean & 4.90 & 1.78 & 5.58 & 4.91 & 2.94 & 6.24 & 0.83 & & \\
$\boldsymbol{n}$ & 2.88 & 1.05 & 1.49 & 1.05 & 0.82 & 1.81 & 0.19 & & \\
\hline
\end{tabular}


Table 4-4: Organic matter percentages over space and time across the RCEW.

Each percentage represents the percentage of total mass that was removed via Loss-On-Ignition methods. High elevation sites in the south of the watershed that were unaffected by the fire recorded the highest percentage organic matter while traps in the sagebrush system with complex topography recorded the lowest organic matter percentages. The increase in organic percent is more a function of the 2-4 times greater mineral flux that is received at the Low, High and Valley Sites relative to the UPW Site in the subalpine ecosystem. Soil samples were collected in the Murphy Creek watershed proximal to both the Low and High subsets of sites.

\begin{tabular}{|c|c|c|c|c|c|c|}
\hline Interval & Season & $\begin{array}{l}\text { Organic } \\
\text { Matter }\end{array}$ & Site & $\begin{array}{c}\text { Organic } \\
\text { Matter }\end{array}$ & Site & $\begin{array}{c}\text { Organic } \\
\text { Matter }\end{array}$ \\
\hline 1 & Fall 15 & $35.1 \%$ & Low & $37.4 \%$ & Mean & \multirow{2}{*}{$1.1 \%$} \\
\hline 2 & Winter 15/16 & $44.1 \%$ & High & $36.7 \%$ & A-horizon & \\
\hline 3 & Summer 16 & $40.1 \%$ & Valley & $43.8 \%$ & North & \multirow{2}{*}{$1.5 \%$} \\
\hline 4 & Fall 16 & $28.5 \%$ & UPW & $47.8 \%$ & Facing & \\
\hline 5 & Winter 16/17 & $59.6 \%$ & UPE & $49.0 \%$ & South & \multirow{3}{*}{$0.6 \%$} \\
\hline 6 & Summer 17 & $54.5 \%$ & & & Facing & \\
\hline 7 & Fall 17 & $50.8 \%$ & & & & \\
\hline
\end{tabular}




\section{Table 4-5: $\quad$ Particle size distribution metrics for all sampling intervals.}

Standard Deviation is highest within the $\mathrm{D}_{90}$ category, influenced by an increase in the $\mathrm{D}_{90}$ grain size in the fire influenced sampling intervals. Standard deviation across all seasons remains within the single digits of microns. A D 50 of $\sim 20$ $\mu \mathrm{m}$ indicates the regional input of silt-sized material. The mode of atmospheric mineral aerosols travelling global distances is 3 $\mu \mathrm{m}$ (d'Almeida and Shultz, 1983). The sampling interval immediately following fire within the burned area recorded the largest grain size distribution and highest $\mathrm{D}_{90} \mathrm{pf}$ the study period.

\begin{tabular}{|cccc|}
\hline Season & $\begin{array}{c}\text { D16 } \\
\text { (um) }\end{array}$ & $\begin{array}{c}\text { D50 } \\
\text { (um) }\end{array}$ & $\begin{array}{c}\text { D90 } \\
\text { (um) }\end{array}$ \\
\hline Fall & 6.9 & 22.10 & 52.60 \\
Winter & 4.5 & 17.00 & 47.30 \\
Summer & 6.1 & 20.00 & 52.00 \\
Total & 6 & 21.50 & 52.60 \\
PostFire & 6.8 & 22.30 & 61.30 \\
Undisturbed & 6.2 & 20.30 & 51.80 \\
Range & $\mathbf{2 . 4}$ & $\mathbf{5 . 3}$ & $\mathbf{1 4 . 0}$ \\
Standard & $\mathbf{0 . 9}$ & $\mathbf{2 . 0}$ & $\mathbf{4 . 6}$ \\
Deviation & $\mathbf{0 . 9}$ & & \\
\hline
\end{tabular}


Table 4-6: Trace element data from the dust trap samples throughout the sampling period.

The original concentrations normalized by average Upper Continental Crust (UCC) composition. The dust trap samples are enriched in Barium, Uranium, Strontium, Europium, and Titanium.

\begin{tabular}{|c|c|c|c|c|c|c|c|c|c|c|c|c|c|c|c|c|c|c|c|c|c|c|c|c|}
\hline \multicolumn{25}{|c|}{ Trace Element Concentration/Upper Continental Crust Concentration } \\
\hline Element & High 1 & High 2 & High 3 & High 4 & Low 1 & Low 2 & Low 3 & Low 4 & Low 6 & UPE1 & UPE2 & UPE4 & UPE6 & UPW1 & UPW3 & UPW4 & UPW5 & UPW6 & Valley 1 & Valley3 & Valley 4 & Valley 5 & Valley 6 & Valley \\
\hline Cs & 0.93 & 0.99 & 0.25 & 0.29 & 0.99 & 1.23 & 0.28 & 0.42 & 1.35 & 0.40 & 0.29 & 0.20 & 1.25 & 1.00 & 0.91 & 0.23 & 1.02 & 1.00 & 1.08 & 0.67 & 0.41 & 0.52 & 0.92 & 0.70 \\
\hline$R b$ & 0.53 & 0.55 & 0.31 & 0.32 & 0.52 & 0.64 & 0.26 & 0.24 & 0.66 & 0.32 & 0.27 & 0.15 & 0.77 & 0.39 & 0.81 & 0.16 & 0.60 & 0.60 & 0.74 & 0.44 & 0.27 & 0.59 & 0.52 & 0.36 \\
\hline $\mathrm{Ba}$ & 1.86 & 1.93 & 1.47 & 3.41 & 1.88 & 1.89 & 1.30 & 0.90 & 1.60 & 1.30 & 2.73 & 1.11 & 1.35 & 1.43 & 2.18 & 1.10 & 1.21 & 1.33 & 1.91 & 1.26 & 0.97 & 0.97 & 1.09 & 0.94 \\
\hline Th & 0.50 & 0.60 & 0.40 & 0.36 & 0.54 & 0.61 & 0.29 & 0.29 & 0.71 & 0.30 & 0.27 & 0.17 & 0.62 & 0.32 & 0.57 & 0.17 & 0.54 & 0.50 & 0.59 & 0.42 & 0.28 & 0.33 & 0.51 & 0.32 \\
\hline$U$ & 1.01 & 0.75 & 1.48 & 2.71 & 1.04 & 0.79 & 0.99 & 1.60 & 0.90 & 0.62 & 1.12 & 1.80 & 0.88 & 0.52 & 0.80 & 1.47 & 0.76 & 0.73 & 0.77 & 0.85 & 1.15 & 0.52 & 0.70 & 0.63 \\
\hline $\mathrm{Nb}$ & 0.45 & 0.63 & 0.32 & 0.28 & 0.51 & 0.58 & 0.28 & 0.21 & 0.54 & 0.26 & 0.24 & 0.12 & 0.49 & 0.35 & 0.46 & 0.12 & 0.46 & 0.42 & 0.50 & 0.38 & 0.22 & 0.26 & 0.40 & 0.28 \\
\hline Ta & 0.31 & 0.41 & 0.22 & 0.20 & 0.36 & 0.38 & 0.19 & 0.16 & 0.41 & 0.19 & 0.17 & 0.09 & 0.37 & 0.26 & 0.35 & 0.09 & 0.32 & 0.31 & 0.38 & 0.29 & 0.17 & 0.19 & 0.30 & 0.21 \\
\hline$k$ & 0.72 & 0.73 & 0.74 & 0.84 & 0.72 & 0.74 & 0.64 & 0.45 & 1.11 & 1.04 & 0.98 & 0.41 & 2.26 & 0.68 & 1.92 & 0.44 & 0.87 & 1.04 & 1.92 & 0.82 & 0.56 & 3.57 & 1.15 & 0.51 \\
\hline La & 0.92 & 1.18 & 0.62 & 0.53 & 1.02 & 1.12 & 0.49 & 0.41 & 1.27 & 0.44 & 0.40 & 0.19 & 0.87 & 0.55 & 0.88 & 0.18 & 0.76 & 0.72 & 0.88 & 0.64 & 0.35 & 0.47 & 0.72 & 0.48 \\
\hline $\mathrm{Ce}$ & 0.82 & 1.06 & 0.53 & 0.47 & 0.92 & 1.01 & 0.43 & 0.37 & 1.09 & 0.40 & 0.35 & 0.17 & 0.75 & 0.56 & 0.77 & 0.17 & 0.68 & 0.63 & 0.76 & 0.58 & 0.30 & 0.41 & 0.62 & 0.41 \\
\hline $\mathrm{Pb}$ & 1.08 & 0.84 & 0.25 & 0.35 & 0.84 & 1.09 & 0.21 & 0.27 & 0.70 & 0.18 & 0.14 & 0.14 & 0.78 & 0.13 & 0.44 & 0.18 & 0.27 & 0.28 & 0.43 & 0.54 & 0.25 & 0.14 & 0.37 & 0.31 \\
\hline $\operatorname{Pr}$ & 0.90 & 1.17 & 0.61 & 0.52 & 1.03 & 1.13 & 0.48 & 0.40 & 1.16 & 0.43 & 0.39 & 0.18 & 0.83 & 0.54 & 0.83 & 0.17 & 0.73 & 0.70 & 0.84 & 0.61 & 0.33 & 0.45 & 0.68 & 0.47 \\
\hline$S r$ & 1.38 & 1.81 & 2.47 & 3.42 & 1.94 & 1.50 & 2.77 & 3.10 & 1.40 & 1.63 & 2.61 & 3.36 & 1.17 & 0.77 & 1.57 & 3.18 & 1.08 & 0.92 & 1.17 & 2.21 & 2.75 & 1.21 & 0.85 & 0.83 \\
\hline Nd & 0.87 & 1.11 & 0.58 & 0.50 & 1.00 & 1.09 & 0.47 & 0.39 & 1.07 & 0.41 & 0.37 & 0.18 & 0.78 & 0.52 & 0.80 & 0.17 & 0.70 & 0.67 & 0.80 & 0.59 & 0.31 & 0.43 & 0.65 & 0.44 \\
\hline$S m$ & 1.06 & 1.27 & 0.69 & 0.58 & 1.19 & 1.29 & 0.56 & 0.46 & 1.15 & 0.50 & 0.46 & 0.22 & 0.96 & 0.65 & 1.00 & 0.19 & 0.85 & 0.83 & 0.98 & 0.71 & 0.39 & 0.52 & 0.79 & 0.55 \\
\hline Zr & 0.83 & 0.95 & 0.64 & 0.48 & 0.91 & 0.95 & 0.42 & 0.41 & 2.66 & 0.43 & 0.42 & 0.24 & 1.46 & 0.72 & 0.75 & 0.21 & 0.79 & 1.11 & 0.82 & 0.72 & 0.32 & 0.48 & 0.88 & 2.85 \\
\hline Hf & 0.76 & 0.87 & 0.60 & 0.45 & 0.86 & 0.88 & 0.41 & 0.40 & 1.98 & 0.41 & 0.39 & 0.25 & 1.10 & 0.63 & 0.72 & 0.23 & 0.73 & 0.83 & 0.76 & 0.65 & 0.32 & 0.45 & 0.79 & 1.91 \\
\hline$E u$ & 1.28 & 1.68 & 0.87 & 0.88 & 1.60 & 1.76 & 0.76 & 0.61 & 1.40 & 0.65 & 0.68 & 0.32 & 1.15 & 0.86 & 1.10 & 0.30 & 1.01 & 1.01 & 1.22 & 0.89 & 0.50 & 0.66 & 0.92 & 0.66 \\
\hline$T i$ & 1.62 & 2.46 & 1.02 & 0.95 & 2.12 & 2.33 & 0.96 & 0.81 & 1.85 & 1.01 & 0.78 & 0.48 & 1.49 & 1.62 & 1.55 & 0.57 & 1.60 & 1.44 & 1.70 & 1.30 & 0.77 & 0.95 & 1.29 & 0.90 \\
\hline$G d$ & 1.10 & 1.29 & 0.77 & 0.62 & 1.28 & 1.36 & 0.61 & 0.50 & 1.19 & 0.54 & 0.50 & 0.24 & 1.03 & 0.73 & 1.11 & 0.23 & 0.90 & 0.92 & 1.05 & 0.77 & 0.42 & 0.57 & 0.84 & 0.60 \\
\hline $\mathrm{Tb}$ & 1.14 & 1.23 & 0.77 & 0.61 & 1.29 & 1.35 & 0.61 & 0.50 & 1.15 & 0.57 & 0.52 & 0.24 & 1.05 & 0.75 & 1.18 & 0.24 & 0.93 & 0.92 & 1.05 & 0.76 & 0.42 & 0.57 & 0.83 & 0.61 \\
\hline Dy & 1.10 & 1.14 & 0.78 & 0.58 & 1.24 & 1.30 & 0.59 & 0.48 & 1.10 & 0.55 & 0.51 & 0.23 & 1.01 & 0.85 & 1.15 & 0.21 & 0.91 & 0.92 & 1.02 & 0.74 & 0.40 & 0.56 & 0.81 & 0.63 \\
\hline$\gamma$ & 1.21 & 1.26 & 0.85 & 0.65 & 1.33 & 1.41 & 0.67 & 0.53 & 1.25 & 0.63 & 0.57 & 0.26 & 1.18 & 0.82 & 1.30 & 0.24 & 0.98 & 1.02 & 1.14 & 0.83 & 0.45 & 0.62 & 0.91 & 0.69 \\
\hline $\mathrm{Ho}_{0}$ & 1.02 & 1.08 & 0.72 & 0.55 & 1.15 & 1.22 & 0.57 & 0.44 & 1.05 & 0.52 & 0.46 & 0.22 & 0.98 & 0.68 & 1.07 & 0.21 & 0.83 & 0.86 & 0.96 & 0.70 & 0.39 & 0.52 & 0.76 & 0.58 \\
\hline Er & 0.97 & 0.97 & 0.65 & 0.52 & 1.09 & 1.11 & 0.53 & 0.43 & 1.02 & 0.53 & 0.45 & 0.21 & 0.91 & 0.77 & 1.02 & 0.22 & 0.77 & 0.79 & 0.90 & 0.65 & 0.37 & 0.51 & 0.72 & 0.59 \\
\hline Im & 0.94 & 0.97 & 0.66 & 0.51 & 1.04 & 1.13 & 0.52 & 0.43 & 1.04 & 0.49 & 0.45 & 0.21 & 0.91 & 0.63 & 1.01 & 0.19 & 0.74 & 0.79 & 0.87 & 0.65 & 0.35 & 0.50 & 0.71 & 0.57 \\
\hline$Y_{b}$ & 0.84 & 0.90 & 0.59 & 0.48 & 0.96 & 1.03 & 0.47 & 0.39 & 0.95 & 0.44 & 0.41 & 0.19 & 0.83 & 0.58 & 0.93 & 0.18 & 0.69 & 0.73 & 0.82 & 0.60 & 0.33 & 0.46 & 0.67 & 0.54 \\
\hline Lu & 1.04 & 1.08 & 0.72 & 0.57 & 1.14 & 1.27 & 0.58 & 0.47 & 1.18 & 0.55 & 0.48 & 0.24 & 1.04 & 0.70 & 1.10 & 0.21 & 0.84 & 0.91 & 1.01 & 0.72 & 0.40 & 0.57 & 0.80 & 0.68 \\
\hline
\end{tabular}


Table 5-1: Deposition rates over 100,000 year time scales for various topographic positions and vegetation types across the RCEW.

Gross deposition is relatively homogenous across the sagebrush sites regardless of topographic position during periods without disturbance. The subalpine sites to the south in alpine fir vegetation record lower rates of deposition than sagebrush sites over time.

\begin{tabular}{|c|ccccc|}
\hline \multicolumn{1}{|c}{} & RCEW & $\begin{array}{c}\text { Complex } \\
\text { Sagebrush }\end{array}$ & Low & Valley & $\begin{array}{c}\text { Complex } \\
\text { Sub } \\
\text { Alpine }\end{array}$ \\
\cline { 2 - 6 } & {$[\mathrm{m}]$} & {$[\mathrm{m}]$} & {$[\mathrm{m}]$} & {$[\mathrm{m}]$} & {$[\mathrm{m}]$} \\
\cline { 2 - 6 } & 1.04 & 1.09 & 1.01 & 1.22 & 0.75 \\
\hline
\end{tabular}



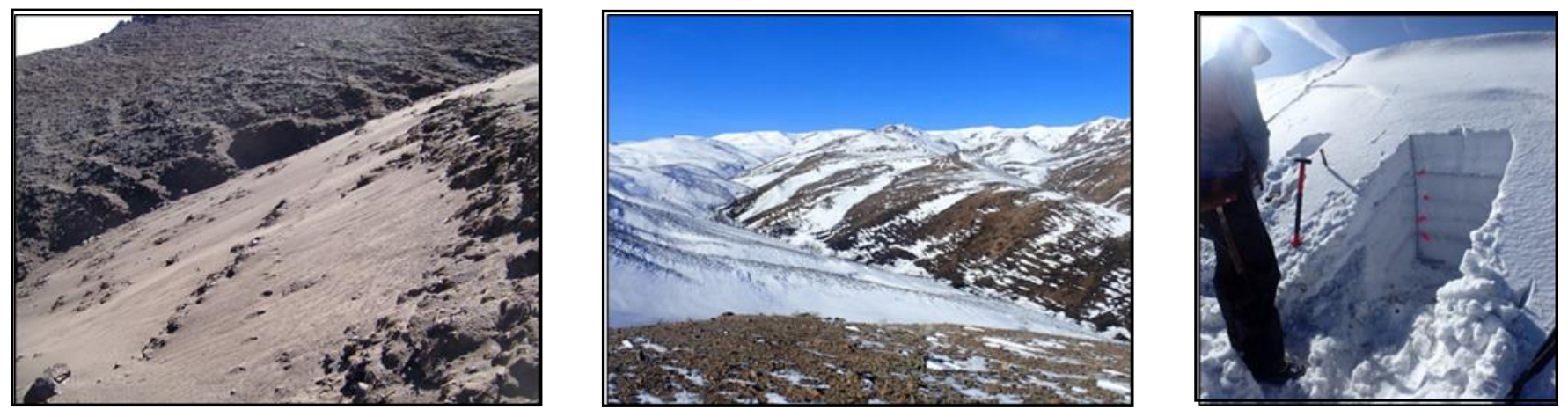

Figure 2-1: Images depicting the analogous behavior of postfire sediment, organic material and snow.

All photos are taken in the Murphy Creek watershed, $100 \%$ burned by the Soda Fire of August 2018. Image A is a "dust drift" on a leeward slope observed in the weeks following the Soda Fire. Notice the windward slope in the background that is bare ground with no deposition. Image B is the distribution of snow drifts on north-east facing aspects and swales, similar to observed locations of dust drifts after the fire. Image $\mathrm{C}$ is a snow pit dug into the nearest drift in Image B. Multiple layers of burnt organic material and sediment were deposited on the surface of the drift and subsequently buried by further snow flux onto the drift. 


\section{Upper Atmosphere} Wet Fallout

- Small Flux

- Fine Silt and Clay

- Upper Continental Crust Geochemistry

- Soluble Salts
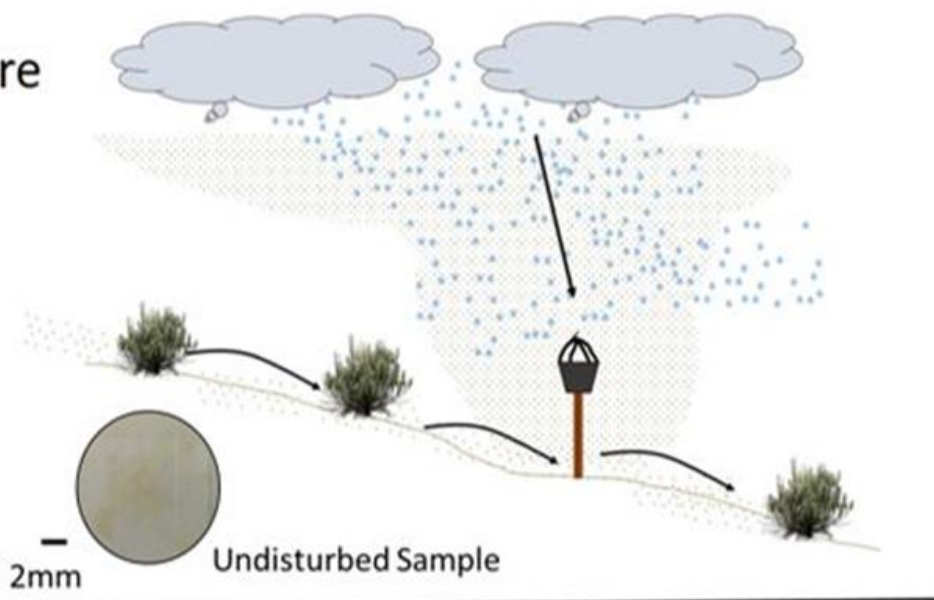

Post Fire Localized

Deposition

- Greater Mass

- Fine Sand

- Local Geochemistry

$2 \mathrm{~mm}$

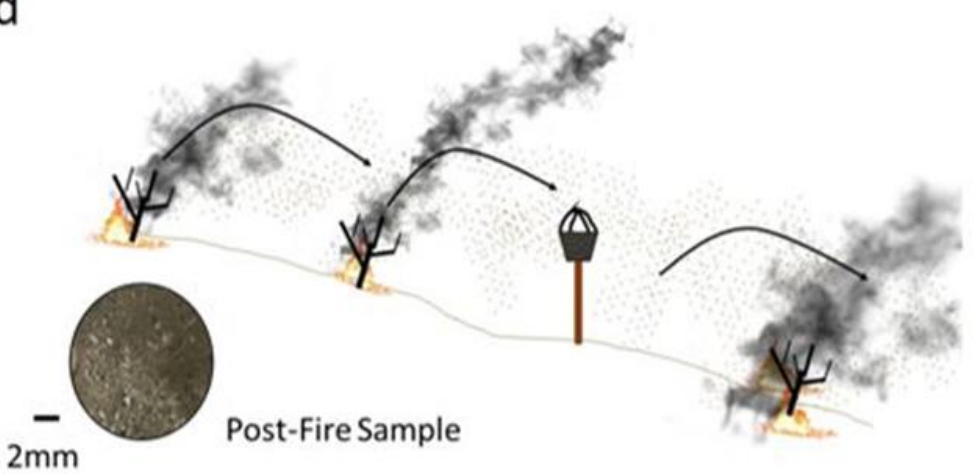

Figure 2-2: Conceptual model depicting differences in aeolian deposit characteristics following fire in the northern Great Basin.

With the removal of surface roughness and decreased aggregate stability we hypothesize that the passive dust traps will record greater mass flux, coarser grain size distribution and a local geochemical fingerprint for postfire samples collected within and proximal to the burned area. 


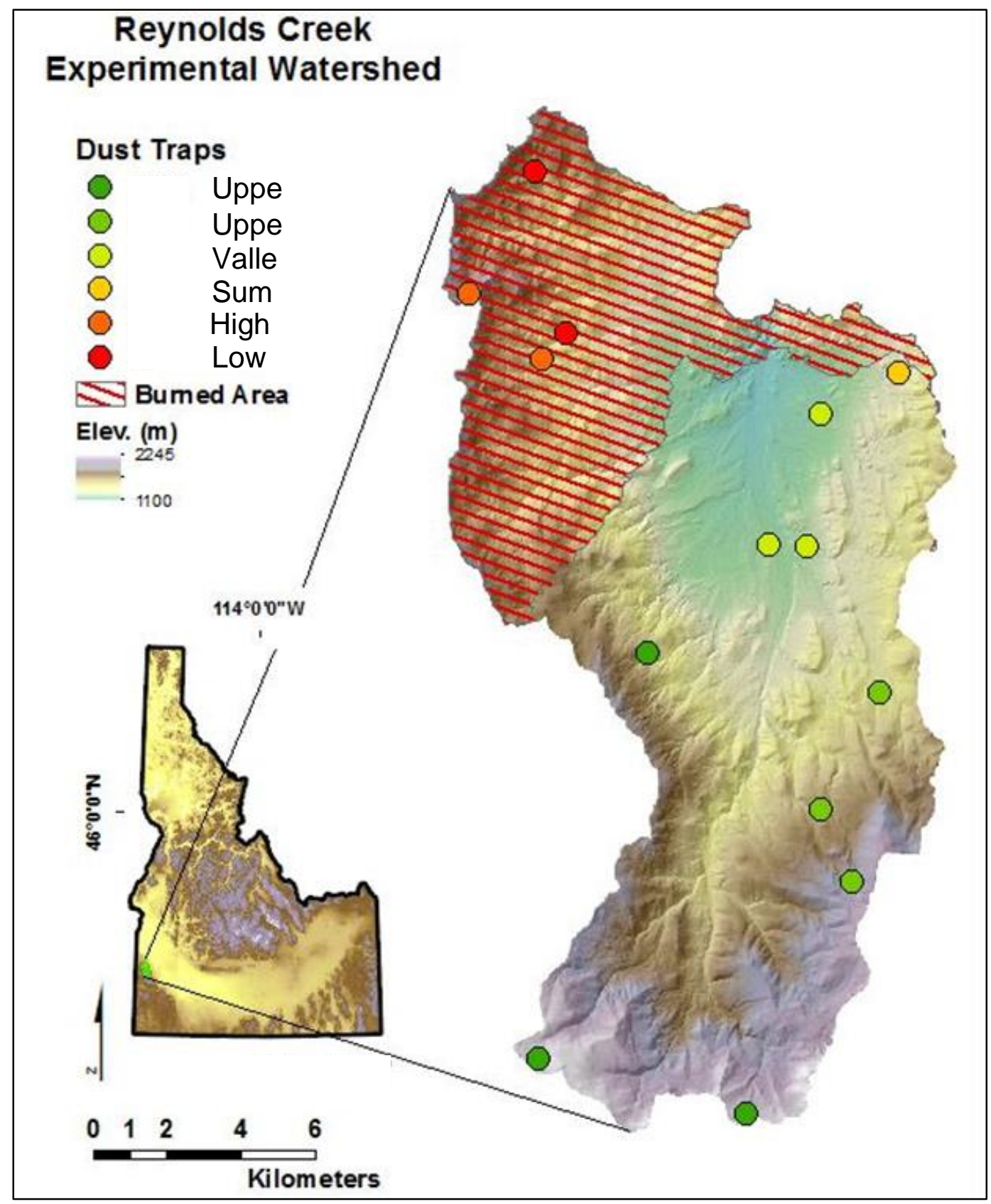

Figure 2-3: Reynolds Creek Experimental Watershed, located in southwestern Idaho, is a xeric watershed with complex topography and strong precipitationvegetation gradients.

The Soda Fire of August 2015 burned through the northwest corner of the watershed. 14 dust traps (circles) are located at weather stations across all elevations and ecosystems. The individual traps were combined into six subsets to provide adequate sample for analysis. 


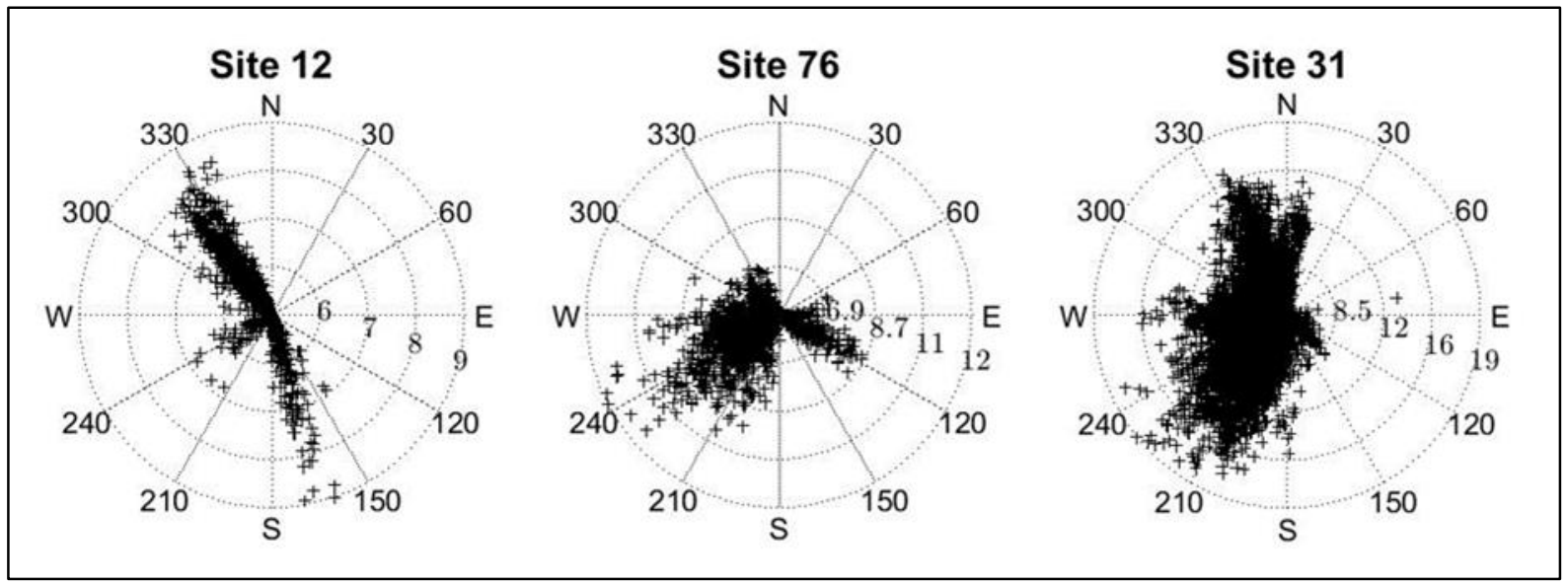

Figure 2-4: 15-minute wind direction data of intervals above $6 \mathrm{~m} / \mathrm{s}$ from three sites across the watershed.

Site 12 is located in a valley bottom confined by steep slopes in complex terrain. Wind direction at this location is largely a function of topography as diurnal winds move up and down the canyon. Site 76 and Site 31 reflect the regional wind directions due to the lack of an influence from complex topography. Site 76 is a regional valley site while Site 31 is located on a higher elevation exposed ridgeline, explaining the increase in the number of values recorded. 


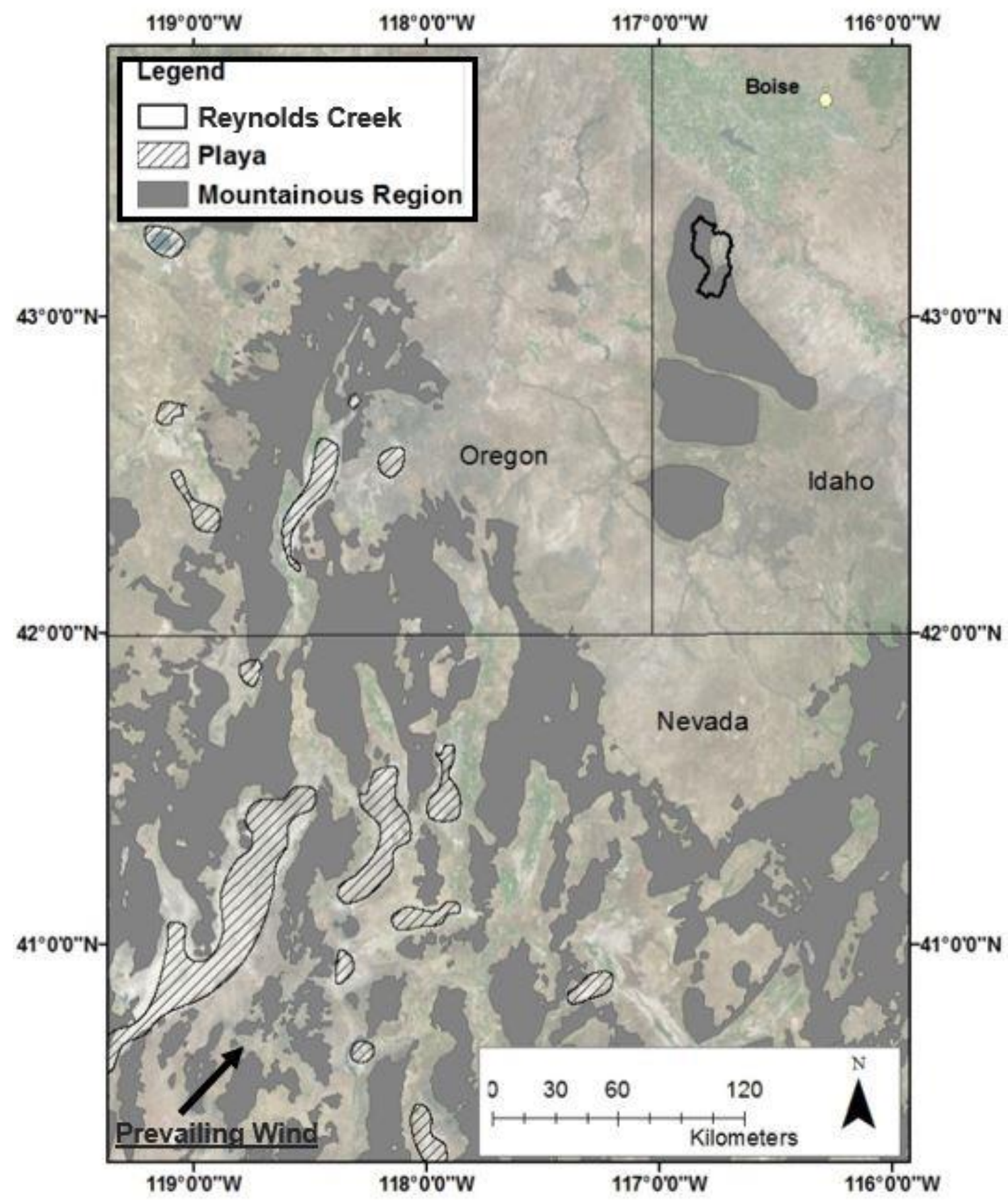

Figure 2-5: Map depicting hypothesized dust source area from wind direction data.

Prevailing wind directions from the southwest of Reynolds Creek Experimental Watershed indicate a potential dust source from playas and alluvial fans of Oregon and Nevada. 


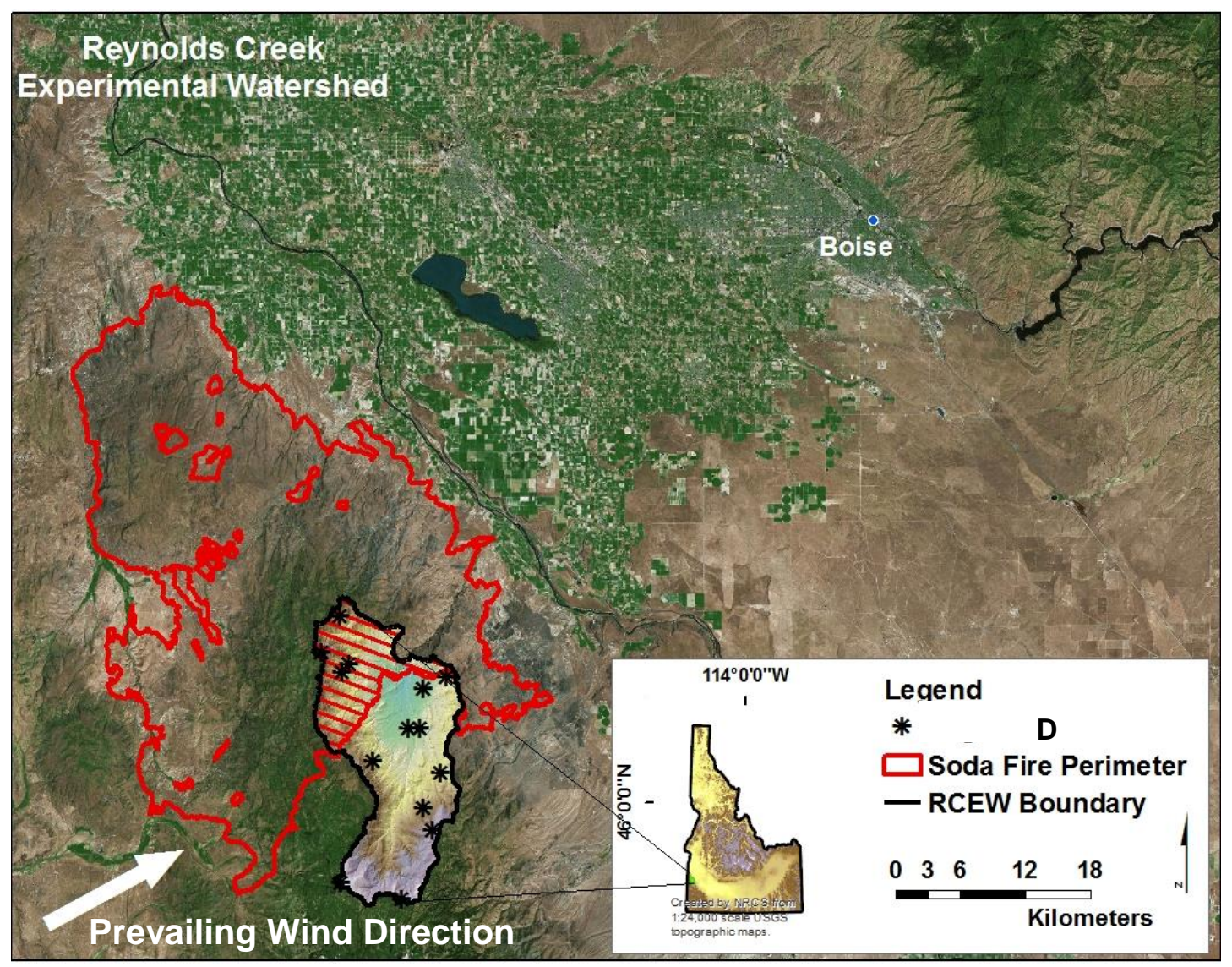

Figure 2-6: Full extent of the Soda Fire of August 2015.

Given the prevailing wind and the extent of the fire dust traps located in the southern portion of the RCEW were unaffected by the fire. No coarse burnt organic material or increase in dust flux was observed at the southern sites. Boise, ID, located $\sim 50$ $\mathrm{km}$ from the fire perimeter experienced hazardous air quality due to the fire. 


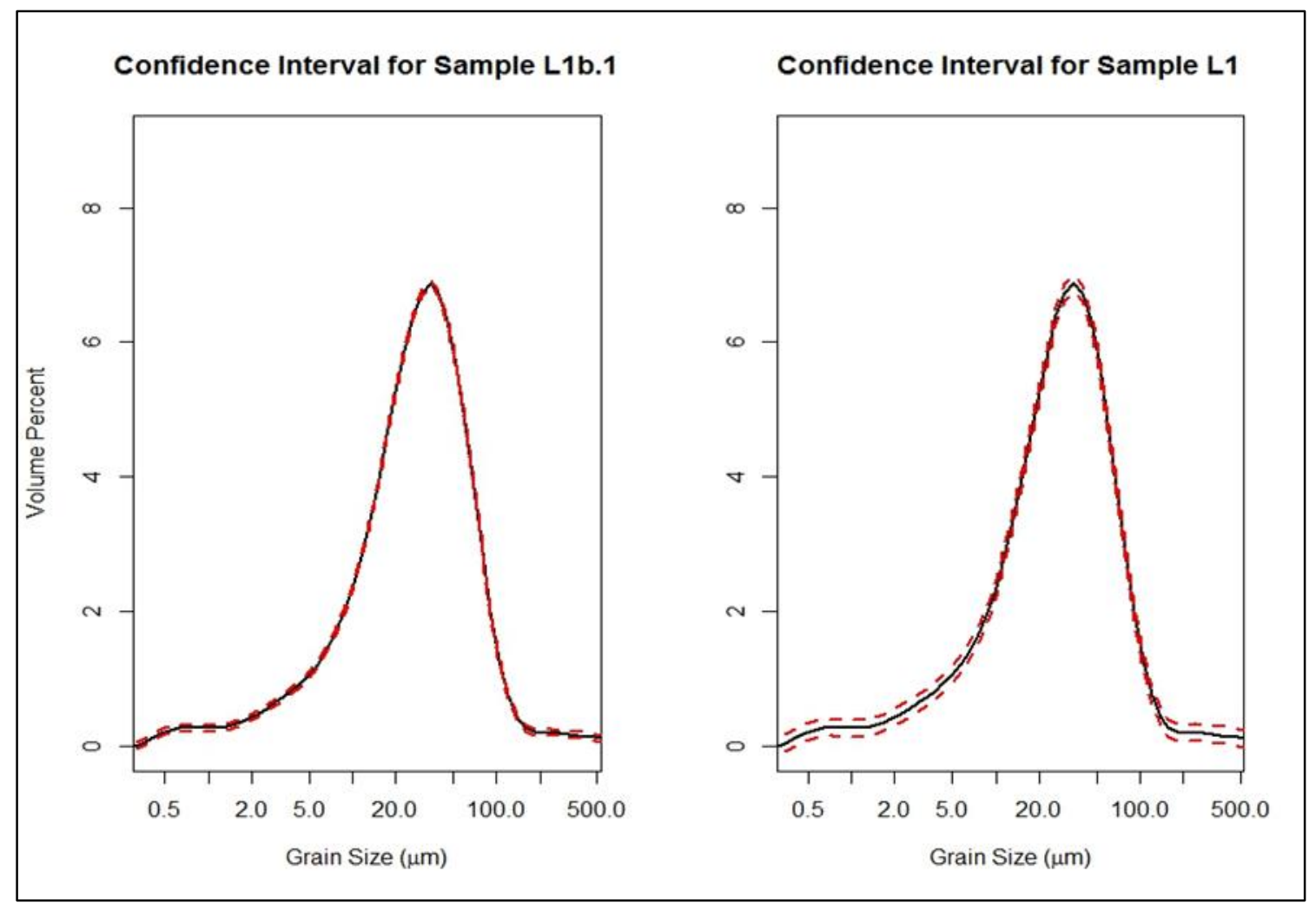

Figure 3-1: $\quad$ Raw data output from laser diffractometry particle size analysis.

Panel on the left is the error from running an aliquot from sample L1 three times (instrument error). The panel on the right is the error associated with three separate aliquots from the L1 sample (sampling error). The error in both cases is sufficiently low $(<0.5 \%)$ to allow for adequate trend analysis. 


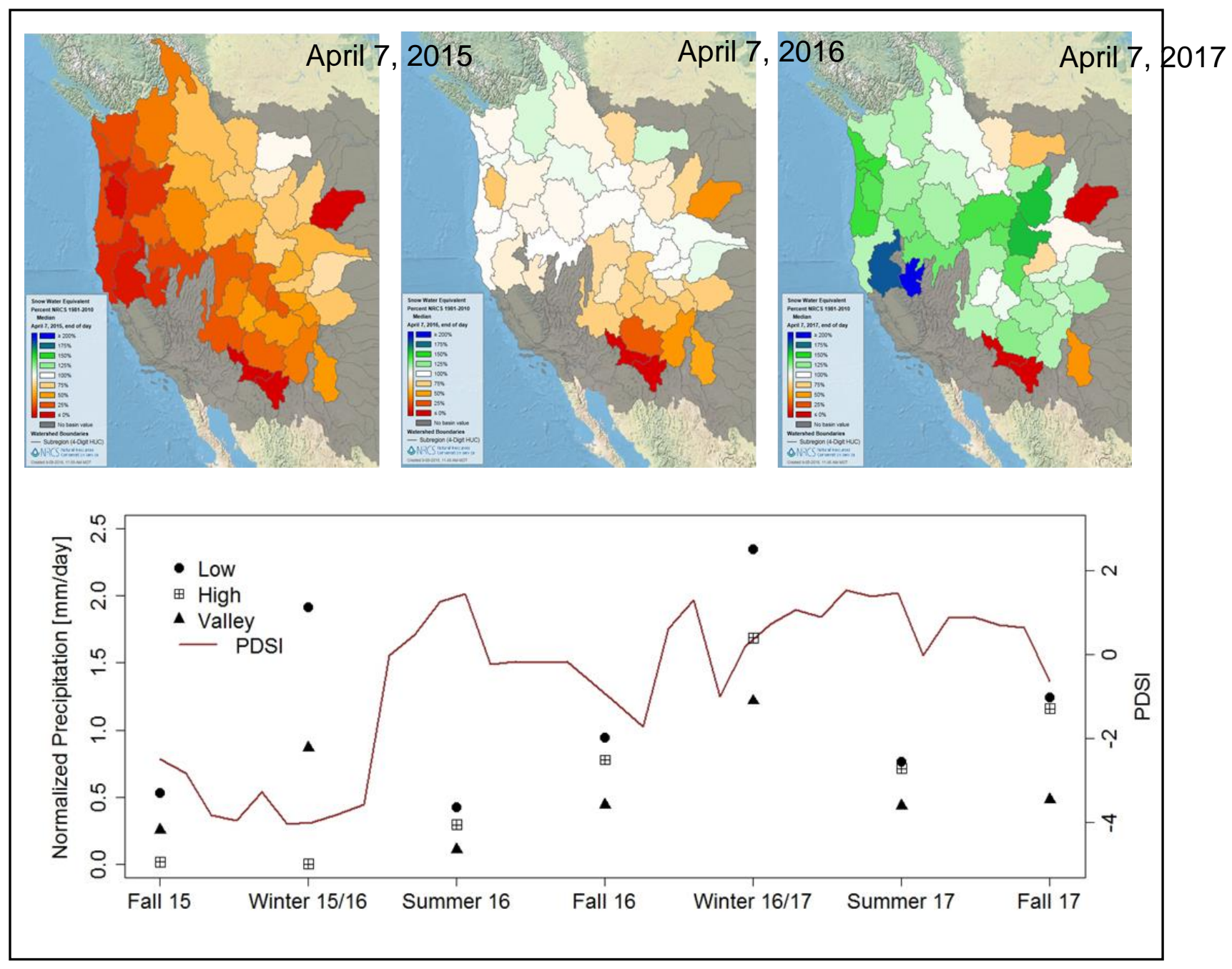

Figure 4-1: Summary of regional trends in precipitation and drought index validated with point data from multiple elevations within the RCEW.

The April $7^{\text {th }}$ SWE values increase each year from 2015 to 2017 as the PDSI also increases from -4 (dry) to nearly 2 (wet) by the summer of 2017. Point data from the RCEW also reveals higher precipitation across the board from the fall of 2016 till the end of the study period. Fall months consistently record higher normalized precipitation than summer months. 


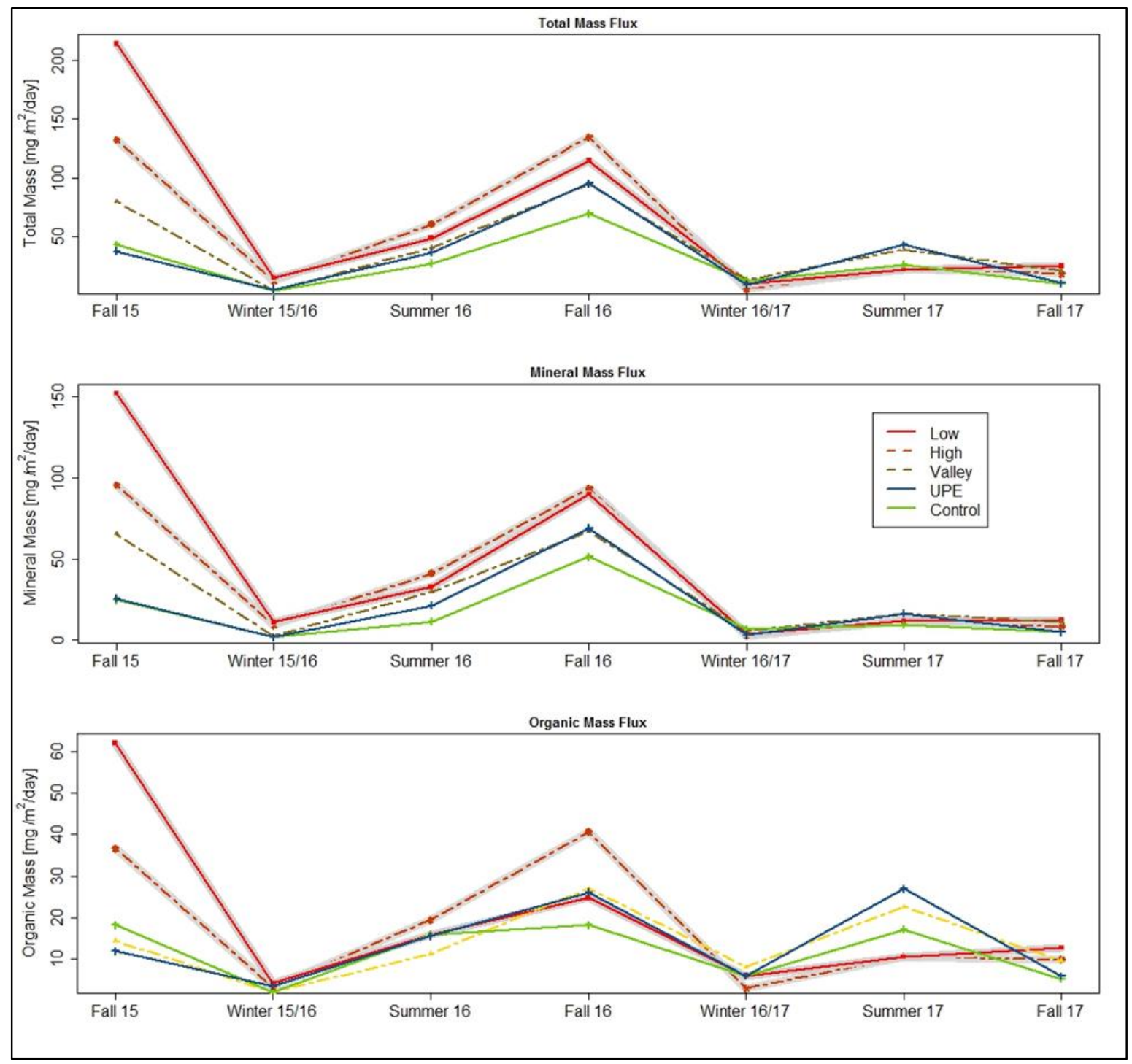

Figure 4-2: Flux data of the subset groups for the two years following the Soda Fire of August 2015.

The green line represents our UPW site totally unaffected by the fire. While flux values are high in the fall of 2016 (1-yr postfire) flux rates are also higher at UPW indicating that climactic variables were more conducive to aeolian deposition in fall of 2016 than fall of 2015. Organic material fluxes (determined through loss-on-ignition) are more variable due to higher error in the sample collection process (flying insects and avian influence) but follow a similar trend to mineral mass. 


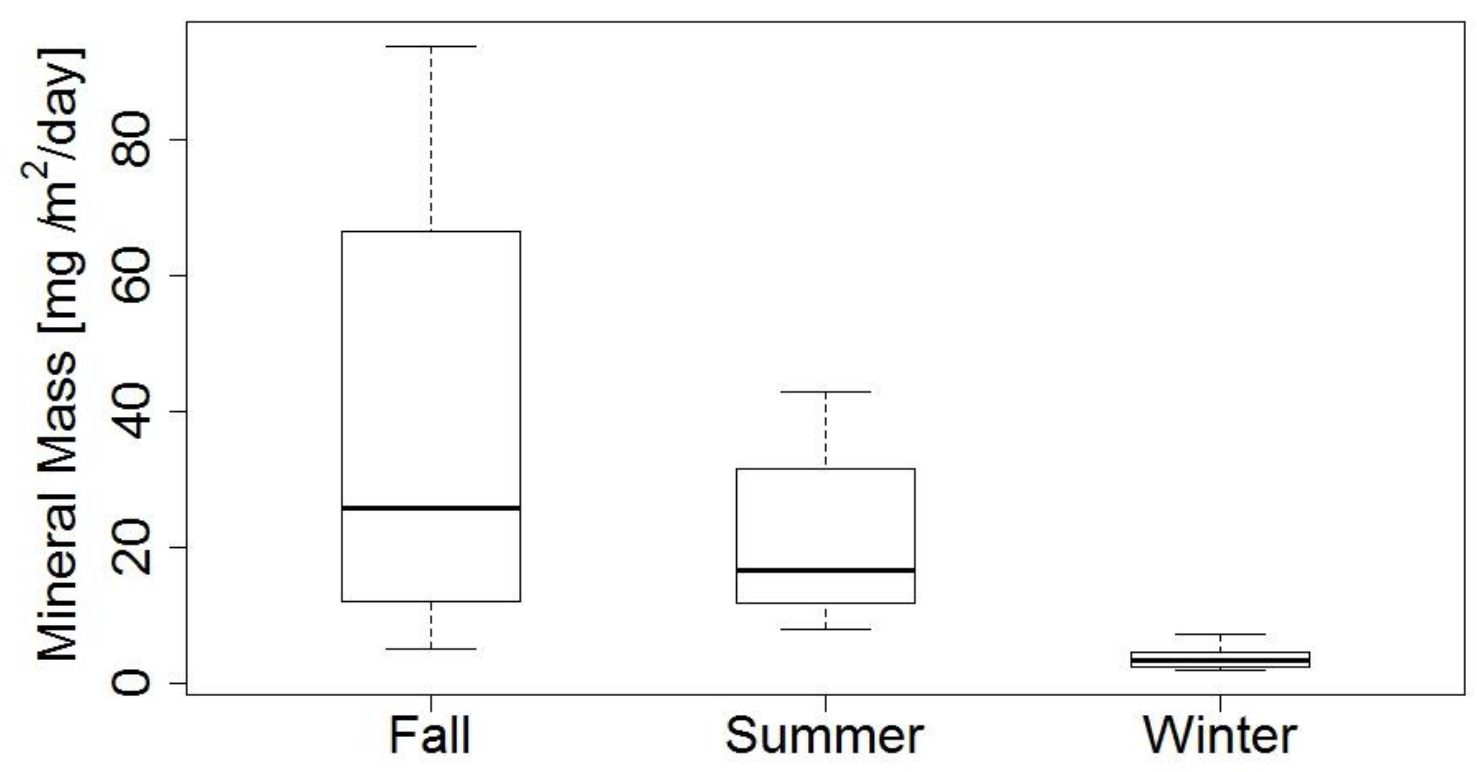

Figure 4-3: Seasonal differences in watershed wide average flux rates indicate that the winter season deposits significantly less material than fall and summer. 


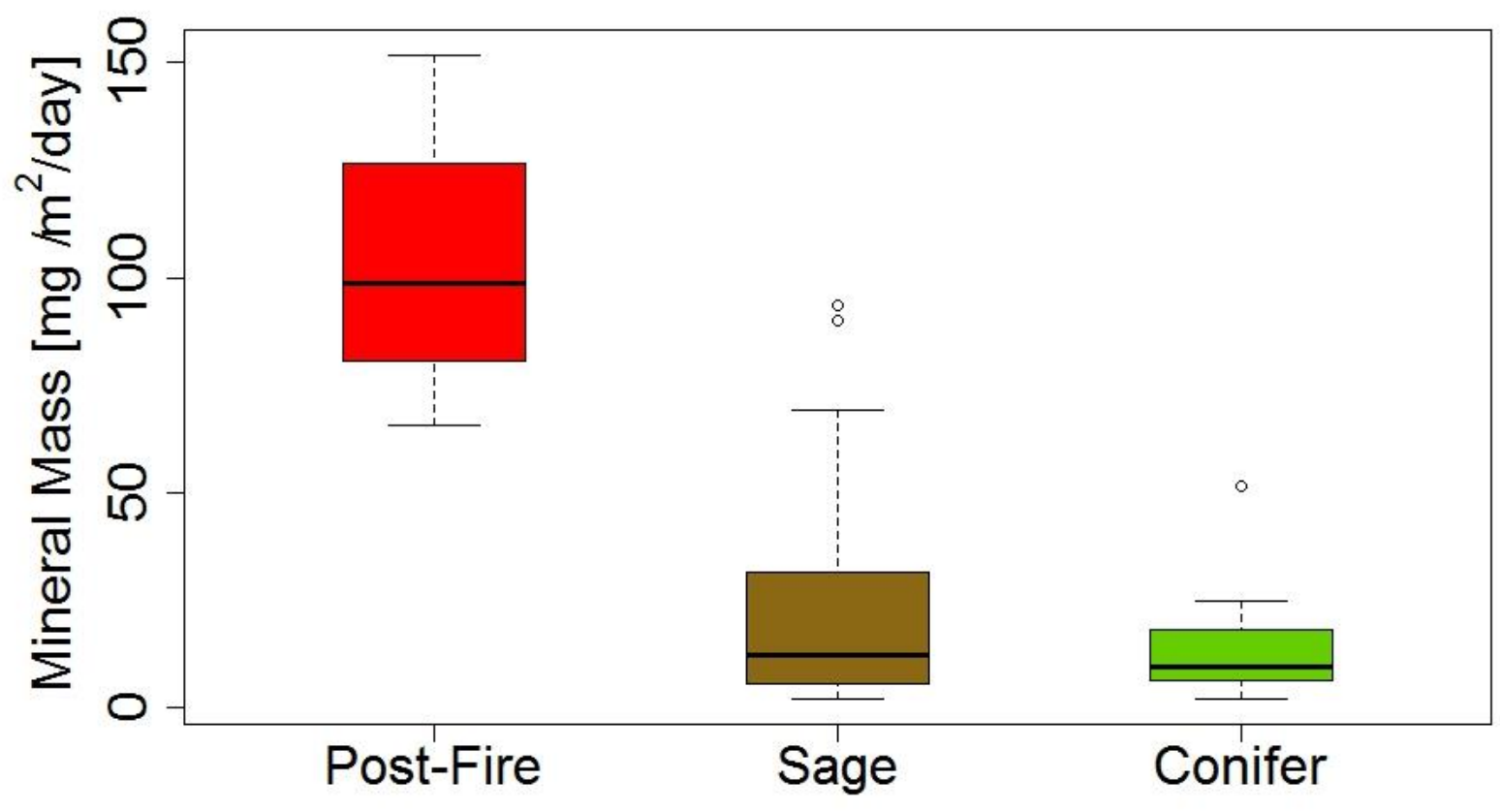

Figure 4-4: Sagebrush and conifer sites are not statistically different from each other while samples collected in the first sampling interval following fire within the burned area contained statistically higher dust flux rates. 


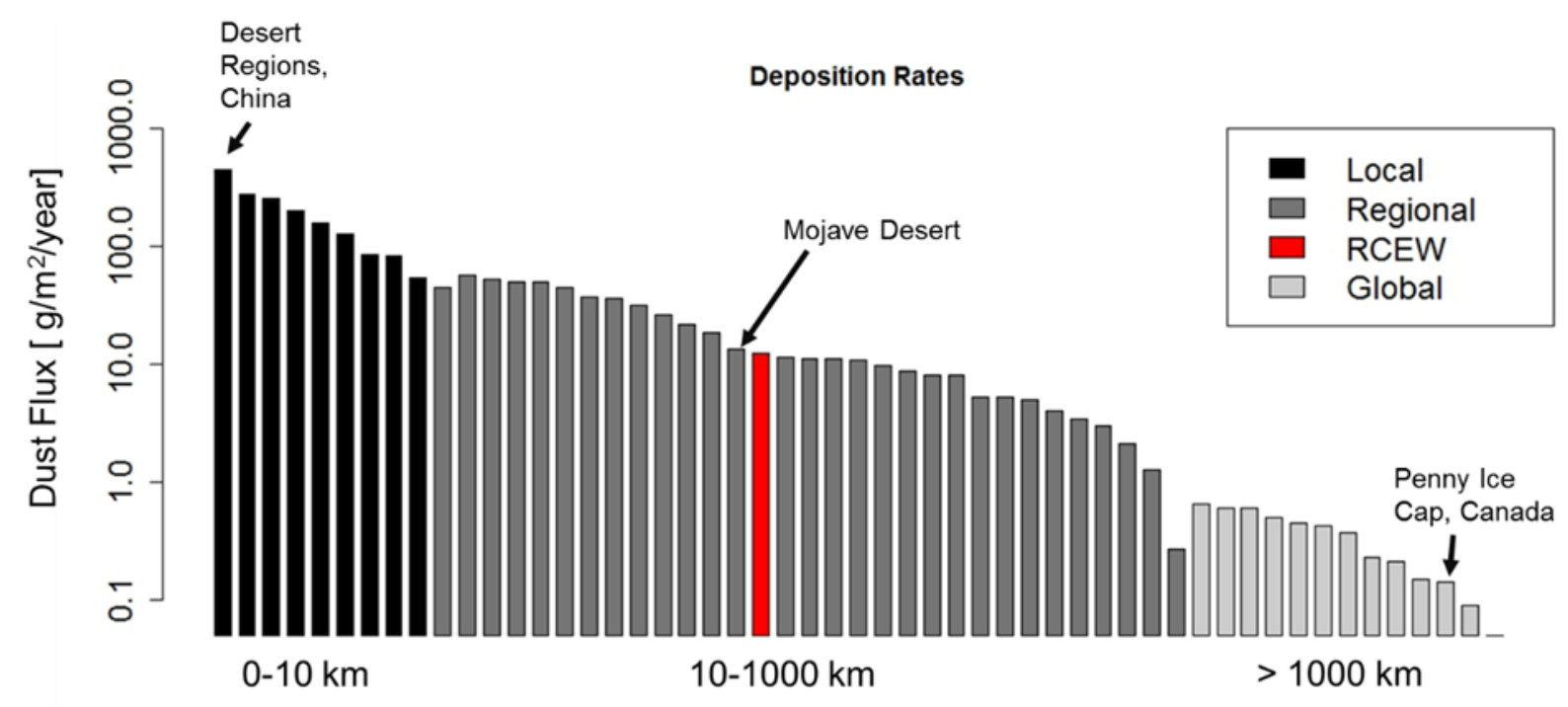

Figure 4-5: RCEW flux rates are comparable to other sites from around the world with regional sources.

Data sourced from Lawrence and Neff (2009), a global review of deposition rates from dust trap studies. RCEW rates are $11.0 \mathrm{~g} / \mathrm{m}^{2}$, similar to those found in the Mojave Desert. Local sites are described as dust traps near the source area such as traps adjacent to playa or alluvial fan surfaces $(0-10 \mathrm{~km})$. Regional sources travel only hundreds of kilometers while global sources are found in polar regions and on ice caps, far removed from any dust sources (>1000 km). 


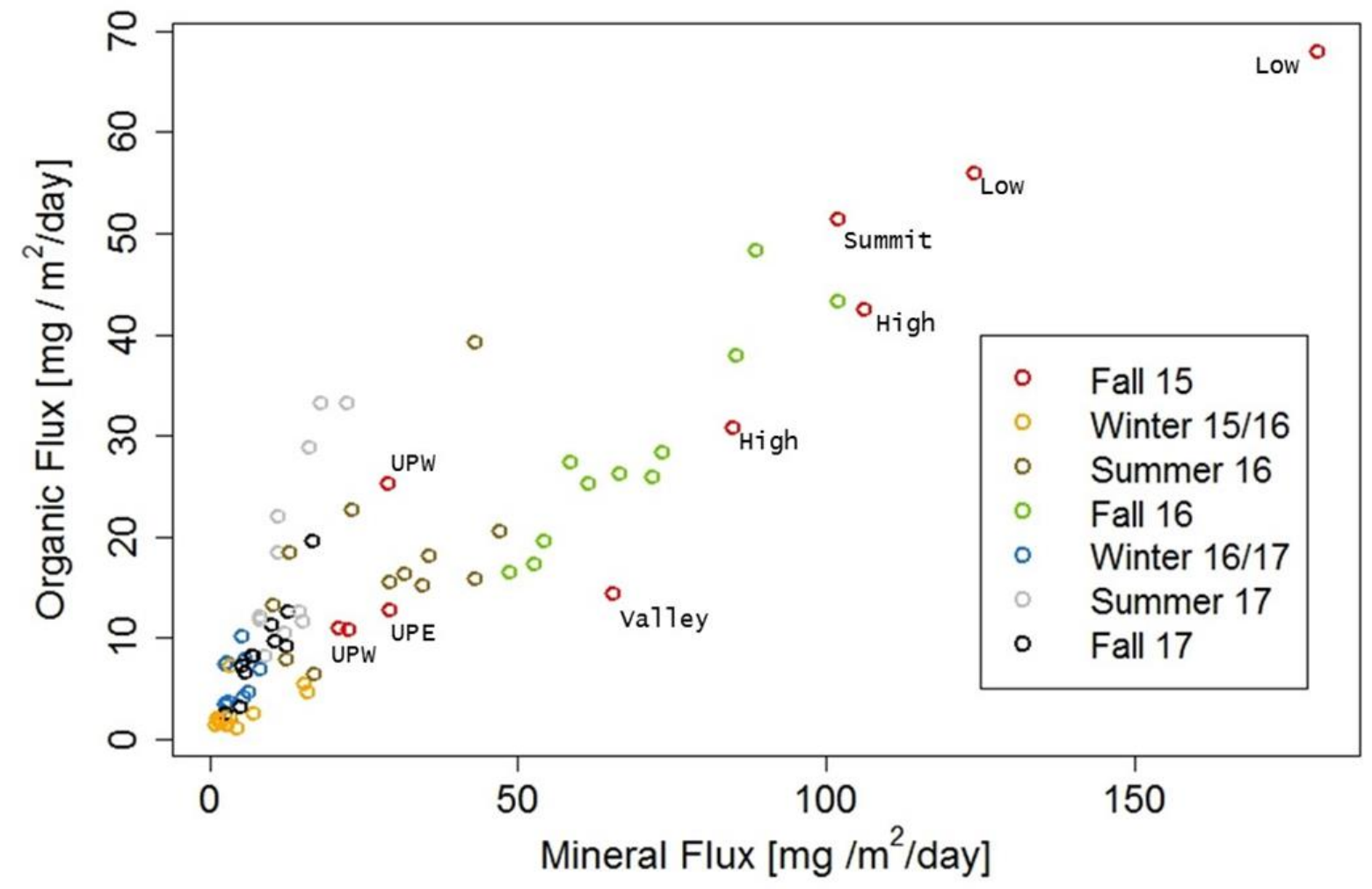

Figure 4-6: Ratio of mineral flux to organic flux at all sites.

Fall 2015, immediately following the fire recorded the highest values for both mineral and organic flux rates, as well as the highest standard deviation of any of the intervals. While the fall of 2016 samples (green) also contained relatively high flux rates, the standard deviation is lower and the value recorded at the UPW site (the pseudo-control site) was over two times that of fall 2015. The increased flux in 2016 was a result of environmental conditions and unrelated to the Soda Fire of 2015 as evidenced by grain size, geochemistry, and organic material data. 


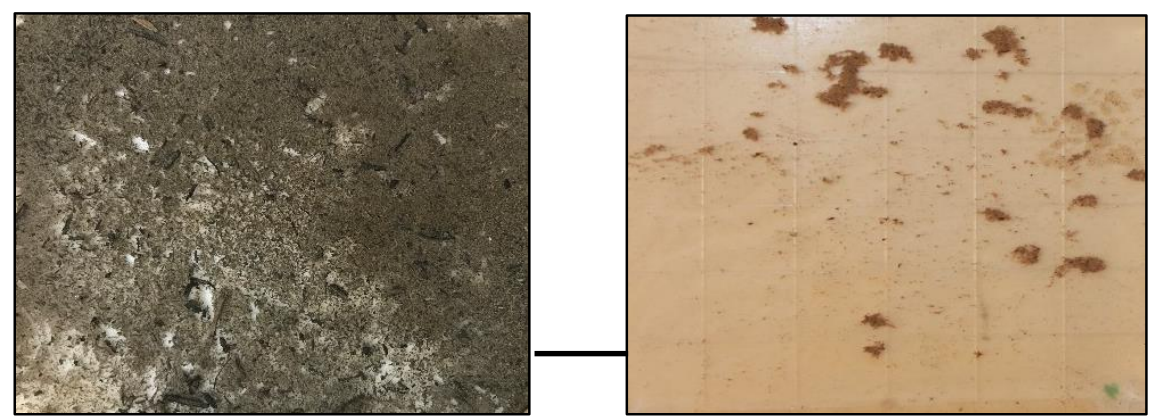

Figure 4-7: Comparison of Murphy Creek Lower (MCL, left) and Reynolds Mountain Cabin (RMC, right) samples from fall of 2015 immediately following the Soda Fire.

MCL is located in a sheltered position within the burned area and received the greatest flux rate of the entire study period. RMC was unaffected by the Soda Fire and contained zero burnt organic material. 

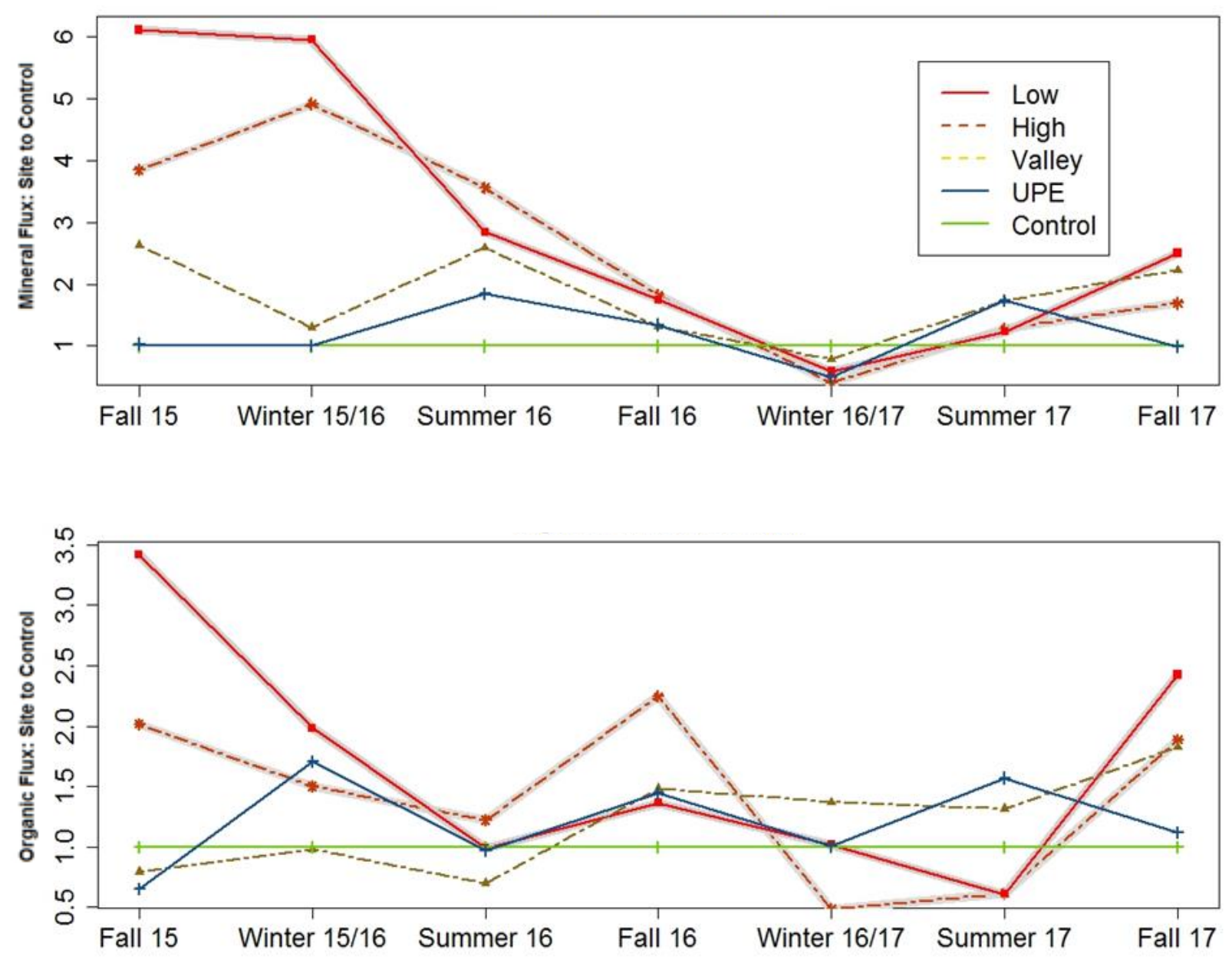

Figure 4-8: Ratio values for individual sites divided by the UPW ("control") site.

The division of individual sites by the UPW site normalizes the deposition by season to relative increases caused by seasonal and climactic variation at the UPW site. If the UPW site receives an increase in flux for environmental reasons, we assume that the rest of the watershed will receive an increase relative to the increase observed at UPW. The first two sampling intervals had anomalous increases within and proximal to the burned area relative to UPW deposition. Using this ratio, we observe a two to four-fold increase in flux at sites within the burned area relative to estimated deposition without wildfire disturbance. 


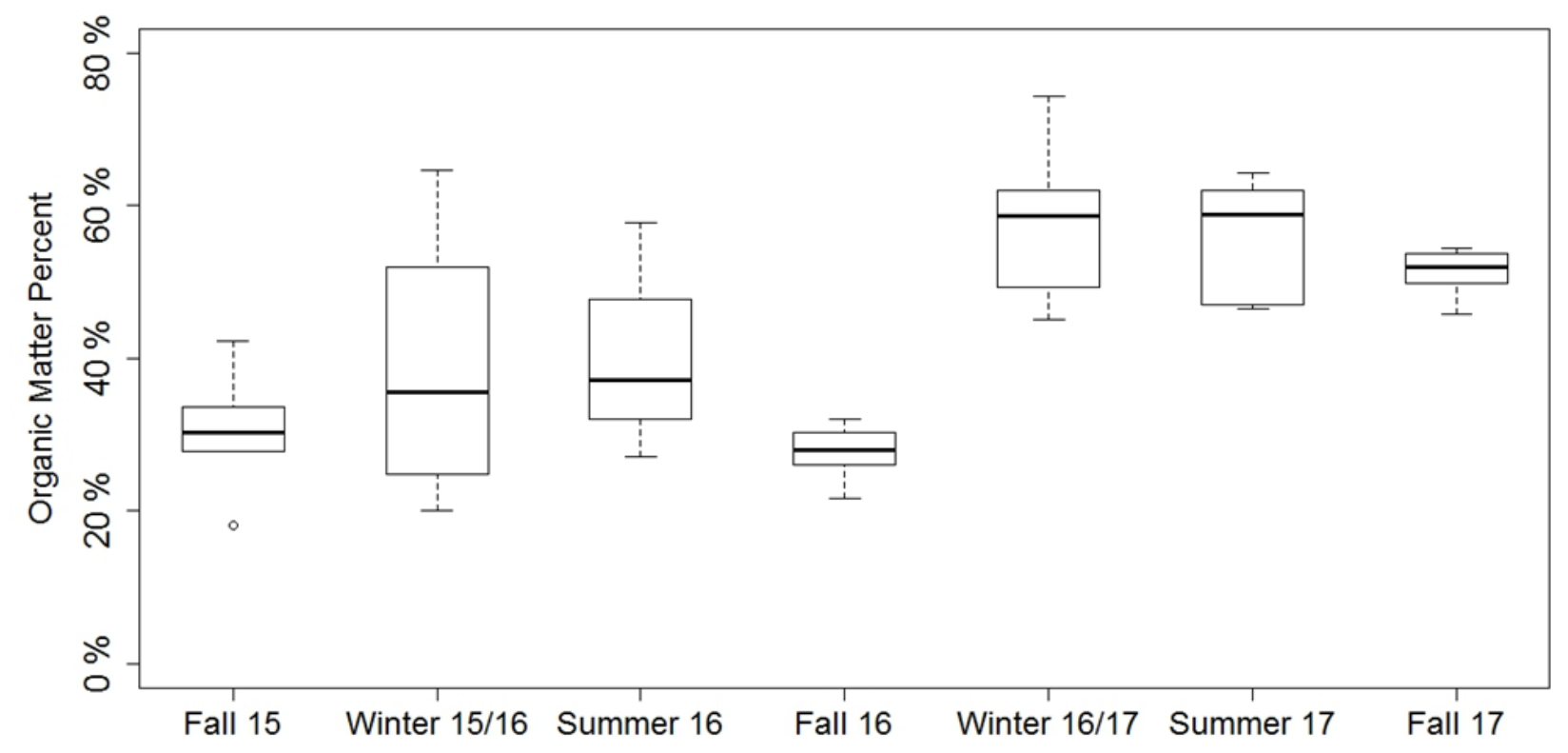

Figure 4-9: Despite an increase in the deposition of burnt organic material following the fire, the increase in local mineral soil deposition drove the organic percentages down across the watershed for the first two sampling intervals following the Soda Fire.

The intervals with the lowest mineral flux winter 2016/2017 - fall 2017 contained the highest percentage organic matter due to low mineral component values. Variance is high across the watershed for all intervals due to sampling error introduced from insects and birds. 

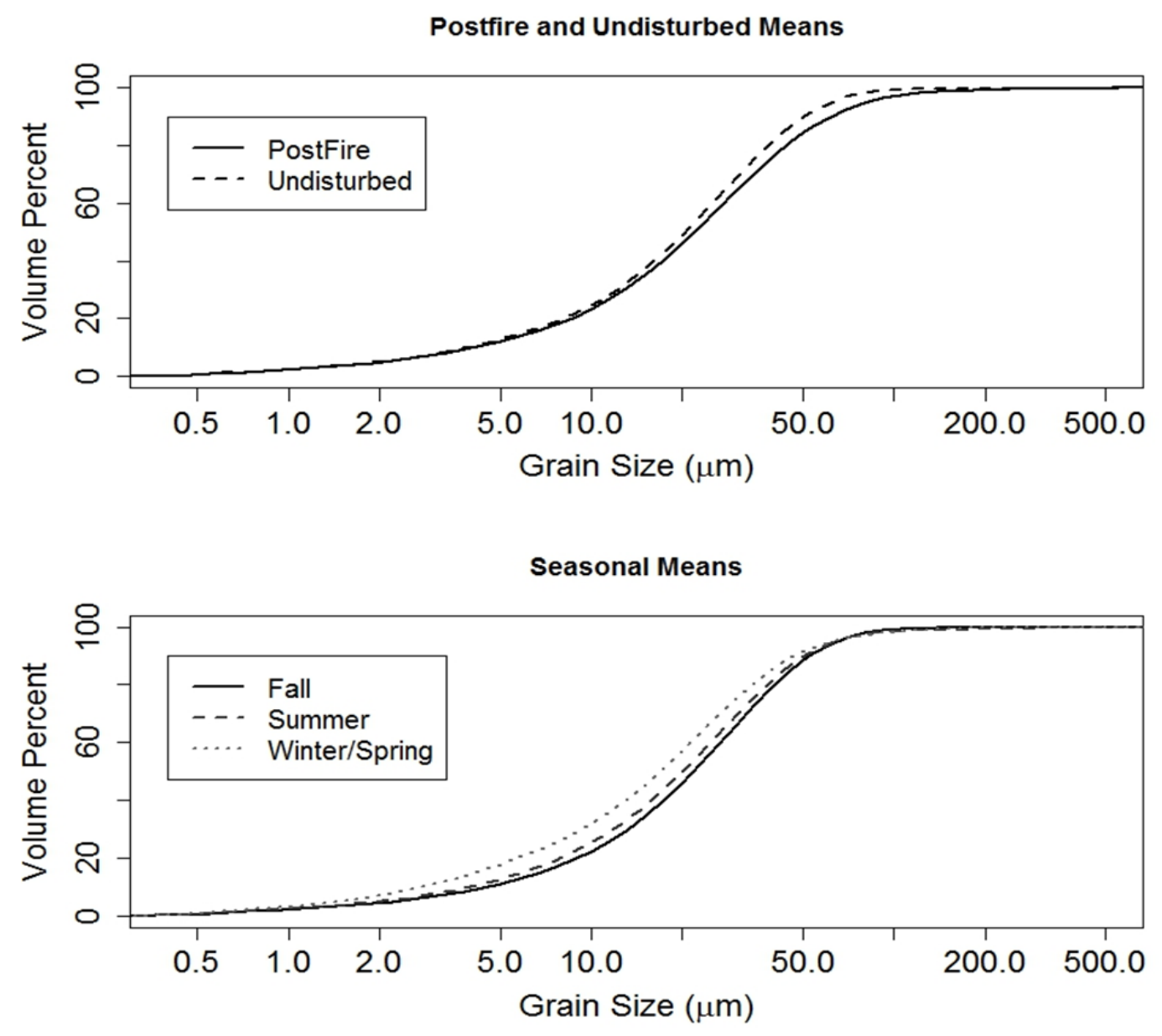

Figure 4-10: Particle size cumulative density functions show an increase in the coarse size fractions following fire.

Seasonally, slight variations exist between the $\mathrm{D}_{50}$ of samples over the entirety of the watershed with fall intervals containing the coarsest $\mathrm{D}_{50}$ and winter samples composed of the finest grains. 
Fall 2015

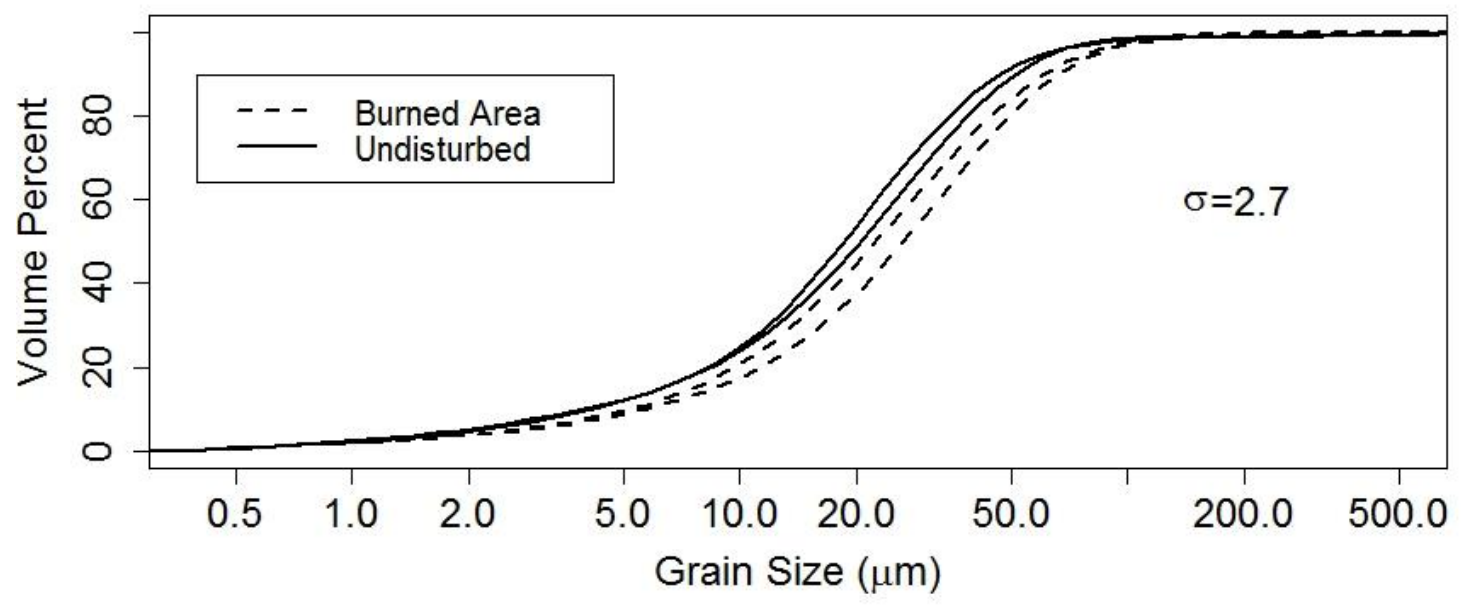

Fall 2016

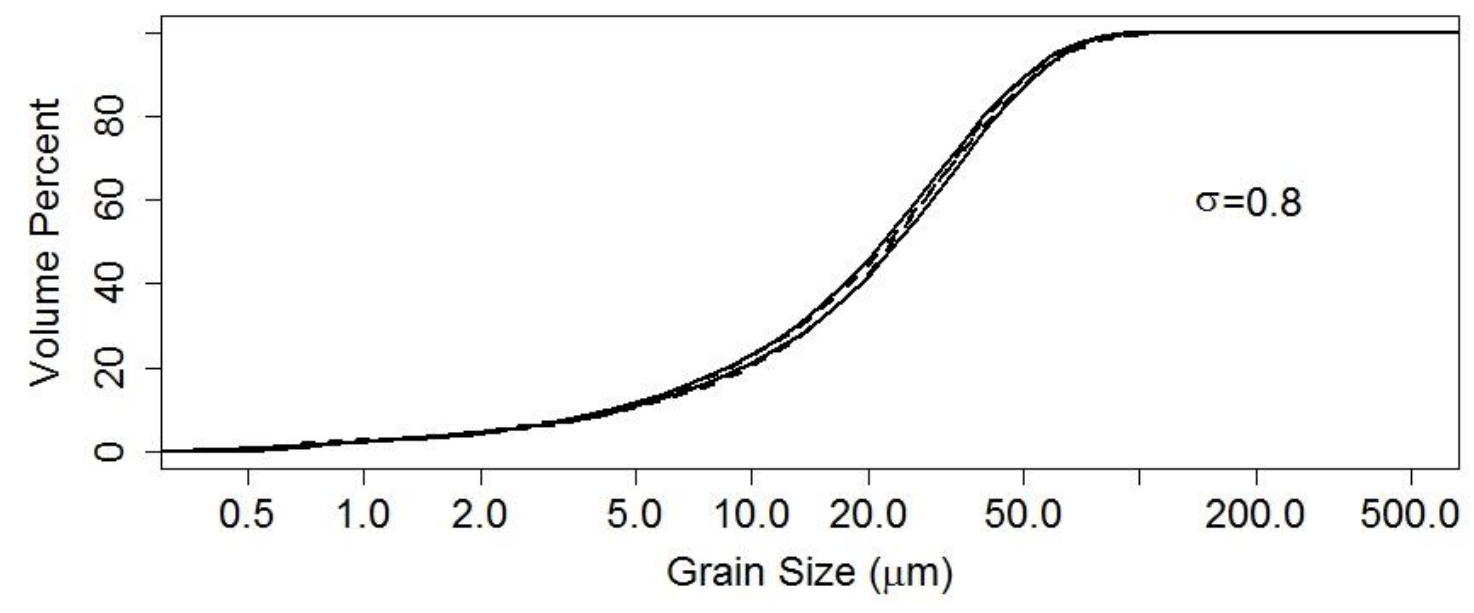

Figure 4-11: Cumulative density functions of grain size distribution reveal a decrease in watershed wide variance one-year postfire in the RCEW.

After fire, the watershed wide variance in grain size distribution is high due to anomalously high $\mathrm{D}_{90}$ values in the burned area while undisturbed sites record grain size distributions determined by environmental conditions. One year following fire, an input of undisturbed aeolian material creates a homogenous grain size distribution across the watershed. 


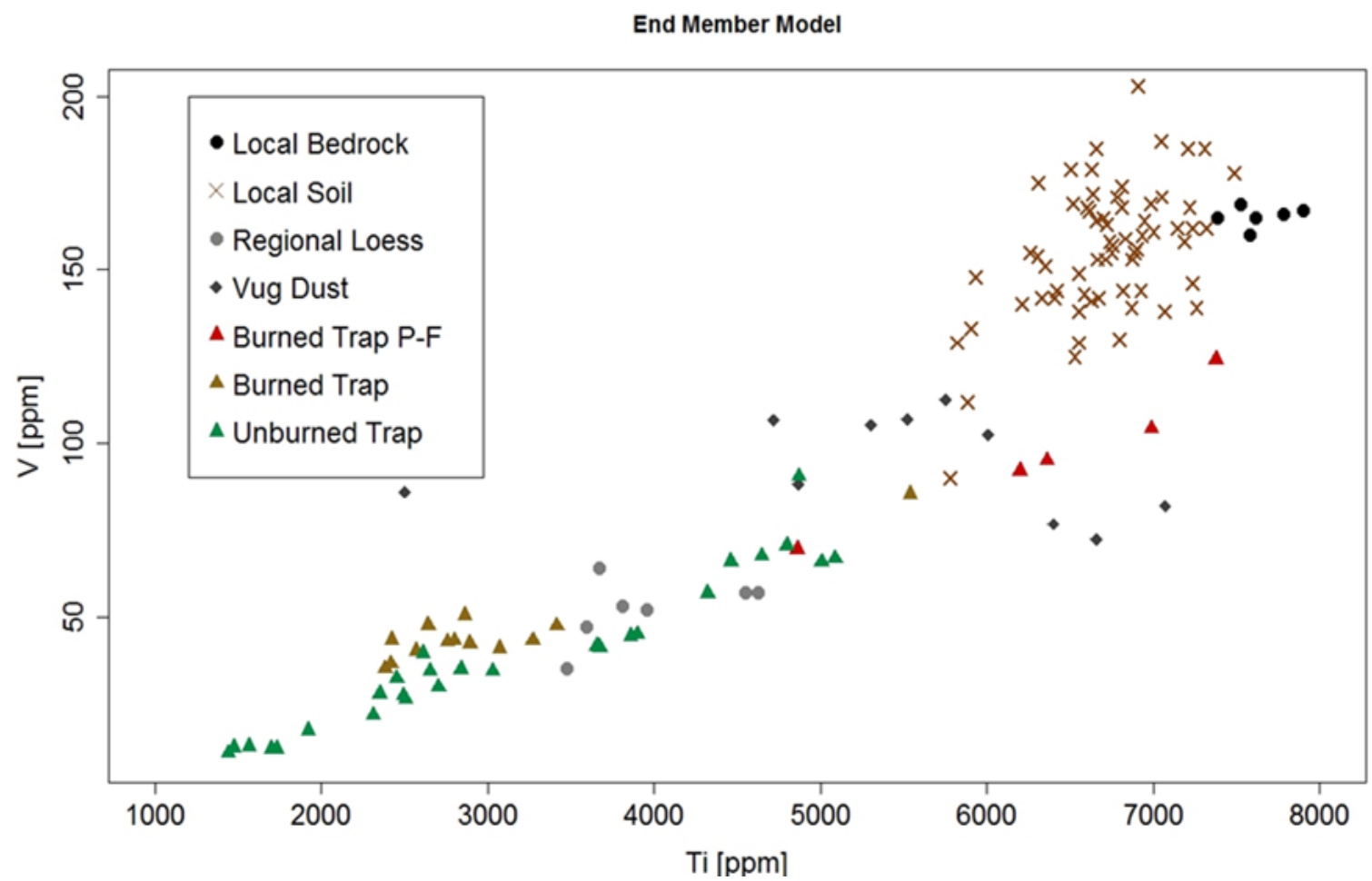

Figure 4-12: A two end member model indicates that sites within the burned area are composed of more locally derived material before the first growing season.

Soil samples were collected from Murphy Creek, a burned watershed with complex topography and unstable hillslopes. While Murphy Creek soils do contain a loess signature, they plot compositionally more similar to the bedrock samples collected from the area. Undisturbed dust samples plot compositionally closer to regional loess samples collected from stable valley bottoms within the watershed and the region. Following the fire, dust traps within the burned area contain elevated $\mathrm{Ti}$ and $\mathrm{V}$, indicating a local transport and deposition of material at the 2 meter height of the dust traps. 


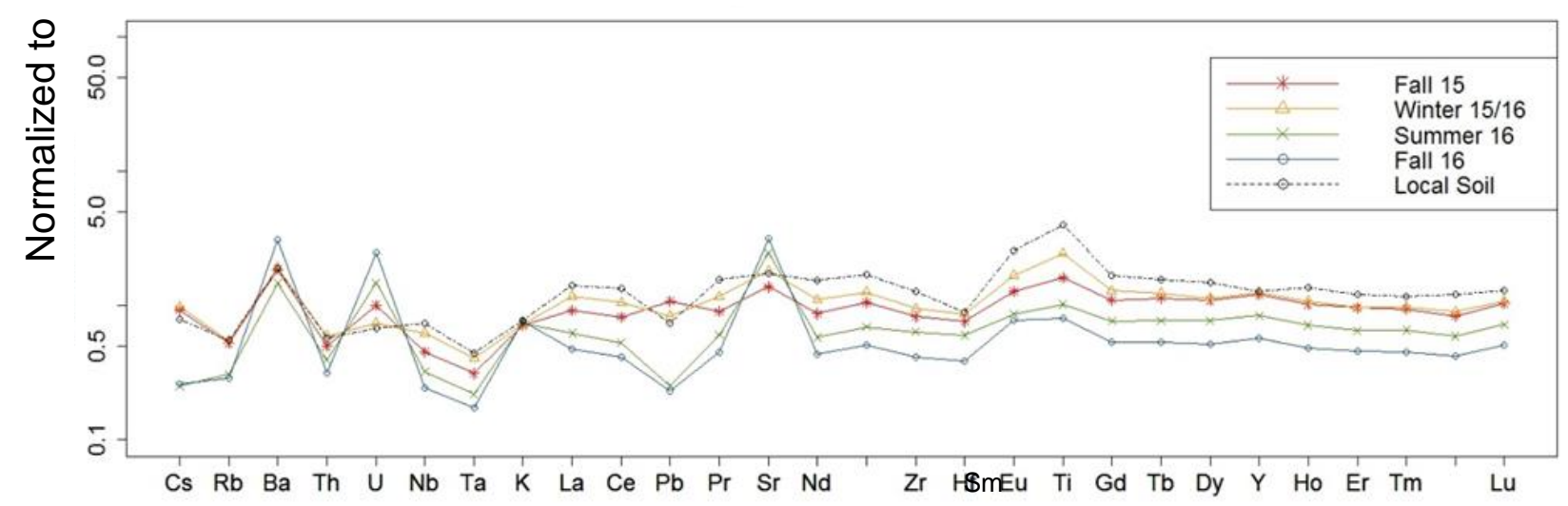

Figure 4-13: A spidergram showing Rare Earth Element (REE) compositions of samples from the Low Sites within the burned area.

Barium (Ba) and Strontium ( $\mathrm{Sr}$ ) peaks, associated with regional soluble salts, are diluted in the first two sampling intervals following fire. Once the local input from postfire associated deposition ceases, the Ba and Sr peaks become more substantial. Titanium (Ti) values are also elevated in the first two sampling intervals. Local soils are enriched in Ti, further evidence of local input. 

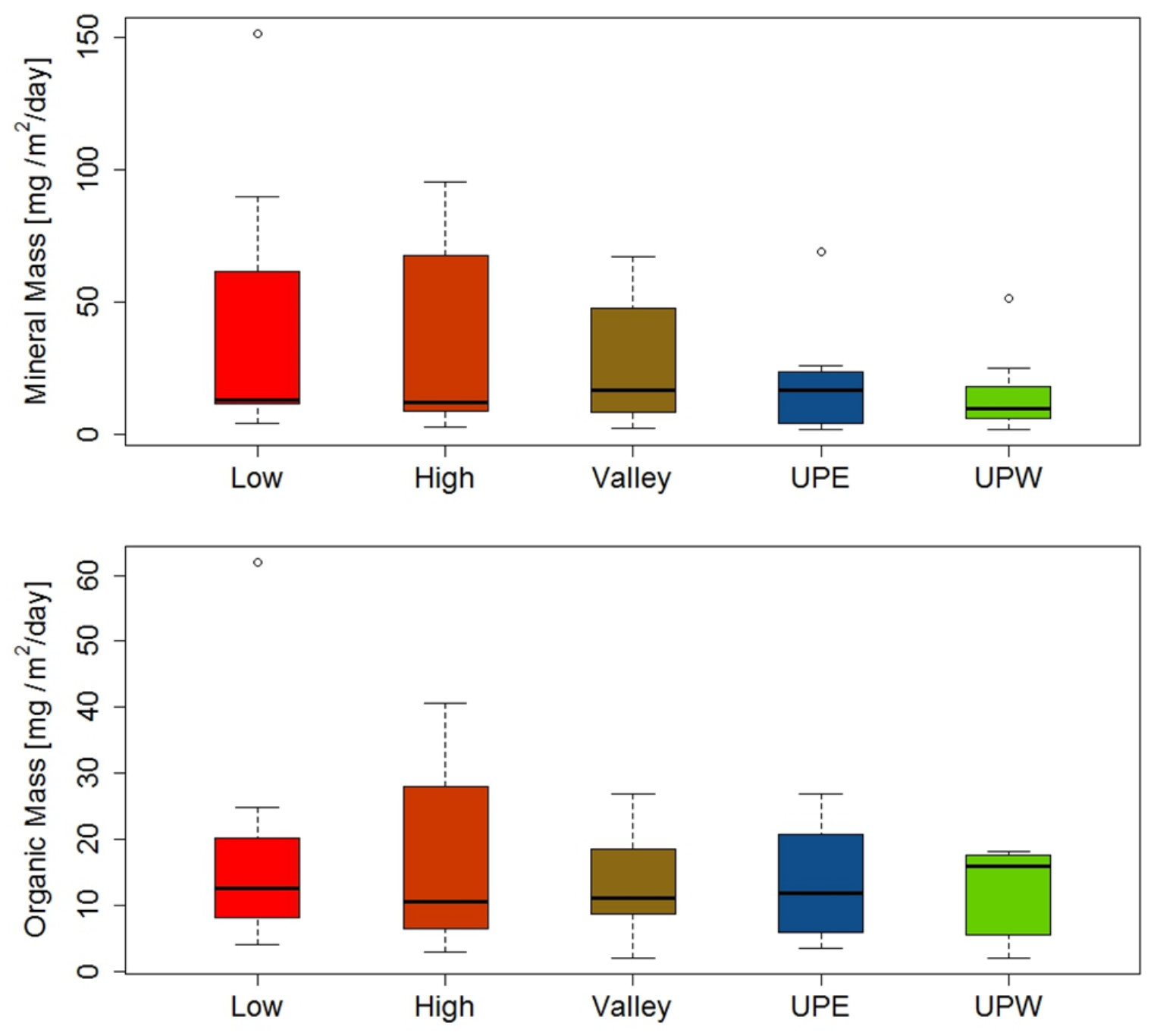

Figure 5-1: Boxplots of mineral and organic material flux indicate that mean values of dust flux are not statistically different across the watershed.

Variance is highest among sites within and downwind of the burned are. The obvious outlier is the first sampling interval after fire at the Low Sites within the burned area where flux reached rates of $150 \mathrm{mg} / \mathrm{m} 2 /$ day. 

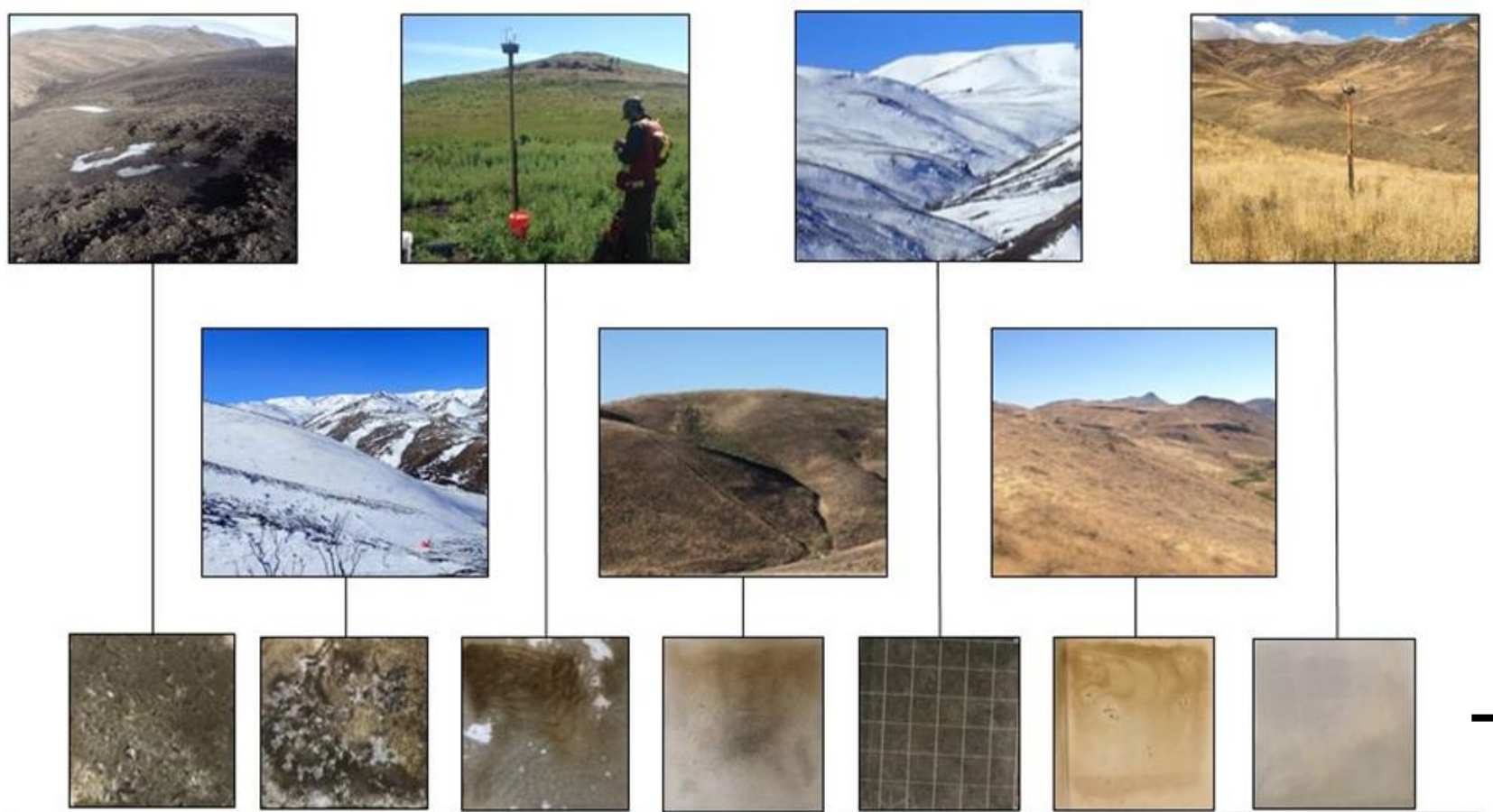

\section{Fall}

2015

\section{Winter} 2015/16

\section{Summer} 2016

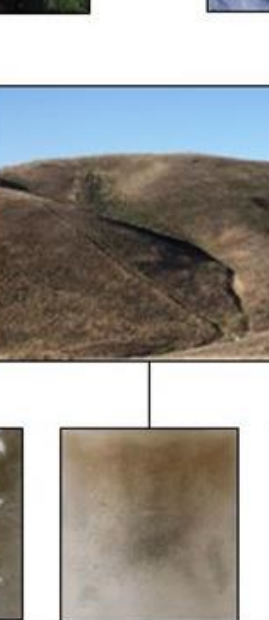

\section{Fall} 2016

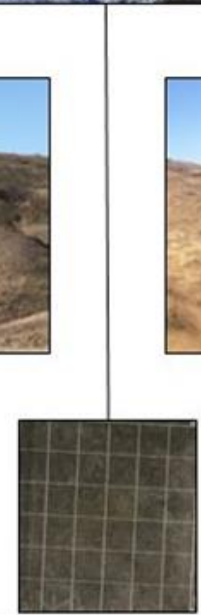

Winter 2016/17

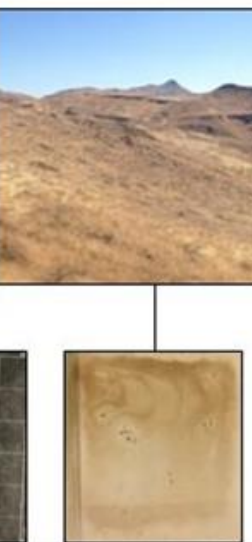

Summer 2017

Figure 5-2: Photos from each sampling interval within the 100\% burned Murphy Creek Watershed of the RCEW.

Coarse burnt organic material deposition ceased after revegetation in the spring of 2016. High antecedent soil moisture caused by the wet winter of 2016/2017 made for low fluxes of material in the summer and fall of 2017. 

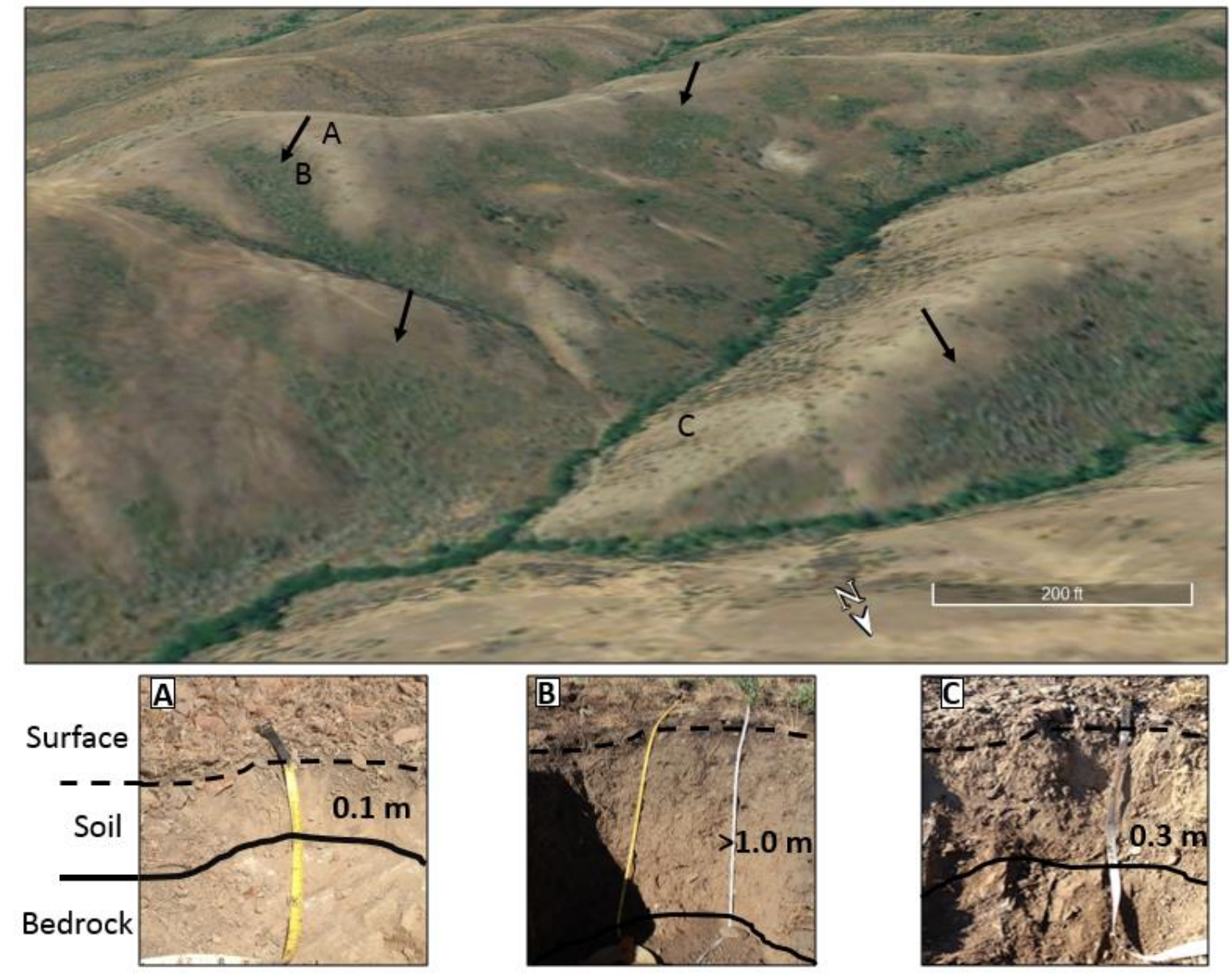

Figure 5-3: Spatially-controlled locations of increased soil water availability, soil depth, and vegetation density found on leeward hollows below topographic slope breaks on north east facing aspects.

Insolation is substantially lower on north through east aspects, but vertical and horizontal flux of fine-grained material and organic matter is also preferentially deposited on those same aspects. Soil pits from within RCEW show high spatial variability over short distances. Site A is made up of $10 \mathrm{~cm}$ of very fine loess material before encountering unweathered bedrock. At Site B, 15 meters away, on a northeast-facing colluvial hollow, over 1 meter of soil sits atop a weathered granite (saprolite) transition zone. 
APPENDIX A 


\section{Site Descriptions}

\section{$\underline{\text { Low }}$}

Two individual dust trap sites make up the Low subset of sites and are located at topographically low areas within the burned area of RCEW. Site 43, Murphy Creek Lower, is located on a north facing toe slope just above the South Fork of Murphy Creek at $1391 \mathrm{~m}$ elevation. Local vegetation is classified as Big Sagebrush-Bitterbrush (Seyfried et al., 2000). The fire incinerated all vegetation (riparian, sagebrush, and bitterbrush) in the immediate vicinity. Soils in the vicinity are entisols with little soil development on hillslopes and unstable floodplains. Site 12, Little Salmon Creek, is located in a sheltered floodplain site within a confined mountain drainage at $1575 \mathrm{~m}$ elevation. The vegetation immediately surrounding the dust trap (big sagebrush and rabbitbrush) was left unburned though the surrounding area received moderate soil burn severity and total vegetation incineration.

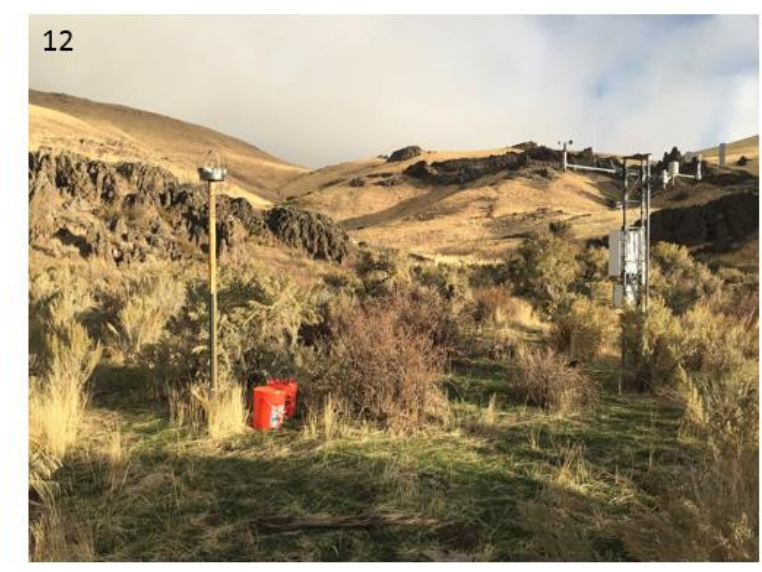

Site 12 UTM: 11T 5139524793788

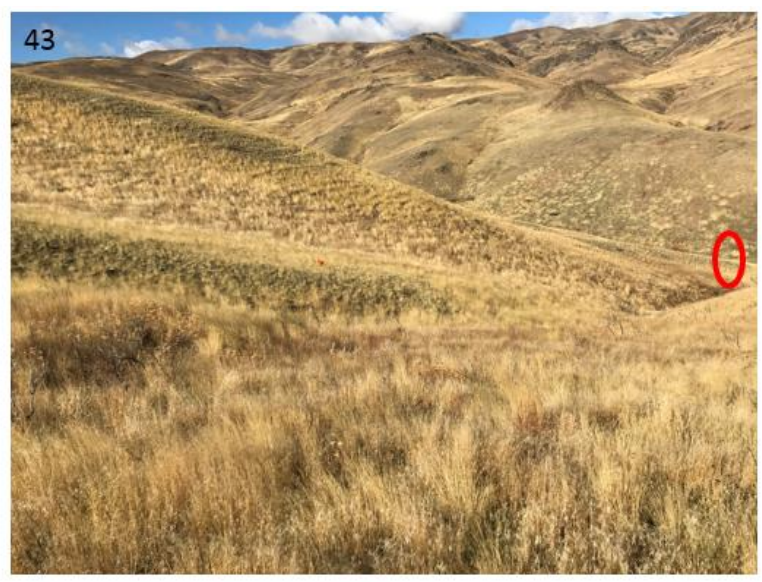

Site 43 UTM: 11T 514792 4788958 
$\underline{\text { High }}$

Two individual dust trap sites make up the High subset of sites and are located at high, exposed areas within the burned area of RCEW. Soils in the vicinity are entisols with little soil development on hillslopes and unstable floodplains. Site MCD, Murphy Creek Divide, is located at $1451 \mathrm{~m}$ on an exposed ridgeline diving Murphy Creek to the north and Cottle Creek to the south. Pre-fire site vegetation is classified as Big Sagebrush-Bitterbrush (Seyfried et al., 2000). All vegetation was incinerated in the Soda Fire. Site 31, Upper Salmon Creek, is located at $1794 \mathrm{~m}$ on a broad ridge line dividing the Reynolds Creek watershed from the Squaw Creek watershed to the west. Pre-fire site vegetation is classified as Big Sagebrush-Bitterbrush (Seyfried et al., 2000). All vegetation was incinerated following the Soda Fire with forbes and grasses returning the following spring.

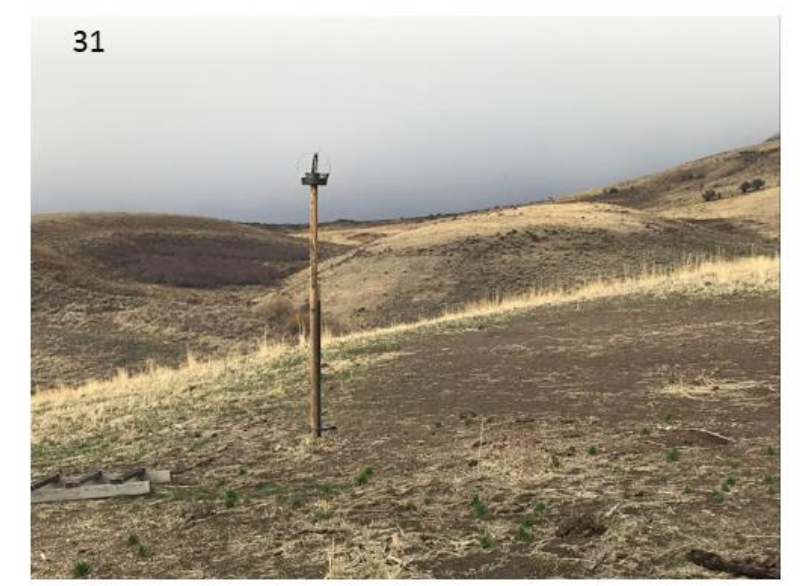

Site 31 UTM: 11T 5121804793788

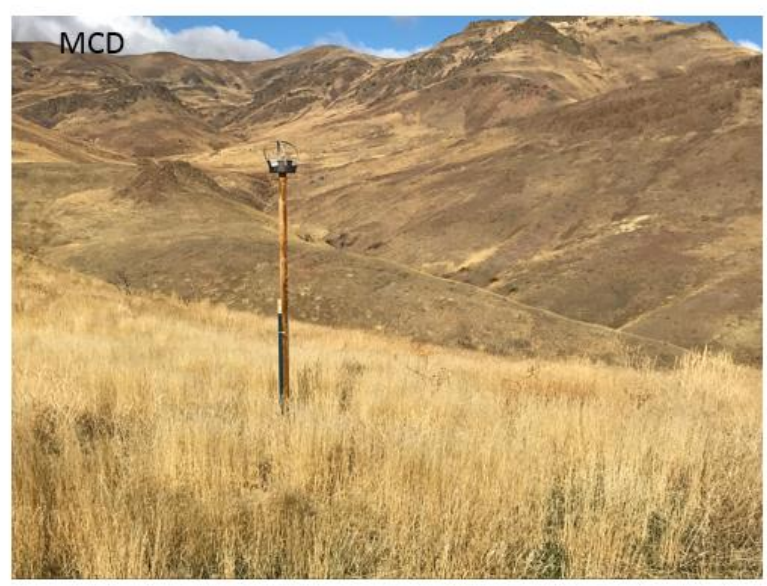

MCD UTM: 11T 514649

4789205 
$\underline{\text { Valley }}$

Three individual sites make up the Valley subset of sites though one site (ATV) was removed from analysis due to excessive anthropogenic contamination. These sites sit in the floodplain and terrace complex of Reynolds Creek, far removed from the complex topography of the surrounding mountains. The vegetation is classified as Wyoming Big Sagebrush and Low Sagebrush (Seyfried et al., 2000). Soils are well developed aridisols derived from loess deposits with well-defined pedogenic calcium carbonate deposits. Site 76, Quonset, is located near the Northwest Watershed Research Center at an elevation of $1201 \mathrm{~m}$. Site 57, Flats, is located at an elevation of $1282 \mathrm{~m}$. Neither site was burned in the Soda Fire of 2015.
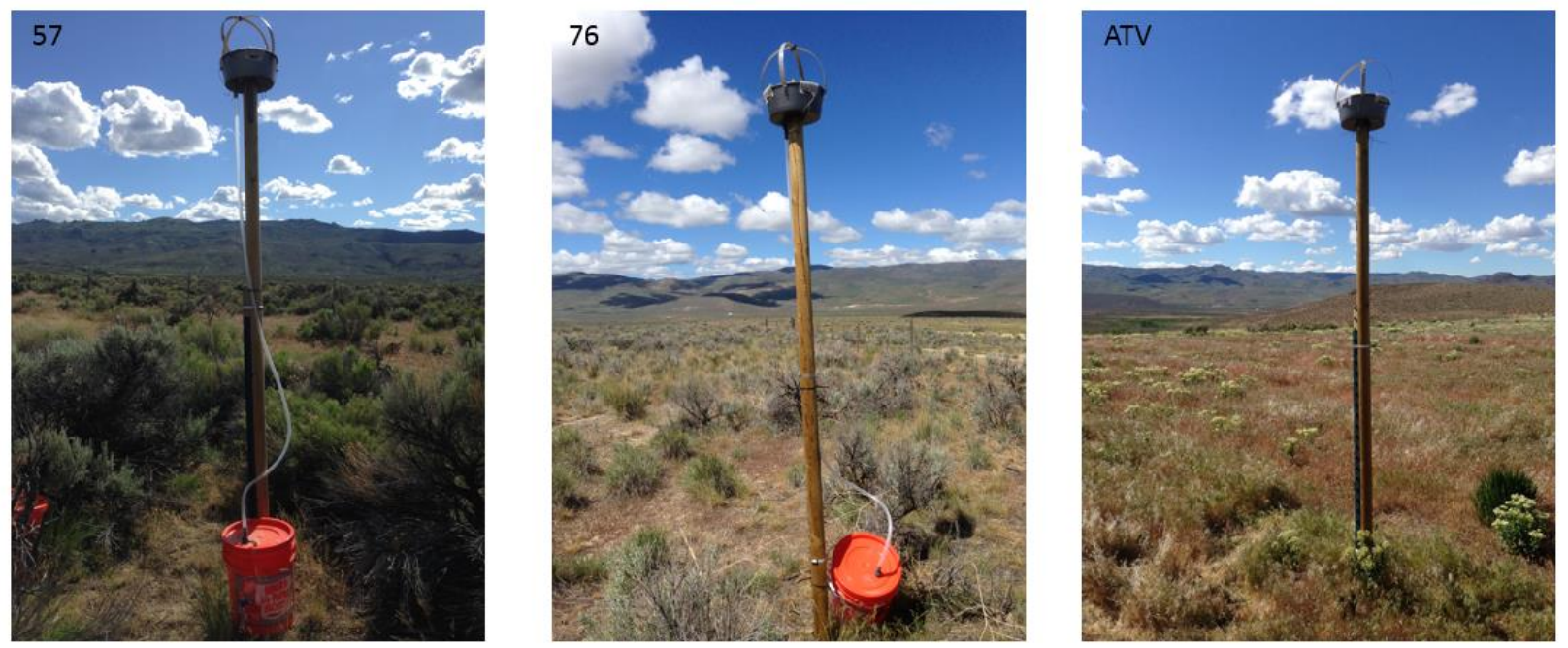

Site 57 UTM: 11T 5213154786231

Site 76 UTM: 11T 5202874783614

Site ATV UTM: 11T 5212924783577 


\section{Upper East Sites}

Three sites are located in the eastern mountains of the Reynolds Creek watershed at various elevation within complex topography. Sites in the Upper East subset are classified as Low Sagebrush and Snowberry (Seyfried et al., 2000). None of the sites were within the burned area though all are various distances downwind from the burn. Site 13803, Upper Sheep Creek, is located at an elevation of $1868 \mathrm{~m}$ and sees persistent snow cover throughout the winter. Site 127, Lower Sheep Creek, is located at 1650 m.a.s.1. Site 98, Nancy’s Gulch is the lowest site on the east side at $1414 \mathrm{~m}$ but remains in complex topography.

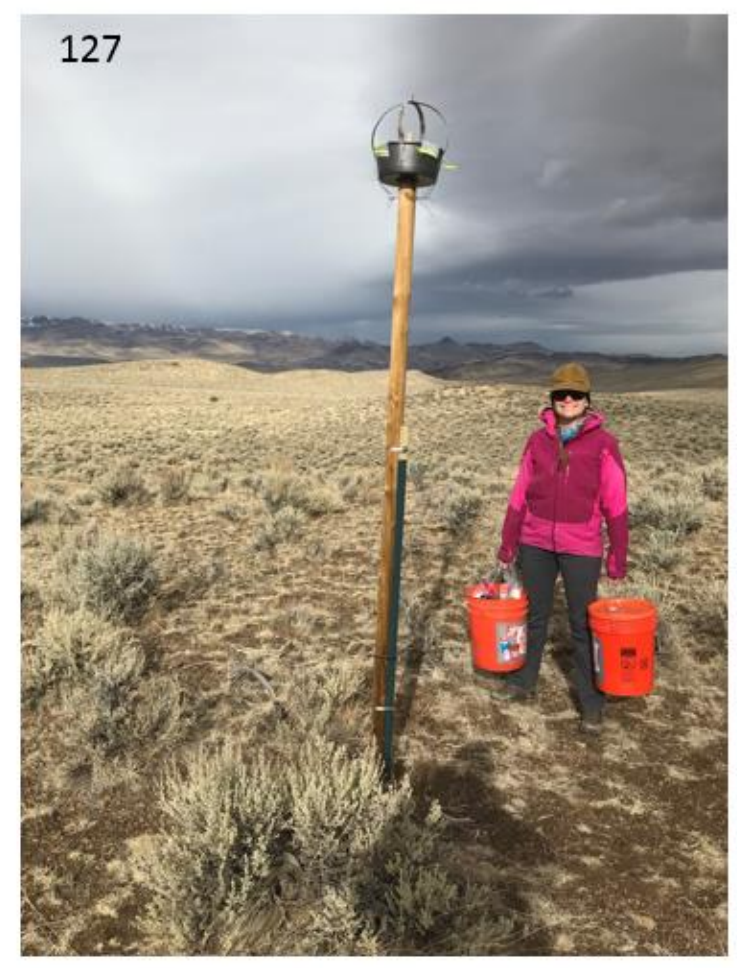

Site 127 UTM: 11 T 5216694776393

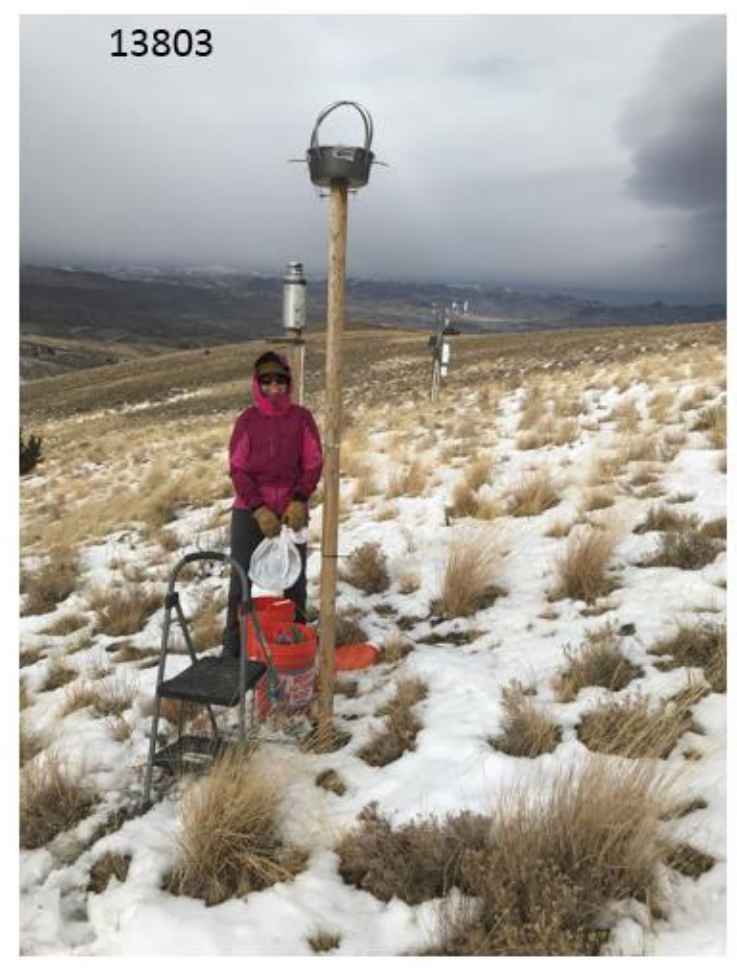

Site 13803 UTM: $11 \mathrm{~T} 522517$

4774425

Site 98 UTM: 11T 5232744779595 


\section{Upper West Sites}

Two dust trap sites make up the Upper West subset of sites. Both of these sites are located in the subalpine ecosystem with vegetation classified as Conifer (Seyfried et al., 2000). These sites have persistent snowcover through the winter months and are usually inaccessible until the end of May. Both of the sites were located to the south of the Soda Fire burned area and were not impacted by the fir or postfire transport of organic material or sediment. Site 176, Reynolds Mountain Cabin, is located on an exposed, sparsely vegetated ridge separating the Reynolds Creek watershed from the Jordan Creek watershed to the south. Site 176 is located at an elevation of $2099 \mathrm{~m}$. Site 163, R163, is sheltered from wind by a large conifer trees to the south and west, resulting in low wind speeds at the accompanying weather station. Site 163 is located at an elevation of 2169 m.
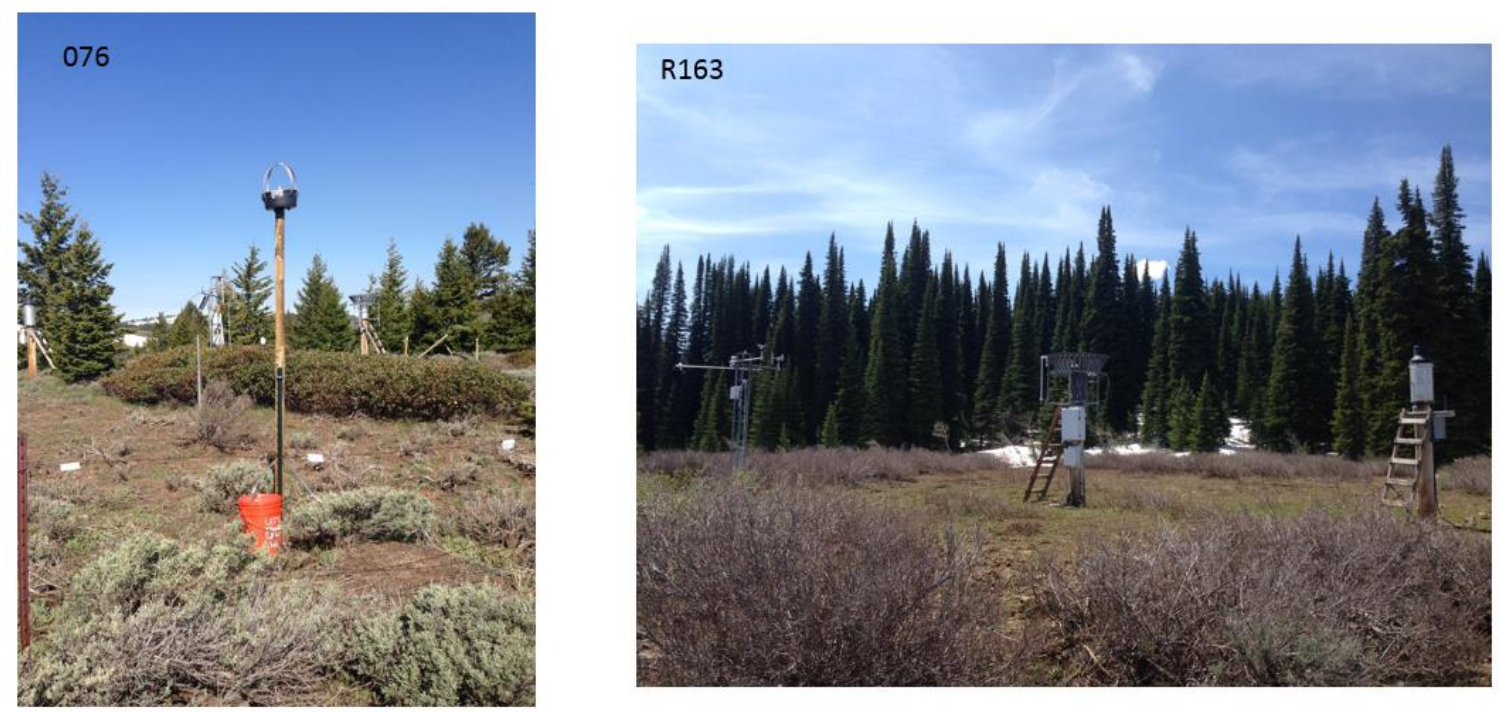

Site 176 UTM: $11 \mathrm{~T} 5196414768118$ Site 163 UTM: $11 T 5140464769618$ 
APPENDIX B 


\section{Dust Sampling}

\section{$\underline{\text { Dust Trap Construction }}$}

Dust trap construction requires a Teflon coated angel food cake pan, Teflon coated mesh material, sterile glass marbles, 1" width strapping, a power drill and drill bit, a box cutter or other cutting implement, and zip-ties. To begin, drill four sets of two holes, side-by-side, 3-4 cm apart horizontally. Each set should be $90^{\circ}$ from each other around the rim of the cake pan. These holes will be used to zip-tie the mesh to the bunt pan. Drill four more sets of two holes, between the previously drilled holes, vertically, about $1 \mathrm{~cm}$ apart. These holes will be used to zip tie the anti-bird roosting straps to the bunt pan. Cut a piece of the Teflon mesh to fit into the pan about $2 \mathrm{~cm}$ below the rim, leaving four little "ears" about $6 \mathrm{~cm}$ long and $4 \mathrm{~cm}$ wide. These will fold over the top of the cake pan and down to the previously drilled horizontal hole sets. The mesh should suspend $2-3 \mathrm{~cm}$ below the rim leaving room for the glass marbles. Cut the strapping so that it makes an arch over the top of the pan connecting two sets of vertical holes. Once Tanglefoot is applied in the field, these straps will deter avian intruders. Be sure to acid wash all materials before they are deployed in the field.

\section{Field:}

1. Hammer in t-posts using a t-post hammer. Nail 2 nails (opposite each other) to top of wood post, directly under where the bunt pan will rest (place bunt pan on top of wood post prior to assembly to mark where to place nails). Attach $8 \mathrm{ft}$ wood poles w/ pointed end (purchased at home depot or lowes) using hose clamps.

2. Fill mesh with marbles to just below the rim of the bunt pan. 
3. Cut 2 strips of galvanized wire (each $\sim 11 / 2 \mathrm{ft}$ long), loop through two sets of zip ties that hold the mesh to bunt pan (choose ones that are directly across from one another). These wires will be used to tie bunt pan to nails on wood pole.

4. Attach gray straps in a crisscross fashion using zip ties.

5. Place tanglefoot on crisscross straps.

6. Using a step ladder, carefully place dust collector on top of wood pole, loop wire around nails to secure bunt pan in place.

7. Viola! You have a dust collector.

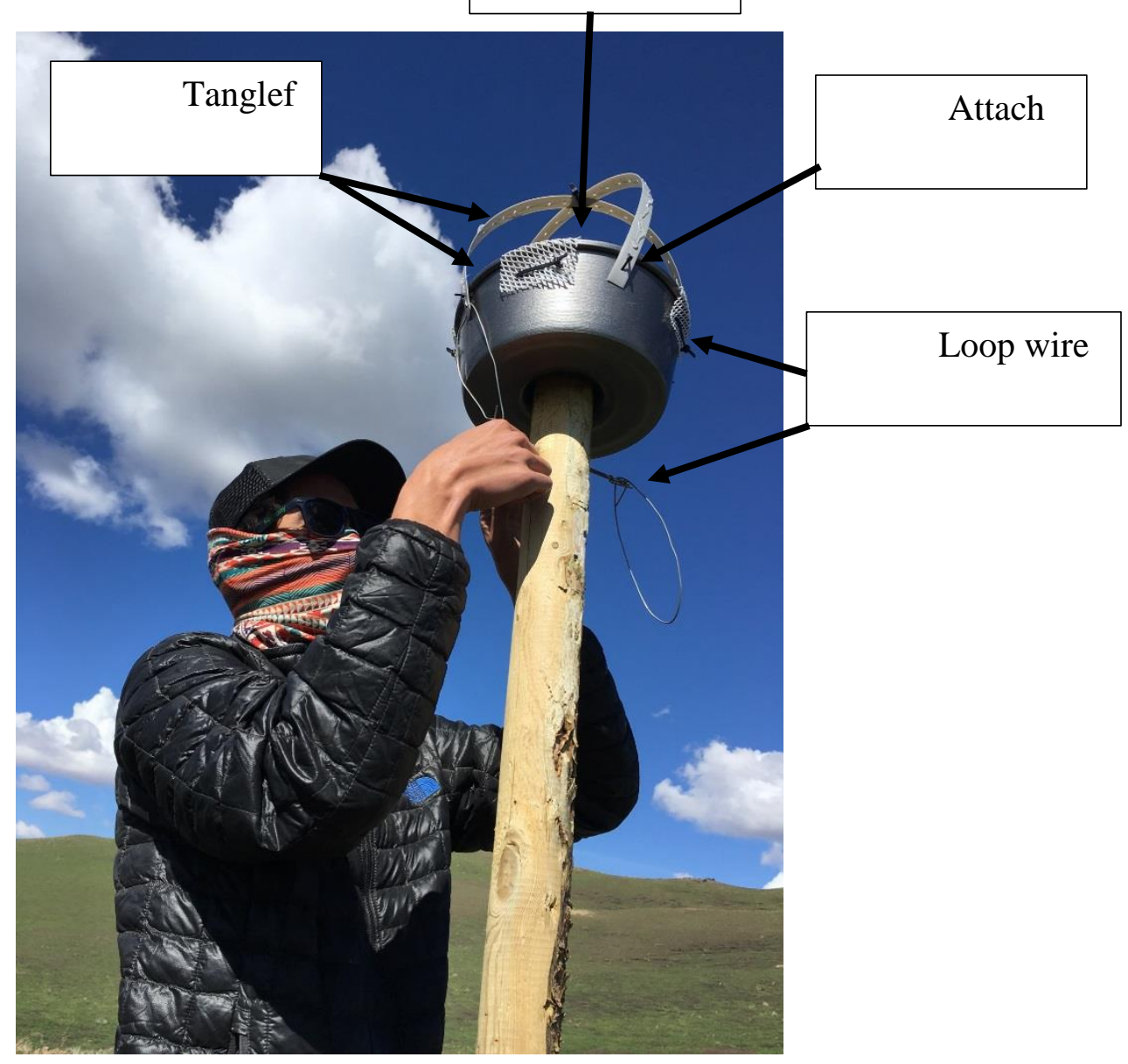




\section{$\underline{\text { Sample Collection }}$}

Required equipment:

- A- Zip Ties

- B - Tanglefoot (Find on Amazon)

- C - Pre-Assembled Dust Trap

- C - Garbage Bag

- D-Marbles

- E-Fresh strapping

- F-Laborer

Not pictured:

- Wire cutter

- Latex Gloves

- Sharpie

- Gallon Ziploc Bags

- Post hole driver

- Flathead Screwdriver

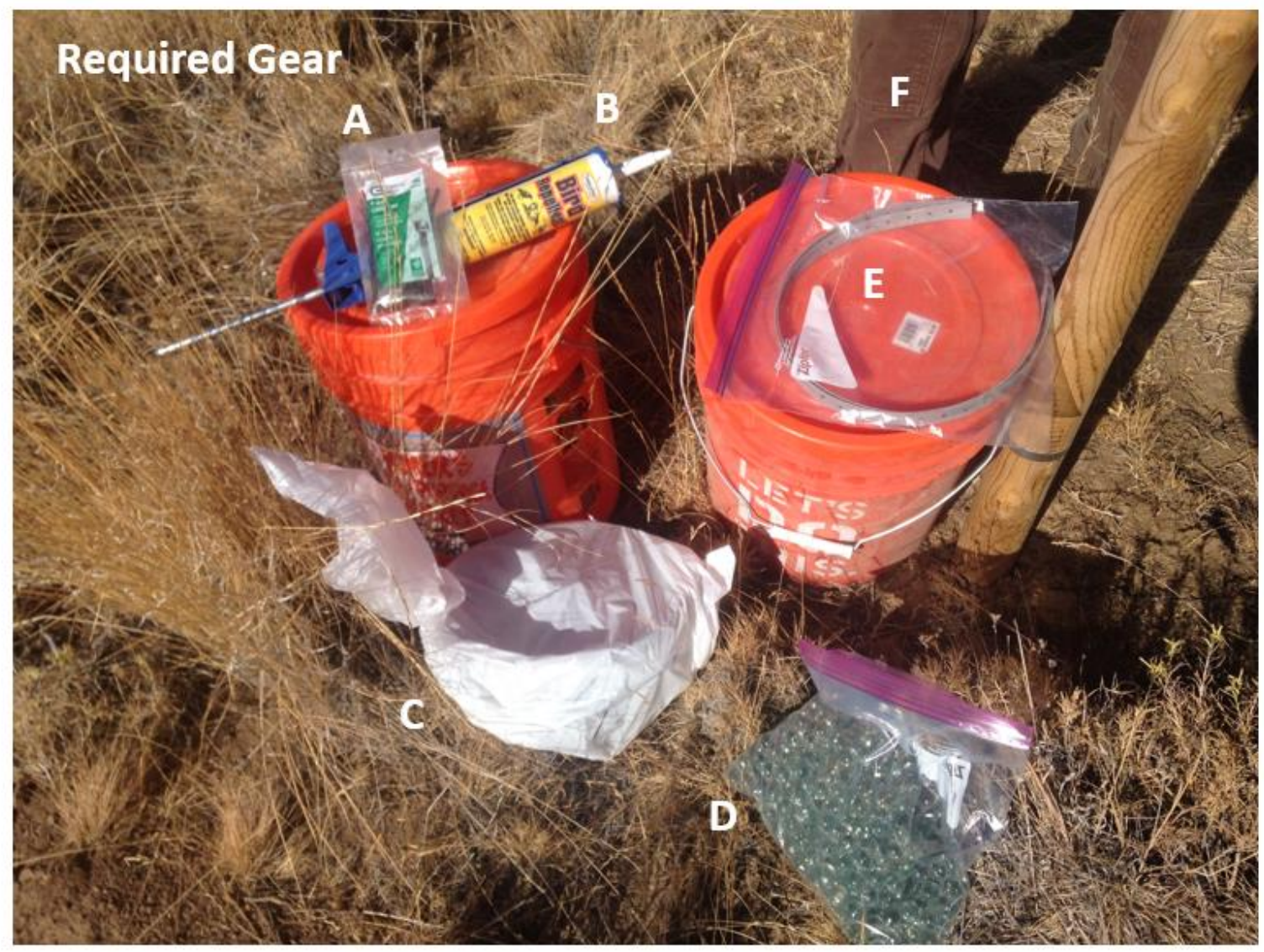


In the lab, prepare as many dust traps as you will need by attaching the mesh to the pan using zip-ties beforehand and place the traps in a garbage bag with a clean bag of marbles. Place clean marbles in a gallon Ziploc bag. Head to the dust trap by car, ATV, bicycle, or foot.

Standing on a step ladder, remove the wires that attach the pan to fence post and lift the pan off of the two meter pole. Set down the trap and remove the bird repellent straps by cutting the zip-ties securing the straps to the pan, trying to keep fingers out of the Tanglefoot. Set the crossed strips aside where dirt won't get stuck on the Tanglefoot. Inspect the trap and look for avian contamination, insects, or local rocks. Pick out any coarse organic matter if possible. Pour any water remaining in the bunt pan, and all of the marbles, into a clean gallon Ziploc bag labelled with the appropriate site ID. Double bag the marbles if fluids are present. Place the pan with the mesh screen still attached into a properly labelled garbage bag. Store both the marbles and the pan in a five-gallon bucket sealed with a tight fitting lid. Place the bird-repellent cross straps on a fresh bunt pan, complete with Teflon mesh, using small zip-ties. Place clean marbles in a new dust trap. Reapply Tanglefoot bird repellent to the edge of the pan and refresh the cross-straps if necessary. Stepping back onto the step-ladder, place the fresh trap atop the pole and secure with bailing wire. Make any relevant notes in a field book and take a picture (ie many dead bugs, excessive amounts of dirt, marbles spilled etc).

Back in the lab, acid wash a pyrex dish using $10 \% \mathrm{HCl}$. Fill the pyrex with about $1 \mathrm{~cm}$ of DI water. Place a handful or two of marbles in the dish and rub with one hand while spraying with a DI water bottle. Remove marbles from the pyrex and repeat until all of the marbles have been rinsed. Using the DI bottle, rinse any dust off the Teflon 
mesh and into the pyrex dish. Avoid the "ears" of the mesh screen, as they were not actually within the area of the dust trap. Rinse the inside of the bunt pan into the pyrex dish using the DI bottle and a plastic spatula or Dutch Oven scraper. Place the tray in the oven at $60^{\circ} \mathrm{C}$ to dry. 
APPENDIX C 


\section{Dust Trap Analysis}

$\underline{\text { Mass }}$

Once the sample has dried in the pyrex tray, obtain a pre-sample, labeled weight for individual plastic gridded petri dishes. Further inspect the pyrex tray for foreign coarse organic material (flying insects, avian contamination etc) and pick out accordingly. Transfer the remaining sample from the pyrex tray into the gridded petri dish using DI water and a plastic scraper. Again, dry the sample at $60^{\circ} \mathrm{C}$ in the oven. After drying, weigh the petri dish with the sample using a balance accurate to the $.001 \mathrm{mg}$ and calculate for the total weight. Photograph the sample and count coarse woody debris (pieces $>1 \mathrm{~mm})$.

\section{$\underline{\text { Loss-On-Ignition }}$}

Our methods for organic material mass analysis were adapted from Simon Frasier University Soil Science Lab (2011). Mark porcelain crucibles with appropriate Sample ID and obtain the pre-sample weight to $.001 \mathrm{mg}$. Transfer the full sample into a crucible using a plastic spatula/Dutch Oven scraper and as little DI water as possible. Dry the samples at $100^{\circ} \mathrm{C}$, let cool, and measure the original sample weight. Crush any coarse material in the crucible with a pestle and place the samples in the muffle furnace at $575^{\circ} \mathrm{C}$ for 4 hours. Once the sample has cooled, measure the postfire weight. Place any samples with visible organic material back in the furnace at $575^{\circ} \mathrm{C}$ and weigh again after a second burning. Continue until the recorded mass stabilizes and all organic material has been consumed. Final mineral aerosol and carbon dates can be calculated from the full sample weight and the amount lost-on-ignition. 


\section{$\underline{\text { Particle Size Distribution }}$}

Full methods as described by Malvern can be found in the Boise State Earth Processes Lab in the Environmental Research Building. Begin by filling a $1000 \mathrm{~mL}$ beaker with room temperature DI water and place beneath the Malvern Hydro 200 MU unit propeller. Turn on the pump and let the machine run, rinsing out the lines of any material previously analyzed. Once rinsed, place a fresh beaker of $1000 \mathrm{~mL}$ of DI water in the unit. Follow the prompts given by the Mastersizer 2000 software "Dirt" SOP. Preset absorption (1.0) and RI values (1.51) are programmed into this SOP. Once the prompt tells you to add sample, begin so with a small scapula until obscuration values reach $\sim 10 \%$. Once steady at $10 \%$ run the sample. The SOP will run each aliquot three times. Export the data to the clipboard and paste to excel for further analysis and data preparation.

\section{$\underline{\text { ICPMS }}$}

We used methods for lithium tetraborate (Li-Tet) acid digestion developed by the Benner Research Group at Boise State University. Due to the small samples $(<500 \mathrm{mg}$ in most cases) and the need for error analysis, we adjusted the material required from 250 $\mathrm{mg}$ to $50 \mathrm{mg}$. We ran triplicates of one sample at $50 \mathrm{mg}, 150 \mathrm{mg}$, and $250 \mathrm{mg}$ and observed less than $6 \%$ difference in the mean concentrations for each analyte with the highest errors in $\mathrm{Hf}$ and $\mathrm{Cr}$. We deemed the error low enough to justify the ability to run triplicates of individual samples at $50 \mathrm{mg}$ as opposed to one sample at $150 \mathrm{mg}$. 
The process is as follows:

1) If coarse material exists, grind the sample to a fine powder in a SPEX CertiPrep Shatterbox using an alumina ceramic container.

2) Mix $50 \mathrm{gm}$ of sample to $100 \mathrm{mg}$ of lithium tetraborate flux (1:2 sample to flux)

3) Transfer to a clean graphite crucible.

4) Place in a $900^{\circ} \mathrm{C}$ muffle furnace for 25 minutes.

5) Allow to cool. Weigh the bead and place in a $500 \mathrm{~mL} \mathrm{HDPE}$ bottle

6) Bring to $250 \mathrm{mg}$ with $2 \% \mathrm{HNO}_{3}, 8$ drops of $\mathrm{HF}$ and 15 drops of $\mathrm{H}_{2} \mathrm{O}_{2}$

7) Leave overnight on the shaker table to dissolve

Sample prep complete. Contact the Isotope Geology Lab at Boise State University lab to run the samples. Laboratory manual with ICPMS methods can be found online at: https://earth.boisestate.edu/isotope/labshare/laboratory-handbooks/. 